\author{
Universidade de São Paulo \\ Instituto de Física
}

\title{
Modelagem de problemas da dinâmica de populações por meio da dinâmica estocástica
}

\author{
David Rodrigues de Souza
}

Orientadora: Prof $^{\mathrm{a}}$. Dr ${ }^{\mathrm{a}}$. Tânia Tomé Martins de Castro

Dissertação de mestrado apresentada ao Instituto de Física para a obtenção do título de Mestre em Ciências.

Banca examinadora:

Prof $^{\mathrm{a}}$. Dr ${ }^{\mathrm{a}}$. Tânia Tomé Martins de Castro(IFUSP)

Prof. Dr. Franscisco de Assis Ribas Bosco (UNIFESP)

Prof. Dr. Everaldo Arashiro (UFOP)

São Paulo - 2009 
FICHA CATALOGRÁFICA

Preparada pelo Serviço de Biblioteca e Informação do Instituto de Física da Universidade de São Paulo

Souza, David Rodrigues de

Modelagem de problemas da dinâmica de populações por meio da dinâmica estocástica - São Paulo, 2009.

Dissertação (Mestrado) - Universidade de São Paulo. Instituto de Física, Departamento de Física Geral

Orientador: Profa Dra Tânia Tomé Martins de Castro

Área de Concentração: Física

Unitermos: 1. Física; 2. Processo Estocástico;

3. Mudança de Fase, 4. Modelos Epidemiológicos,

5. Dinâmica de Populações 


\section{Agradecimentos}

Agradeço à minha orientadora, Prof ${ }^{a} \operatorname{Dr}^{a}$ Tânia Tomé, pela orientação e paciência dedicada durante este trabalho.

Ao Prof ${ }^{0} \operatorname{Dr}^{0}$ Mário José de Oliveira, pelas críticas e sugestões, muito construtivas.

Aos meus amigos, em especial aos da Física, pela diversão ou pelos momentos de descontração e pelas discussões sobre ciência e soluções para nossos problemas, entre outros tantos assuntos.

Aos professores J. A. Redinz, M. L. Martins, S. C. Ferreira Jr e S. O. Ferreira, pelo incentivo à pesquisa científica.

Ao CNPq, pelo auxílio financeiro. 



\section{Resumo}

Apresentamos o estudo de três modelos estocásticos, governados por equações mestras, que descrevem a propagação de epidemias em uma comunidade de indivíduos: o modelo de contato, o modelo suscetível-infectadorecuperado (SIR) e o modelo suscetível-infectado-recuperado-suscetível (SIRS). Os modelos são definidos em uma rede regular em que cada sítio da rede representa um indivíduo ao qual associamos uma variável estocástica que representa seu estado epidêmico. No modelo de contato cada indivíduo pode assumir apenas dois estados: suscetível (S) ou infectado (I), enquanto os outros dois modelos, que descrevem o processo de propagação de uma epidemia com imunização, apresentam um estado adicional que se refere ao indivíduo estar imune/recuperado ( $R$ ). Esses modelos exibem um estado absorvente de suscetíveis, correspondente à ausência da propagação da epidemia, e uma fase ativa, em que há a disseminação da epidemia. A fase ativa do modelo SIR é tal que, para tempos suficientemente grandes, os indivíduos permanecem suscetíveis ou se tornaram imunes devido a imunização de todos os indivíduos infectados.

Para a análise dos modelos, utilizamos as simulações de Monte Carlo, as aproximações de campo médio dinâmico e o processo estocástico denominada nascimento-e-morte, deduzido a partir da equação mestra. Construímos o diagrama de fase e determinamos a linha crítica entre a fase ativa e a fase absorvente. As simulações ao redor da linha crítica indicam que o modelo SIRS pertence à classe de universalidade da percolação direcionada. Para o modelo SIRS, observamos a existência, na fase ativa, do comportamento oscilante além do comportamento usual não oscilante. Também verificamos que, para o modelo de contato e o modelo SIR, a difusão explícita dos indivíduos, considerada como responsável pela migração, apresenta forte influência no limiar epidêmico. 



\section{Abstract}

We present a study of three stochastic models, governed by master equations, that describe the an epidemic spreading in a community of individuals: the contact model, the susceptible-infected-recovered (SIR) model and the susceptible-infected-recovered-susceptible (SIRS) model. The models are defined on a regular lattice in which each site represents an individual to whom we associate a stochastic variable that represents his epidemic state. In the contact model each individual can take only two states: susceptible (S) or infected (I), while the other two models, that describe the propagation process of an epidemic with immunization, present an additional state associated to the individual being immune/recovered ( $R$ ). These models exhibit an absorbing state of susceptibles, corresponding to the absence of epidemic spreading, and an active, in which there is epidemic dissemination. The active phase of the SIR model is such that, for sufficient long times, either the individuals have remained susceptible or have become immune by the immunization of all infected individuals.

To analyze the models, we used Monte Carlo simulations, dynamic meanfield approximations and the so called birth-and-death stochastic process, derived from the master equation. We built the phase diagram and determined the critical line between the active and absorbing phases. The simulations around the critical line indicates that the SIRS model belong to the directed percolation universality class. For the SIRS model, we observed the existence, in the active phase, of an oscillatory behavior in addition to the usual nonoscillatory behavior. We also verified that, for the contact and SIR model the diffusion of individuals, considered as responsible for migration, presents strong effect in the epidemic threshold. 



\section{Sumário}

Agradecimentos i

Resumo iii

Abstract $\quad$ v

1 Introducão 1

2 Modelo de Contato 5

2.1 Equacão Mestra para o Modelo de Contato . . . . . . . . . . 6

2.1.1 Aproximacão de Campo Médio Simples . . . . . . . . 8

2.1.2 Campo Médio com Aproximacão de Pares . . . . . . . 10

2.2 Modelo de Contato com Difusão . . . . . . . . . . . . . . . 14

2.2.1 Processo Difusivo Unidimensional . . . . . . . . . . . 14

2.2.2 Processo Difusivo Bidimensional . . . . . . . . . . . . 17

2.3 Simulacões de Monte Carld . . . . . . . . . . . . . . . . . . . . 19

2.3.1 Simulacões Estacionárias . . . . . . . . . . . . 20

2.3.2 Simulacões Dependentes do Tempo . . . . . . . . . . 28

3 Modelo SIR 33

3.1 Descricão do Modelo . . . . . . . . . . . . . . . . . . . 33

3.2 Aproximacão de Campo Médio Simples . . . . . . . . . . . . 35

3.3 Aproximacão de Campo Médio por Pares . . . . . . . . . . . 36

3.4 Simulacões de Monte Carld . . . . . . . . . . . . . . . . . . 39

3.4.1 Simulacões Estacionárias . . . . . . . . . . . . . . . 39 
3.4 .2 Simulacões Dependentes do Tempo . . . . . . . . . . 46

3.5 Modelo SIR com Difusãd . . . . . . . . . . . . . . . . . . . 49

4 Modelo SIRS

4.1 Descricão do Modelo . . . . . . . . . . . . . . . . . . . . . 59

4.1.1 Aproximacão de Campo Médio Simples . . . . . . . . 60

4.1.2 Aproximacão de Campo Médio por Pares . . . . . . . . 65

4.2 Processo "Birth and Death" . . . . . . . . . . . . . . 67

4.3 Simulacões de Monte Carlo . . . . . . . . . . . . . . . . 79

4.3.1 Simulacões Dependentes do Tempo . . . . . . . . . . 79

4.3.2 Simulacões Computacionais Estacionárias . . . . . . . 89

5 Conclusão $\quad 95$ 


\section{Capítulo 1}

\section{Introdução}

Historicamente o primeiro modelo matemático elaborado para estudo da propagação de doenças epidemicas foi desenvolvido por Daniel Bernoulli em 1760 [1]. Contudo somente no último século houve maior interesse em modelar processos de espalhamento de doenças. Em 1927, Kermack e McKendrick 2] propuseram um modelo relativamente simples para descrever a transmissão de uma doença epidêmica ocorrendo em uma população cujos indivíduos são dividos em três classes: susceptível (saudável sem contato com o agente causador da doença), infectado e imune (o qual torna-se inerte em relação à doença, de modo que nunca mais ficará doente devido a ela). Embora seja um modelo simples, os autores obtiveram uma curva epidêmica que apresenta uma descrição qualitativa da peste ocorrida em Bombaim entre dezembro de 1905 e julho de 1906. Além disso o modelo permite, conhecidos os parâmetros envolvidos, uma descrição qualitativa para o limiar de espalhamento de uma certa epidemia cujas características sejam concordantes às hipóteses do modelo.

Usualmente, a dinâmica de transmissão é modelada em termos de equações diferenciais baseadas na lei de ação das massas, e como todo modelo, é necessário que o conjunto de equações possa descrever os mecânismos essênciais envolvidos no processo de propagação da doença [?, 3, 4, 5, 6, 17. 8]. Entretanto, conciliar uma boa descrição da realidade e minimizar a quantidade de parâmetros não é uma tarefa fácil [9]. É necessário o conhecimento da relação vetor (patógeno)-hospedeiro e seus ciclos de vida [10, 11], bem como a profilaxia da doença [12, 13. Ao fazer esta análise, pode-se determinar o tempo de incubação, a durabilidade da infecção e imunidade, taxa de transmissão, resposta imunólogica e outros fatores envolvidos. Atualmente, há um conhecimento relativamente grande sobre diversas doenças epidêmicas, o que permite determinar alguns dos parâmetros associados à transmissão com precisão satisfatória [8, 13, 14, 15, 16, 17, 18, 19. 
Os modelos estocásticos para espalhamento de uma epidemia são importantes para a área de saúde pública e ciências médicas em geral, pois podem possibilitar uma melhor compreensão da dinâmica de espalhamento de uma doença. Do ponto de vista da física estatística, estes modelos, analisados no âmbito da dinâmica estocástica, possibilitam a investigação de transições de fase de não-equilíbrio e caracterização de classes de universalidade de modelos irreversíveis. Atualmente, já existe um bom desenvolvimento teórico na área de transições de fase de não equilíbrio [20, 21, 22, 23]. Este tem sido empregado em diversos problemas como percolação [24, 25, 26], cinética química [27, 28, 29, dinâmica de populações [?, 28, 30, 31, 32, 33, 34, 35, 36, 37, 38, teoria de jogos [39, 40, e da computação [41, 42].

Usando o formalismo da mecânica estatística de não-equilíbrio estudamos três diferentes modelos estocásticos, nos quais consideramos os indivíduos da população residindo em reticulados, com interações locais, e evoluindo no tempo de acordo com uma equação mestra. Nestes modelos consideramos que cada indivíduo é alocado em um sítio da rede e classificado conforme seu estado de saúde. Buscamos aprimorar estes modelos introduzindo a estrutura espacial e para dois deles analisamos também o efeito de migração populacional.

No capítulo 2 é apresentado o estudo do modelo de contato também denominado processo de contato [4, 20, 26, 43, 44]. Neste modelo cada indivíduo pode estar infectado ou suscetível. Um indivíduo suscetível pode tornarse infectado devido ao contato com um primeiro vizinho infectado. Não é considerado que haja período de latência e um indivíduo infectado pode espontâneamente recuperar-se, ficando novamente suscetível, entretanto o processo de recuperação não garante imunidade ao indivíduo.O processo de infecção é auto-catalítico, isto significa que para criar um novo infectado é necessário que haja a presença de pelo menos um vizinho infectado. A probabilidade de contaminação é proporcional ao número de vizinhos infectados. Dadas estas regras de reação, vemos que probabilidades baixas de contaminação não permitem a manutenção de disseminação da doença e em algum instante não resta nenhum infectado no agregado e, portanto, a epidemia cessa atingindo um estado absorvente em que toda a população está suscetível. Entretanto, a partir de um certo limiar de contaminação o regime estacionário é caracterizado por exibir densidade não nula de infectados, correspondendo à um estado ativo no qual a epidemia nunca cessa. Portanto, embora seja um modelo simples, o processo de contato exibe uma transição de fase fora do equilíbrio termodinâmico, o que faz dele um importante modelo para estudo de transições de fase.

No capítulo 3, analisamos o modelo SIR [2, 5, 6, 13, 30, no qual supõe-se que a contaminação, como no processo de contato, seja um processo auto- 
catalítico, e uma vez infectado o indivíduo espontaneamente pode recuperarse ficando imune. Assim os indivíduos podem pertencer a uma das seguintes classes: susceptível (S), infectado (I) ou recuperado/imune (R). Ao analisar este modelo percebe-se que há um limiar de contaminação/recuperação que define se partindo de um único foco, haverá ou não proliferação da doença. Neste modelo o parâmetro de ordem é a densidade de imunes e há uma fase que apresenta densidade nula de imunes, correspondente ao caso em que a epidemia cessa rapidamente sem se espalhar, e uma outra fase em que a epidemia se espalha afetando uma parcela significativa da população e que portanto apresenta densidade não nula de imunes. Para tempos longos, sempre é atingido um estado absorvente pois uma vez que o indivíduo torna-se imune ele não sai mais deste estado. Deste modo o modelo apresenta estados absorvente em ambas as fases. O que as diferencia é que em uma a epidemia se espalha e na outra ela se encerra rapidamente sem deixar vítimas. Este modelo tem sido amplamente estudado e apresenta uma série de aplicações no estudo de diversas doenças em que o processo de recuperação conduz naturalmente à imunização [45, 46, 47, 48, 49, 50].

Embora o modelo SIR seja um pouco mais realístico que o modelo de contato, há doenças que o processo de recuperação garante apenas uma imunidade temporária e espontaneamente um indivíduo imune perde sua resistência à doença tornando-se suscetível. Nestes casos temos um processo cíclico, no qual um indivíduo suscetível torna-se infectado, e uma vez infectado ele pode recuperar-se espontâneamente ficando temporariamente imunizado, mas espontaneamente ele perde a resistência adquirida e volta a ficar suscetível a uma nova contaminação. Com estas regras de reação define-se o modelo SIRS [51, 52, 53], definido no capítulo 4, o qual pode ser entendido com uma generalização do modelo SIR devido à adição de mais uma transição espontânea. Entretanto, diferentemente do modelo SIR, este modelo apresenta um único estado absorvente correspondente à população totalmente susceptível e um estado ativo, no qual as densidades de susceptíveis, infectados e imunes são não nulas. Ademais, temos o interesse em determinar a classe de universalidade do modelo SIRS, pois embora tenha sido apontado que modelos com um único estado absorvente pertencem à classe da percolação direcionada [54, 55], não temos conhecimento de estudos específicos para o modelo SIRS estruturado.

Para o modelo de contato e SIR analisamos também o efeito de difusão entre os indivíduos na rede. A existência de um processo localmente difusivo permite um indivíduo migrar e assim pode ser interpretado como um mecanismo gerador da mobilidade dos indivíduos na rede [35, 56, 57]. Esta é uma tentativa de agregar uma dinâmica de difusão à população e como veremos apresenta forte influência nos limiares de contaminação. 


\section{Capítulo 2}

\section{Modelo de Contato}

O modelo de contato é um modelo estocástico definido em uma rede de $N$ sítios. Em cada sítio reside um indivíduo que pode assumir somente os estados suscetível ou infectado. Os indivíduos infectados podem contaminar seus primeiros vizinhos e assim, para que um indivíduo suscetível fique infectado é necessário que haja pelo menos um vizinho infectado, e a probabilidade de infecção é proporcional ao número de vizinhos infectados. Por outro lado, um infectado pode espontâneamente recuperar-se, ficando novamente suscetível.

Na figura 2.1 representamos os processos de contaminação (criação de infectado) e recuperação (aniquilação de infectado) para uma rede linear onde cada sítio possui apenas dois vizinhos. A transmissão ocorre com taxa $n \lambda / \zeta$ em que $n$ é o número de vizinhos infectados e $\zeta$ é a coordenação da rede.

\section{processo de contaminação}

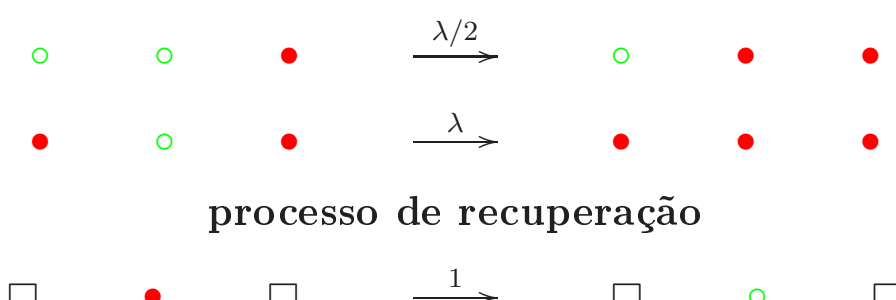

Figura 2.1: Representação dos processos de contaminação e recuperação. Neste diagrama $\circ$ representa um indivíduo suscetível e • denota um indivíduo infectado. O símbolo $\square$ significa que o processo independe dos vizinhos. 


\subsection{Equação Mestra para o Modelo de Contato}

Usando a equação mestra [22, 29, 43, 44, que governa a dinâmica de processos markovianos

$$
\frac{d}{d t} P(\eta, t)=\sum_{\eta^{\prime}}\left\{W\left(\eta \mid \eta^{\prime}\right) P\left(\eta^{\prime}, t\right)-W\left(\eta^{\prime} \mid \eta\right) P(\eta, t)\right\}
$$

em que $P(\eta, t)$ é a probabilidade do sistema ser encontrado na configuração microscópica $\eta$ no instante $t$. No caso de uma rede com $N$ sítios a configuração do sistema é denotada por,

$$
\eta=\left(\eta_{1}, \eta_{2}, \ldots, \eta_{i}, \ldots, \eta_{N}\right)
$$

em que a variável estocástica $\eta_{i}$ é uma variável estocástica associada ao sítio $i$ que assume dois valores $\eta_{i}=0$ (sítio vazio/suscetível) ou $\eta_{i}=1$ (sítio ocupado/infectado).

A partir da equação mestra podemos calcular a média uma função $f(\eta)$ dependente de $\eta$. Para tanto consideramos uma dinâmica temporal assíncrona em que somente um sítio é atualizado por unidade de tempo (dinâmica de um sítio). Isso significa que a probabilidade de transição $W\left(\eta \mid \eta^{\prime}\right)$ é dada por

$$
W\left(\eta \mid \eta^{\prime}\right)=\sum_{i=1}^{N} \delta\left(\eta_{1}, \eta_{1}^{\prime}\right) \delta\left(\eta_{2}, \eta_{2}^{\prime}\right) \ldots \delta\left(\eta_{i}^{i}, \eta_{i}^{\prime}\right) \ldots \delta\left(\eta_{N}, \eta_{N}^{\prime}\right) w_{i}\left(\eta^{\prime}\right)
$$

em que $\eta^{i}$ (índice superescrito à direita) é a configuração obtida de $\eta^{\prime}$ pela atualização do i-ésimo sítio para seu próximo estado anti-cíclico $(1 \rightarrow 0,0 \rightarrow$ 1) e $\delta(\alpha, \beta)$ denota o delta de Kronecker, $w_{i}\left(\eta^{\prime}\right)$ denota a probabilidade de transição por sítio.

A média da grandeza de estado $f(\eta)$ sobre a distribuição de probabilidade $P(\eta, t)$ é definida por

$$
<f(\eta)>=\sum_{\eta} f(\eta) P(\eta, t)
$$

Utilizando as equações (2.1), (2.3) e (2.4) obtemos a equação de evolução 
temporal de $f(\eta)$

$$
\begin{aligned}
\frac{d}{d t}<f(\eta)>= & \sum_{i}^{N} \sum_{\eta} \sum_{\eta^{\prime}}\left\{f\left(\eta_{1}^{\prime}, \ldots, \eta_{i}^{\prime}, \ldots, \eta_{N}^{\prime}, t\right) \delta\left(\eta_{i}, 1-\eta_{i}^{\prime}\right)\right. \\
& \left.\prod_{\substack{j=1 \\
(j \neq i)}}^{N} \delta\left(\eta_{j}, \eta_{j}^{\prime}\right) w_{i}\left(\eta_{1}^{\prime}, \ldots, \eta_{i}^{\prime}, \ldots, \eta_{N}^{\prime}\right) P\left(\eta_{1}^{\prime}, \ldots, \eta_{i}^{\prime}, \ldots, \eta_{N}^{\prime}, t\right)\right\}- \\
& \sum_{i}^{N} \sum_{\eta} \sum_{\eta^{\prime}}\left\{f\left(\eta_{1}, \ldots, \eta_{i}, \ldots, \eta_{N}, t\right) \delta\left(1-\eta_{i}^{\prime}, \eta_{i}\right)\right. \\
& \left.\prod_{\substack{j=1 \\
(j \neq i)}}^{N} \delta\left(\eta_{j}^{\prime}, \eta_{j}\right) w_{i}\left(\eta_{1}, \ldots, \eta_{i}, \ldots, \eta_{N}\right) P\left(\eta_{1}, \ldots, \eta_{i}, \ldots, \eta, t\right)\right\} .
\end{aligned}
$$

Este procedimento possibilita escrever a variação temporal da média de uma grandeza de estado numa notação compacta, dependente apenas da probabilidade de transição por sítio $w_{i}(\eta)$.

Como todos os deltas de Kronecker serão nulos, exceto $\delta\left(\eta_{i}, 1-\eta_{i}^{\prime}\right)=\delta\left(\eta_{i}, \eta_{i}^{i}\right)$ e $\delta\left(1-\eta_{i}, \eta_{i}^{\prime}\right)=\delta\left(\eta_{i}^{i}, \eta_{i}\right)$. Podemos escrever

$$
\begin{gathered}
\frac{d}{d t}<f(\eta)>=\sum_{i} \sum_{\eta}\left\{f(\eta) \omega_{i}\left(\eta^{i}\right) P\left(\eta^{i}, t\right)-f(\eta) \omega_{i}(\eta) P(\eta, t)\right\} \\
=\sum_{i}<\left\{f\left({ }^{i} \eta\right)-f(\eta)\right\} \omega_{i}(\eta)>
\end{gathered}
$$

${ }^{i} \eta$ denota a configuração obtida de $\eta$ em o i-ésimo sítio atinge seu próximo estado cíclico $(0 \rightarrow 1,1 \rightarrow 0)$.

Para calcular a probabilidade do i-ésimo sítio estar ocupado (infectado) consideramos

$$
f(\eta)=\delta\left(\eta_{i}, 1\right)
$$

e definimos a densidade de infectados

$$
P_{i}(1)=<\delta\left(\eta_{i}, 1\right)>.
$$

Usando a equação (2.6) temos

$$
\frac{d}{d t} P_{i}(1)=<\left\{\delta\left({ }^{i} \eta_{i}, 1\right)-\delta\left(\eta_{i}, 1\right)\right\} \omega_{i}(\eta)>
$$

$\operatorname{mas} \delta\left({ }^{i} \eta_{i}, 1\right)=\delta\left(\eta_{i}, 0\right)$ e $\operatorname{assim}$

$$
\frac{d}{d t} P_{i}(1)=<\delta\left(\eta_{i}, 0\right) \omega_{i}(\eta)-\delta\left(\eta_{i}, 1\right) \omega_{i}(\eta)>.
$$


A probabilidade de transição para o processo de contato pode ser escrita como

$$
\omega_{i}(\eta)=\frac{1}{1+\lambda} \delta\left(\eta_{i}, 0\right)+\frac{1}{\zeta} \frac{\lambda}{1+\lambda} \sum_{\delta} \delta\left(\eta_{\delta}, 1\right),
$$

em que $\zeta$ é a coordenação da rede, $\lambda$ é a taxa de infecção e a soma é feita sobre os primeiros vizinhos do sítio $i$.

Substituindo a equação (2.9) na equação (2.8) obtemos

$$
\frac{d}{d t} P_{i}(1)=<\frac{\lambda}{\zeta} \delta\left(\eta_{i}, 0\right) \sum_{\delta} \delta\left(\eta_{i+\delta}, 1\right)-\delta\left(\eta_{i}, 1\right)>
$$

$\mathrm{Ou}$

$$
\frac{d}{d t} P_{i}(1)=\frac{\lambda}{\zeta} \sum_{\delta} P_{i, i+\delta}(01)-P_{i}(1),
$$

o índice $\delta$ no somatório representa a soma sobre os primeiros vizinhos do sítio $i$, contabilizando o total de vizinhos infectados. A probabilidade conjunta $P_{i, i+\delta}(01)$ é a probabilidade do sítio $i$ estar vazio (suscetível) e seu vizinho estar ocupado (infectado).

Considerado que a rede seja espacialmente isotrópica, temos

$$
\frac{d}{d t} P_{i}(1)=\lambda \sum_{\delta} P_{i, i j}(01)-P_{i}(1) .
$$

Uma breve discussão deste mesmo modelo com anisotropia espacial é apresentada na referência [20].

\subsubsection{Aproximação de Campo Médio Simples}

A aproximação de campo médio simples consiste em descorrelacionar a probabilidade conjunta

$$
P_{i j}(\alpha \beta)=P_{i}(\alpha) P_{j}(\beta)
$$

nesta aproximação a equação (2.11) se escreve:

$$
\frac{d}{d t} \rho=\lambda \rho(1-\rho)-\rho,
$$

em que introduzimos $P_{i}(1)=\rho$ (densidade de sítios ocupados) e usamos a condição de normalização $P_{i}(0)+P_{i}(1)=1$.

As soluções estacionárias da equação (2.13) são

$$
\rho=0
$$


e

$$
\rho=\frac{\lambda-1}{\lambda} .
$$

A primeira solução corresponde ao estado absorvente (todos os indivíduos suscetíveis) enquanto a segunda corresponde à fase ativa, com coexistência de indivíduos saudáveis e infectados. A transição de fase ocorre no ponto crítico $\lambda_{c}=1$ e o parâmetro de ordem apresenta o comportamento

$$
\rho \sim\left(\lambda-\lambda_{c}\right)^{\beta}, \quad \lambda>\lambda_{c},
$$

em que $\beta$ é o expoente crítico associado ao parâmetro de ordem $\rho$; na aproximação de campo médio temos $\beta=1$.

A equação (2.13) pode ser analiticamente resolvida tendo como resultado

$$
\rho(t)=\frac{\lambda-\lambda_{c}}{\lambda\left(1-e^{-\left(\lambda-\lambda_{c}\right) t}\right)} .
$$

No limite assintótico de tempo longos temos

$$
\lim _{t \rightarrow \infty} \rho(t)=\left\{\begin{array}{rcc}
0 & \text { se } & \lambda<\lambda_{c} \\
\frac{\lambda-1}{\lambda} & \text { se } & \lambda \geq \lambda_{c} .
\end{array}\right.
$$

Na figura 2.2 mostramos a dependência do parâmetro de ordem em relação à taxa de infecção $\lambda$ na aproximação de campo médio simples para uma rede unidimensional. Vemos abaixo do limiar de infecção $\lambda_{c}=1$ a densidade de infectados é nula (correspondendo ao estado absorvente de suscetíveis) e para $\lambda>\lambda_{c}$ a densidade de infectados é não nula, o que corresponde à fase ativa.

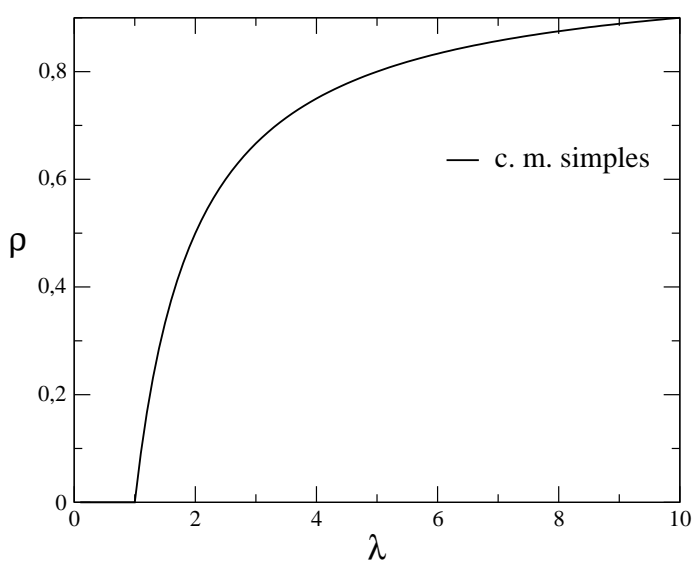

Figura 2.2: Densidade estacionária de infectados $\rho$ versus taxa de infecção $\lambda$, na aproximação de campo médio simples para uma rede unidimensional. 


\subsubsection{Campo Médio com Aproximação de Pares}

A equação de evolução temporal para a correlação de pares $P(01)$ é calculada usando a equação (2.6) com

$$
f(\eta)=\delta\left(\eta_{i}, 0\right) \delta\left(\eta_{j}, 1\right), \quad \text { e, portanto, } \quad<\delta\left(\eta_{i}, 0\right) \delta\left(\eta_{j}, 1\right)>=P_{i j}(01) .
$$

Podemos escrever

$$
\frac{d}{d t} P_{i j}(01)=\sum_{k=1}^{N}<\left\{\delta\left({ }^{k} \eta_{i}, 0\right) \delta\left({ }^{k} \eta_{j}, 1\right)-\delta\left(\eta_{i}, 0\right) \delta\left(\eta_{j}, 1\right)\right\} \omega_{k}(\eta)>
$$

Analisando a soma do lado direito da equação (2.19) há três casos há considerar

1. Se $k \neq i$ e $k \neq j$ então:

$$
\begin{aligned}
& \delta\left({ }^{k} \eta_{i}, 0\right) \delta\left({ }^{k} \eta_{j}, 1\right)-\delta\left(\eta_{i}, 0\right) \delta\left(\eta_{j}, 1\right)= \\
& \delta\left(\eta_{i}, 0\right) \delta\left(\eta_{j}, 1\right)-\delta\left(\eta_{i}, 0\right) \delta\left(\eta_{j}, 1\right)=0 .
\end{aligned}
$$

2. Se $k=1$ e $k \neq j$ então:

$$
\begin{gathered}
\delta\left({ }^{k} \eta_{i}, 0\right) \delta\left({ }^{k} \eta_{j}, 1\right)-\delta\left(\eta_{i}, 0\right) \delta\left(\eta_{j}, 1\right)= \\
\delta\left({ }^{i} \eta_{i}, 0\right) \delta\left({ }^{i} \eta_{j}, 1\right)-\delta\left(\eta_{i}, 0\right) \delta\left(\eta_{j}, 1\right)= \\
\delta\left(\eta_{i}, 1\right) \delta\left(\eta_{j}, 1\right)-\delta\left(\eta_{i}, 0\right) \delta\left(\eta_{j}, 1\right)= \\
\left\{\delta\left(\eta_{i}, 1\right)-\delta\left(\eta_{i}, 0\right)\right\} \delta\left(\eta_{j}, 1\right)
\end{gathered}
$$

que substituido na somatória, contribui com o termo

$$
\begin{gathered}
<\left\{\delta\left(\eta_{i}, 1\right)-\delta\left(\eta_{i}, 0\right)\right\} \delta\left(\eta_{j}, 1\right) \omega_{i}(\eta)>= \\
<1 \delta\left(\eta_{i}, 1\right) \delta\left(\eta_{j}, 1\right)-\frac{\lambda}{\zeta} \sum_{\delta} \delta\left(\eta_{i}, 0\right) \delta\left(\eta_{j}, 1\right) \delta\left(\eta_{i+\delta}, 1\right)>
\end{gathered}
$$

3. Se $k \neq i$ e $k=j$ então:

$$
\begin{gathered}
\delta\left({ }^{k} \eta_{i}, 0\right) \delta\left({ }^{k} \eta_{j}, 1\right)-\delta\left(\eta_{i}, 0\right) \delta\left(\eta_{j}, 1\right)= \\
\delta\left({ }^{j} \eta_{i}, 0\right) \delta\left({ }^{j} \eta_{j}, 1\right)-\delta\left(\eta_{i}, 0\right) \delta\left(\eta_{j}, 1\right)= \\
\delta\left(\eta_{i}, 1\right)\left\{\delta\left(\eta_{j}, 0\right)-\delta\left(\eta_{j}, 1\right)\right\},
\end{gathered}
$$


e, portanto, este termo contribui, na somatória com

$$
<\delta\left(\eta_{i}, 0\right)\left\{\delta\left(\eta_{j}, 0\right)-\delta\left(\eta_{j}, 1\right)\right\} \omega_{j}(\eta)>.
$$

Tomando $\eta_{j}=0$ no primeiro termo entre chaves e $\eta_{j}=1$ no segundo, temos

$$
<\frac{\lambda}{\zeta} \sum_{\delta} \delta\left(\eta_{i}, 0\right) \delta\left(\eta_{j}, 0\right) \delta\left(\eta_{j+\delta}, 1\right)-1 \delta\left(\eta_{i}, 0\right) \delta\left(\eta_{j}, 1\right)>
$$

Para exemplificar como se contabiliza a quantidade de infectados vizinhos a uma dado sítio, na expressão (2.21), usaremos uma rede regular quadrada, que portanto tem coordenação $(\zeta=4)$. Neste caso o aglomerado de sítios a ser analisado é escrito na forma

$$
P\left(\begin{array}{cccc} 
& \eta_{2} & \eta_{3} & \\
\eta_{1} & \eta_{i} & \eta_{j} & \eta_{4} \\
& \eta_{6} & \eta_{5} &
\end{array}\right)
$$

Então, a soma realizada na vizinhança do sítio $i, \operatorname{com} \eta_{i}=0$ e $\eta_{j}=1$ é

$$
\begin{aligned}
& P_{i, j, i+\delta}(011)=\sum_{\delta} \delta\left(\eta_{i}, 0\right) \delta\left(\eta_{j}, 1\right) \delta\left(\eta_{i+\delta}, 1\right)= \\
& \sum_{\eta_{1}, \eta_{2}, \eta_{6}}\left(1+\delta\left(\eta_{1}, 1\right)+\delta\left(\eta_{2}, 1\right)+\delta\left(\eta_{6}, 1\right)\right) P\left(\begin{array}{ccc} 
& \eta_{2} & \\
\eta_{1} & 0 & 1 \\
& \eta_{6} &
\end{array}\right) \\
& =\sum_{\eta_{1}, \eta_{2}, \eta_{6}} P\left(\begin{array}{ccc} 
& \eta_{2} & \\
\eta_{1} & 0 & 1 \\
& \eta_{6} &
\end{array}\right)+\sum_{\eta_{1}, \eta_{2}, \eta_{6}} \delta\left(\eta_{1}, 1\right) P\left(\begin{array}{ccc} 
& \eta_{2} & \\
\eta_{1} & 0 & 1 \\
& \eta_{6}
\end{array}\right)+ \\
& +\sum_{\eta_{1}, \eta_{2}, \eta_{6}} \delta\left(\eta_{2}, 1\right) P\left(\begin{array}{ccc} 
& \eta_{2} & \\
\eta_{1} & 0 & 1 \\
& \eta_{6} &
\end{array}\right)+\sum_{\eta_{1}, \eta_{2}, \eta_{6}} \delta\left(\eta_{6}, 1\right) P\left(\begin{array}{ccc} 
& \eta_{2} & \\
\eta_{1} & 0 & 1 \\
& \eta_{6} &
\end{array}\right) \\
& =P(01)+P(101)+P\left(\begin{array}{ll}
1 & \\
0 & 1
\end{array}\right)+P\left(\begin{array}{ll}
0 & 1 \\
1 &
\end{array}\right) .
\end{aligned}
$$

Como estamos tratando uma rede com isotropia espacial,

$$
\sum_{i, j, i+\delta} P(011)=P(01)+(\zeta-1) P(101)
$$

A soma na vizinhança do sítio $j, \operatorname{com} \eta_{i}=0$ e $\eta_{j}=0$ é

$\sum_{\delta} P_{i, j, j+\delta}(001)=<\delta\left(\eta_{i}, 0\right) \delta\left(\eta_{j}, 0\right)\left\{\delta\left(\eta_{i}, 1\right)+\delta\left(\eta_{3}, 1\right)+\delta\left(\eta_{4}, 1\right)+\delta\left(\eta_{5}, 1\right)\right\}>$ 


$$
\begin{gathered}
=\sum_{\eta_{3}, \eta_{4}, \eta_{5}}\left\{\delta\left(\eta_{3}, 1\right)+\delta\left(\eta_{4}, 1\right)+\delta\left(\eta_{5}, 1\right)\right\} P\left(\begin{array}{ccc} 
& \eta_{3} & \\
0 & 0 & \eta_{4} \\
& \eta_{5}
\end{array}\right) \\
=P\left(\begin{array}{ll}
0 & 1 \\
0 & 0
\end{array}\right)+P(001)+P\left(\begin{array}{cc}
0 & 0 \\
& 1
\end{array}\right) .
\end{gathered}
$$

Portanto, na ausência de anisotropia,

$$
\sum_{\delta} P_{i, j, j+\delta}(001)=(\zeta-1) P(001)
$$

Deste modo, com auxílio das equações (2.22) e (2.23), a equação (2.19) pode ser escrita como

$$
\frac{d}{d t} P_{i j}(01)=P_{i j}(11)-P_{i j}(01)+\lambda \frac{\zeta-1}{\zeta}\left[P_{i, j, k}(001)-P_{k, i, j}(101)\right] .
$$

Na aproximação de pares, truncamos a dependência nas correlações de três sítios da forma

$$
P_{i j k}(\alpha \beta \gamma)=\frac{P_{i j}(\alpha \beta) P_{j k}(\beta \gamma)}{P_{j}(\beta)},
$$

considerando no máximo probabilidades correlacionadas até segunda ordem.

As expressões (2.12) e (2.25) advém de uma expressão geral, como descrito na referência [31], em que um agregado de sítios $C$, formado pelo núcleo $A$ e vizinhança $B$ é descorrelacionado fazendo a aproximação

$$
P(C)=P(A) P(B \mid A) \cong P(A) \prod_{i \in B} \frac{P(i, A)}{P(A)} .
$$

Assim, na aproximação de pares, devemos usar as equações (2.11) e (2.24), descorrelacionando probabibilidades de distribuições de ordem superior a dois sítios.

Quando as redes apresentam isotropia espacial, aplicando a aproximação com pares, as equações para evolução dos momentos da distribuição são:

$$
\begin{array}{r}
\frac{d \rho}{d t}=\lambda \varphi-\rho, \\
\frac{d \varphi}{d t}=-2 \lambda \frac{\zeta-1}{\zeta} \frac{\varphi^{2}}{1-\rho}+\left[\lambda \frac{\zeta-2}{\zeta}-2\right] \varphi+\rho,
\end{array}
$$

em que

$$
P(1)=\rho \quad \text { e } \quad P(01)=\varphi
$$


e foi empregado as condições de normalização

$$
\begin{array}{r}
P(1)+P(0)=1, \\
P(01)+P(11)=P(1) .
\end{array}
$$

No regime estacionário,

$$
\frac{d \rho}{d t}=0 \quad \therefore \quad \varphi=\frac{\rho}{\lambda}
$$

e substituindo este resultado na expressão (2.27) temos

$$
\frac{d \varphi}{d t}=0=-2 \frac{\zeta-1}{\zeta} \frac{\rho^{2}}{\lambda(1-\rho)}+\left(\lambda \frac{\zeta-2}{\zeta}-2\right) \frac{\rho}{\lambda}+\rho
$$

cujas soluções são

$$
\rho=0 \quad \text { (estado absorvente) }
$$

e

$$
\rho=\frac{\lambda(\zeta-1)-\zeta}{\lambda(\zeta-1)-1} \quad(\text { estado ativo })
$$

Assim, a transição de fase ocorre no limiar

$$
\lambda_{c}=\frac{\zeta}{\zeta-1}
$$

Na figura 2.3 temos o parâmetro de ordem $\rho$ versus a taxa de infecção $\lambda$ na aproximação de campo médio simples e por pares, para o processo de contato em uma rede regular bidimensional $(\zeta=4)$. Vemos que na aproximação de campo médio simples a taxa crítica é $\lambda_{c(c m s)}=1$ enquanto na aproximação de campo médio com pares $\lambda_{c(\mathrm{cmp})}=4 / 3$, valor este que está mais próximo de valor obtido por simulações de Monte Carlo $\lambda_{c}=1,6488(1)$ [20]. Assim, vemos que considerando correlações de ordem superior nas correlações obtemos uma significativa melhora na determinação do ponto crítico. 


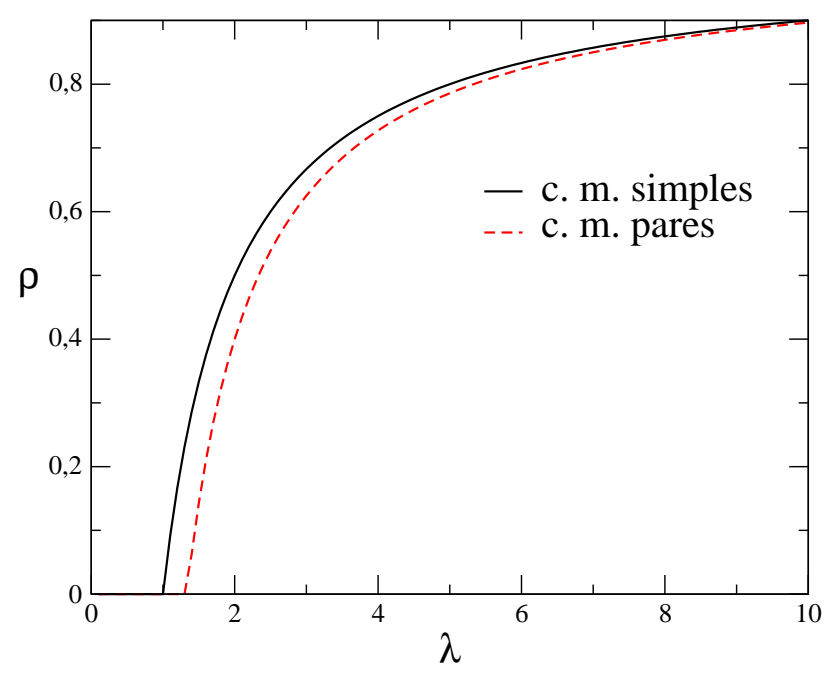

Figura 2.3: Densidade estacionária de infectados $\rho$ versus taxa de infecção $\lambda$, na aproximação de campo médio simples e por pares para uma rede bidimensional $(\zeta=4)$.

\subsection{Modelo de Contato com Difusão}

Desejamos tratar o modelo de contato numa população não sedentária, cujos indivíduos, embora estejam dispostos em reticulados, possam realizar migrações locais. Analisamos o caso em que a migração explícita ocorra através de um processo de difusão simples, no qual o movimento da partícula no reticulado seja efetuado por meio de uma troca de posição com um de seus primeiros vizinhos. Assim a dinâmica do modelo de contato é sutilmente modificada, adicionando o termo difusivo. O algoritmo consiste em sortear um sítio do reticulado, optar por realizar difusão (permutando a posição da partícula com um de seus primeiros vizinhos) ou realizar o processo de reação (processo de contato intrínseco). O processo de difusão ocorre com probabilidade $d$ e a reação com probabilidade complementar $1-d$. Quando $d$ vai a zero recaimos no modelo de contato original e o extremo $d=1$ representa o movimento aleatório.

\subsubsection{Processo Difusivo Unidimensional}

Como o modelo de contato exibe transição de fase em uma dimensão, primeiramente analisamos as propriedades do modelo em uma dimensão. Por meio de aproximações de campo médio encontramos o diagrama de fase do modelo em função da probabilidade de difusão, e posteriormente estendemos o procedimento para uma rede quadrada. 
Como o processo difusivo não aniquila nem cria partículas, a solução de campo médio simples não sofre modificação alguma quando há difusão. Entretanto, na aproximação de campo médio com pares, é necessário calcular a probabilidade de encontrar infectados ao lado de suscetíveis e o processo de difusão altera a densidade destes pares.

Representando um sítio ocupado (infectado) por • e vazio (suscetível) por $\odot$, mostramos na tabela 2.1 os aglomerados de sítios que apresentam mudança no número de pares devido ao processo difusivo, com as respectivas taxas de transição e variação no total de pares $P(01)=\Delta \circ \bullet$ criados (sinal + ) ou aniquilados (sinal - ).

Tabela 2.1: Aproximação de pares para o processo de contato unidimensional com difusão.

\begin{tabular}{lllc}
\hline \hline Processo & aproximação de pares & taxa & $\Delta \circ \bullet$ \\
$\circ \circ \circ \bullet \bullet \stackrel{d}{\rightarrow} \circ \bullet \bullet$ & $\frac{P(00) P(01) P(11)}{P(0) P(1)}$ & $\frac{(1-\rho-\varphi)(\rho-\varphi) \varphi}{\rho(1-\rho)}$ & +2 \\
$\bullet \bullet \circ \stackrel{d}{\rightarrow} \bullet \bullet \circ \circ$ & $\frac{P(01)^{3}}{P(0) P(1)}$ & $\frac{\varphi^{3}}{\rho(1-\rho)}$ & -2 \\
\hline \hline
\end{tabular}

Assim, as equações (2.11) e (2.24) se escrevem

$$
\begin{gathered}
\frac{d P_{i}(1)}{d t}=\lambda P(10)-P(1), \\
\frac{d}{d t} P_{i j}(01)=(1-d)\left\{P_{i j}(11)-P_{i j}(01)+\lambda \frac{\zeta-1}{\zeta}\left[P_{i, j, k}(001)-\right.\right. \\
\left.\left.P_{k, i, j}(101)\right]\right\}+d\{P(0011)-P(1010)\} .
\end{gathered}
$$

Realizando a aproximação de campo médio com pares e usando as definições (2.28) juntamente com a condição de normalização (2.29) temos

$$
\begin{gathered}
\frac{d \rho}{d t}=\lambda \varphi-\rho \quad \text { e } \\
\frac{d \varphi}{d t}=(1-d)\left\{-\frac{\lambda \varphi^{2}}{1-\rho}-2 \varphi+\rho\right\}+ \\
d \rho(1-\rho)\left\{(1-\rho-\varphi)(\rho-\varphi) \varphi-\varphi^{3}\right\} .
\end{gathered}
$$

No regime estacionário, temos a seguinte equação

$$
\varphi=\frac{\rho}{\lambda}
$$


que substituida na equação (2.34) resulta

$$
0=(1-d) \frac{\rho}{\lambda}\left[-\frac{\rho}{1-\rho}-2+\lambda\right]+\frac{d \rho}{\lambda(1-\rho)}\left\{\left(1-\rho-\frac{\rho}{\lambda}\right)\left(1-\frac{1}{\rho}\right)-\frac{\rho}{\lambda^{2}}\right\} .
$$

As soluções dessa equação são:

$$
\rho=0
$$

$\mathrm{Ou}$

$$
0=(1-d)\{-\rho+(\lambda-2)(1-\rho)\}+d\left\{1-\rho-\frac{1}{\lambda}\right\}
$$

Isolando $\rho$ nesta última equação temos:

$$
\begin{gathered}
\rho\{(1-d)(\lambda-1)+d\}=(1-d)(\lambda-2)+d\left(1-\frac{1}{\lambda}\right), \\
\rho=\frac{(1-d)(\lambda-1)+d-(1-d)+\frac{d}{\lambda}}{(1-d)(\lambda-1)+d} \\
\rho=1-\frac{(1-d)+\frac{d}{\lambda}}{\lambda-1+d(2-\lambda)} ; \quad \lambda \geq \lambda_{c} .
\end{gathered}
$$

No ponto crítico:

$$
\begin{gathered}
\lambda-1+d(2-\lambda)=(1-d)+\frac{d}{\lambda}, \\
\frac{\lambda^{2}(1-d)+(3 d-2) \lambda-d}{\lambda}=0 \quad \mathrm{e} \\
\lambda_{c}=\frac{(2-3 d) \pm \sqrt{(2-3 d)^{2}+4 d(1-d)}}{2(1-d)} .
\end{gathered}
$$

Mas, analisando o caso $d=0$ percebe-se que apenas a raiz positiva apresenta significado físico.

Na figura 2.4 exibimos o diagrama de fase deste modelo no plano $d-\lambda \mathrm{e}$ também o comportamento de $\rho$ como função de $d$ e $\lambda$. Conforme a equação (2.37) há uma linha crítica, no plano $d-\lambda$ na qual, cada probabilidade de difusão se associa a um ponto crítico. 


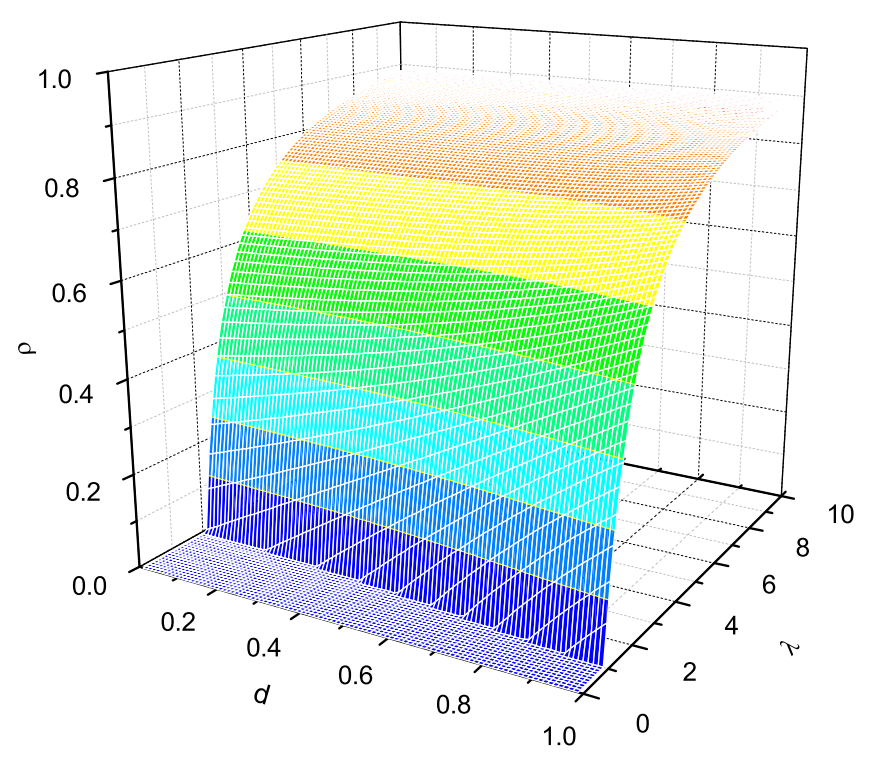

Figura 2.4: Diagrama de fase, no plano $d-\lambda$, para o processo de contato difusivo unidimensional. Este gráfico também exibe o parâmetro de ordem $\rho$ dado pela equação (2.36), em função da probabilidade de difusao $d$ e parâmetro de controle de infecção $\lambda$.

\subsubsection{Processo Difusivo Bidimensional}

Conforme aumentamos a coordenação da rede, havendo difusão, ampliamos também os graus de liberdade de movimento de uma partícula. Para uma rede quadrada $(z=4)$, devemos analisar todos os aglomerados de sítios cuja alteração dos sítios centrais provocam modifição do número de pares $\Delta$ • a fim de que possamos escrever o termo difusivo na equação (2.24).

Como esboçado na figura 2.5, representamos um aglomerado de oito sítios, formado por um par central $\eta_{i} \eta_{j}$, em que $\eta_{i}=0$ e $\eta_{j}=1$ os quais permutam com a probabilidade de difusão $d$. A vizinhança pode ser representada pela variável estocástica $\eta_{k},(k=1, \ldots, 6)$, a qual pode tomar os valores 0 ou 1 .

Para o caso unidimensional obtemos facilmente os aglomerados de sítios que sofrem alteração da quantidade de pares devido ao processo difusivo. Porém, para uma rede quadrada, temos um total de $2^{6}$ aglomerados de oito sítios a serem analisados, e portanto é conveniente calcular as taxas de transição e as respectivas variações de pares computacionalmente. Nesta análise devemos tomar o cuidado de excluir estruturas que diferem entre si apenas por reflexão, como está exemplificado na figura 2.6 


$$
\begin{array}{ccccccccc} 
& \eta_{1} & \eta_{6} & & & & \eta_{1} & \eta_{6} & \\
\eta_{2} & 0 & 1 & \eta_{5} & \stackrel{d}{\rightarrow} & \eta_{2} & 1 & 0 & \eta_{5} \\
& \eta_{3} & \eta_{4} & & & & \eta_{3} & \eta_{4} &
\end{array}
$$

Figura 2.5: Representação de um processo difusivo em uma rede quadrada. Devido à permutação de posições dos sítios centrais; dependendo da vizinhança podemos ter variação da quantidade de pares $P(01)$.

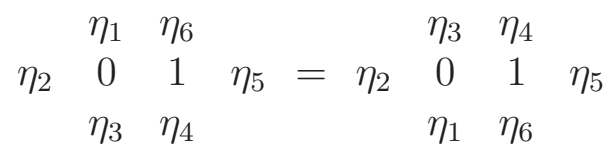

Figura 2.6: Uma vez fixado os estados dos sítios que formam a vizinhança do agregado, aglomerados que diferem entre si por uma reflexão devem ser contabilizados uma única vez no cálculo da criação/aniquilação de pares. Os dois agregados mostrados nesta figura distinguem-se por uma rotação de $180^{\circ}$.

Uma vez determinados as taxas de transição e o número de pares criados/aniquilados (em consequência do processo difusivo), reescrevemos as equações (2.11) e (2.24) como

$$
\frac{d \rho}{d t}=\lambda \varphi-\rho
$$

$\mathrm{e}$

$$
\begin{aligned}
\frac{d \varphi}{d t}= & (1-d)\left\{-\frac{\lambda \varphi^{2}}{1-\rho}-2 \varphi+\rho\right\}+\frac{2 d \varphi}{[\rho(1-\rho)]^{3}}\left\{( 1 - \rho - \varphi ) ^ { 3 } ( \rho - \varphi ) \left[2 \varphi^{2}+\right.\right. \\
& \left.4 \varphi(\rho-\varphi)+3(\rho-\varphi)^{2}\right]+(1-\rho-\varphi)^{2} \varphi\left[-2 \varphi^{3}+5 \varphi(\rho-\varphi)^{2}+\right. \\
& \left.2(\rho-\varphi)^{3}\right]+(1-\rho-\varphi) \varphi^{2}\left[-4 \varphi^{3}-5 \varphi^{2}(\rho-\varphi)+2(\rho-\varphi)^{3}\right]- \\
& \left.\varphi^{4}\left[3 \varphi^{2}+2 \varphi(\rho-\varphi)+2(\rho-\varphi)^{2}\right]\right\} .
\end{aligned}
$$

Para determinar o ponto crítico, resolvemos numericamente este sistema de equações usando o método de Runge-Kutta de quarta ordem (RK4). Na figura 2.7 é mostrado o diagrama de fase do modelo obtido com esta aproximação. 


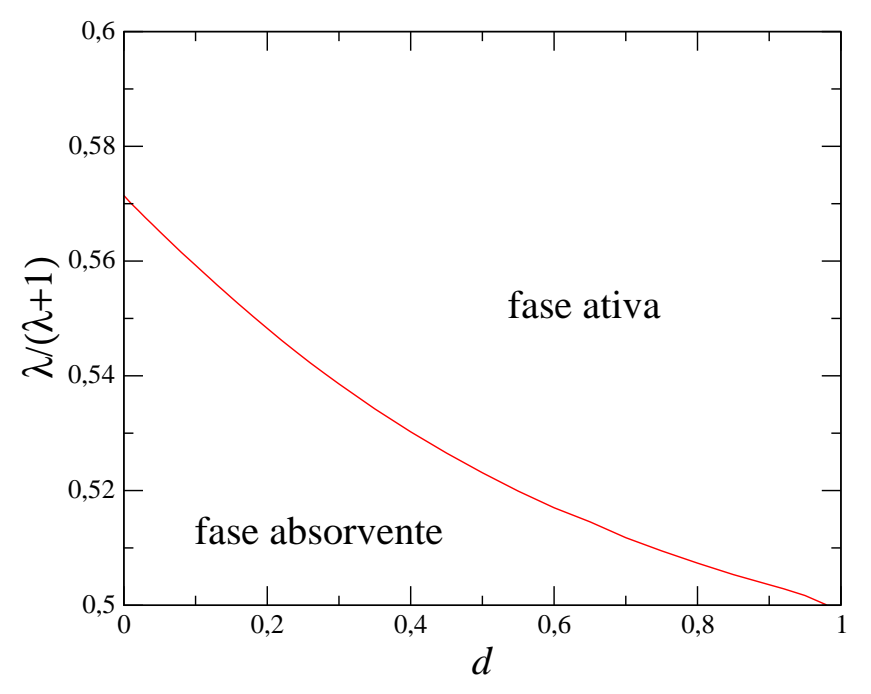

Figura 2.7: Probabilidade crítica de infecção versus probabilidade de difusão, na aproximação de campo médio com pares, para o processo de contato bidimensional com difusão. A partir deste gráfico vemos que a difusão provoca a redução no limiar de infecção, e assim quanto maior a mobilidade dos indivíduos maiores serão as chances de espalhamento da epidemia.

\subsection{Simulações de Monte Carlo}

O método de Monte Carlo [58, 43] permite reproduzir a natureza estocástica de um dado sistema realizando simulações computacionais. Para isso, desenvolvemos um algoritmo que possibilita gerar configurações microscópicas que evoluem a partir de uma dinâmica temporal que compreende as probabilidades de transição do modelo.

Para o modelo de contato usaremos o seguinte algoritmo:

1. Gera-se uma configuração da rede regular com $L^{d}$ sítios, em que $d$ é a dimensão da rede, na qual todos os sítios vazios com exceção do sítio central, se encontram no estado infectado.

2. Efetua-se o sorteio de um sítio da rede e um número aleatório $\gamma$ pertencente ao intervalo $[0,1)$.

3. Compara-se a probabilidade de transição. Se $\gamma<d$, em que $d$ é a probabilidade de difusão, então escolhe-se um sítio vizinho e permutase seus estados. Senão aplica-se o processo de reação (item seguinte). 
3.a Sorteia outro número aleatório e compara com a probabilidade de transição do sítio (equação 2.9). Se o número aleatório for maior que a probabilidade de transição, então o sítio é alterado para seu próximo estado cíclico.

3.b Se houver apenas um infectado na rede, impedimos que ele seja aniquilado.

4. Após o sorteio de $L^{d}$ sítios, contabiliza-se um passo de Monte Carlo e calcula-se as médias das grandezas de interesse.

5. Repete-se o ciclo a partir do passo 2 por um número de passos que o programador estipular.

A condição (3.b) introduzida em [59] consiste em uma pequena perturbação que impede uma realização cair no estado absorvente, pois para sistemas finitos o estado absorvente sempre é atingido. Note que esta condição é fundamental apenas nas proximidades do ponto crítico, e esta perturbação se torna desprezível para redes muito grandes. Uma alternativa à esta hipótese é apresentada em [60 está relacionada à geração da distribuição de probabilidades das distribuições das configurações microscópicas no regime quasi-estacionário.

Há outros algoritmos similares ao aqui descrito, que apresentam otimização de processamento computacional. Um dos mais usados está descrito nas referências 61, 62 e consiste em criar uma lista dos sítios ocupados e suas respectivas coordenadas. Isto permite sortear somente sítios ocupados, ou primeiros vizinhos de infectados, aos quais o processo de reação se aplica. Neste caso, o tempo passa a ser incrementado em intervalos $\Delta t=1 / N_{i}$, em que $N_{i}$ é o número de sítios ocupados.

\subsubsection{Simulações Estacionárias}

As simulações estacionárias são assim denominadas porque neste tipo de simulação calcula-se médias de grandezas no estado estacionário. A média é efetuada sobre um intervalo de tempo em que a realização esteja "termalizada", isto é, que não esteja sob efeito transiente. Para cada realização computa-se a densidade

$$
\rho_{t}=\frac{1}{N} \sum_{i=1}^{N} \delta\left(\eta_{i}, 1\right), \quad \mathrm{t}>\text { tempo transiente }\left(t_{t}\right)
$$


em que $N=L^{d}$ é o total de sítios da rede. O valor médio, é calculado sobre todo o intervalo de tempo

$$
<\rho>=\frac{1}{t_{\max }-t_{t}} \sum_{t>t_{t}}^{t_{\max }} \rho_{t},
$$

em que $t_{\max }$ é o tempo máximo de evolução desejado (dado em passos de Monte Carlo). Na prática uma simulação é feita utilizando várias realizações, sobre as quais se calcula o valor médio.

O modelo de contato exibe transição de fase de segunda ordem, e, portanto, o parâmetro de ordem vai a zero continuamente na transição. Contudo isto só ocorre no limite termodinâmico, no qual o tamanho do sitema é infinito. Para tamanhos finitos, como está ilustrado na figura 2.8 o que se percebe é que, na transição, a medida que se aumenta o tamanho da rede, o parâmetro de ordem torna-se mais próximo de zero nas vizinhanças de $\lambda_{c}$.

A teoria de escala de tamanho finito [58, 20, 21, 22, 59] mostra que podemos determinar o ponto crítico usando o cumulante reduzido de segunda ordem,

$$
u=\frac{<\rho^{2}>-<\rho>^{2}}{<\rho>^{2}}
$$

cuja magnitude no ponto crítico independe do tamanho do sistema. Mostrase ainda que próximo ao ponto crítico o parâmetro de ordem escala com o tamanho da rede segundo a relação

$$
\rho(\Delta, L) \sim L^{-\beta / \nu_{\perp}} f\left(\Delta L^{1 / \nu_{\perp}}\right)
$$

em que $f(x)$ é uma função universal, $\Delta=\lambda-\lambda_{c}, \operatorname{com} \lambda>\lambda_{c} ; \beta$ é o expoente crítico associado ao parâmetro de ordem da transição,

$$
\rho \sim(\Delta)^{\beta}
$$

e $\nu_{\perp}$ é o expoente crítico associado ao comprimento de correlação espacial $\xi$ que comporta-se como

$$
\xi \sim|\Delta|^{-\nu_{\perp}}
$$

Nas sub-seções seguintes são apresentados resultados de simulações computacionais do processo de contato difusivo em redes unidimensionais e bidimensionais com os respectivos diagramas de fase. 


\section{(a) Caso Unidimensional}

Na figura 2.8 é mostrada a densidade estacionária de infectados $\rho$ versus a taxa de infecção $\lambda$ para diferentes tamanhos de rede unidimensionais de tamanho $L$ com condições periódicas de contorno. Embora seja esperado que o parâmetro de ordem, no limite termodinâmico se anule na transição de fase, como realizamos simulações computacionais em redes de tamanho finito, devemos usar um método complementar para determinar com maior precisão o ponto crítico. Neste trabalho usamos o cumulante reduzido de segunda ordem, calculado conforme a equação (2.40). Na figura 2.9 temos gráfico do cumulante reduzido em função da taxa de infecção $\lambda$ para diferentes tamanhos de rede unidimensional de tamanho $L$. Como no ponto crítico, o cumulante independe do tamanho da rede, as curvas de cumulantes de diferentes tamanhos apresentam uma intersecçao, e assim podemos delimitar o ponto crítico com razoável precisão numérica.

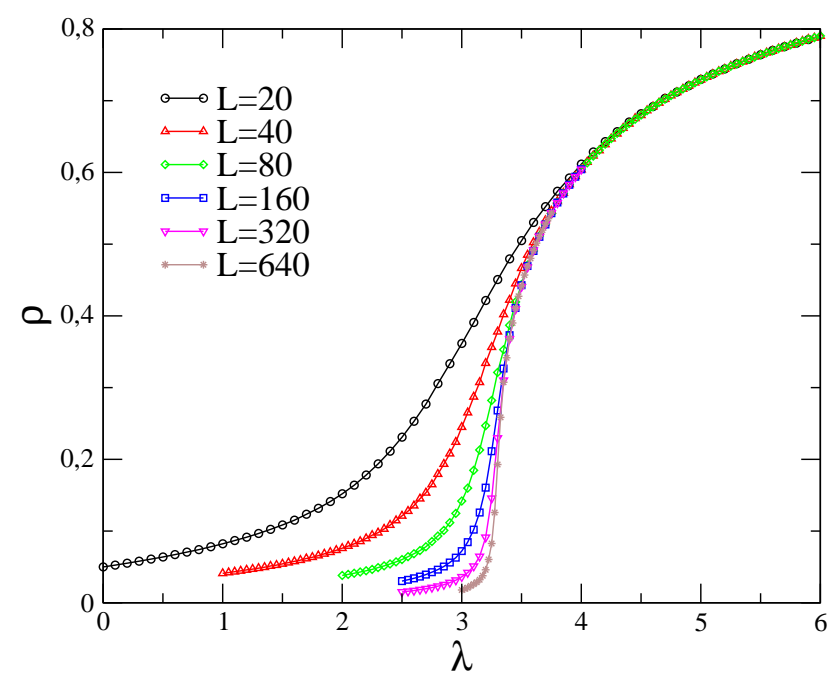

Figura 2.8: Densidade estacionária de infectados versus a taxa de infecção para vários tamanhos de rede.

Conforme a equação (2.42), podemos calcular o expoente crítico associado ao parâmetro de ordem da transição a partir de um gráfico $\log \rho$ versus $\log \Delta$, como mostrado na figura 2.3.1 Ao fazer esta análise devemos lembrar que a equação (2.42) é válida no limite $L \rightarrow \infty$, e assim, é necessário que as simulações para calcular a densidade de infectados, sejam realizadas para redes de tamanho grande. 


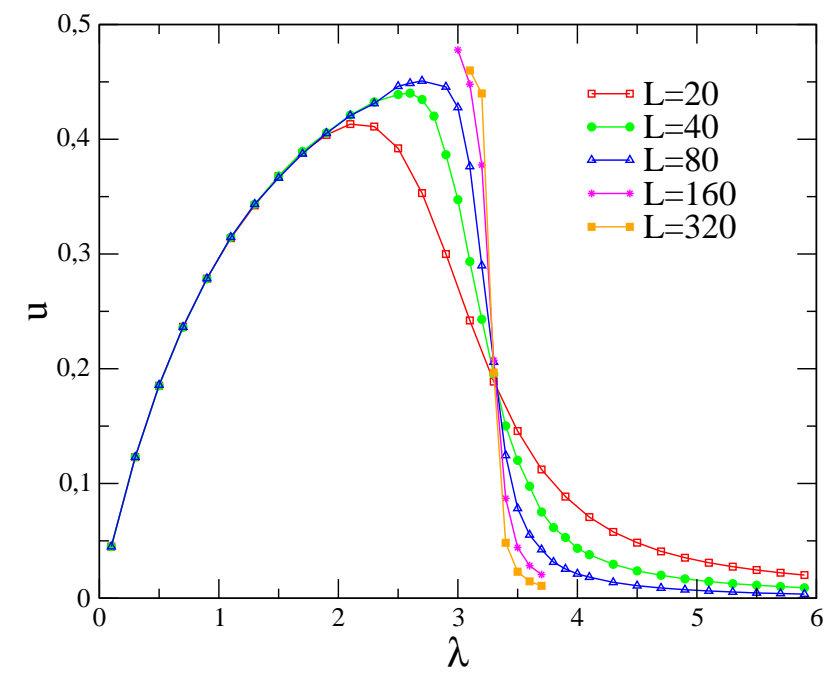

Figura 2.9: Cumulante reduzido versus o parâmetro de controle $\lambda$ para diversos tamanhos de rede $L$. O ponto de intersecção das curvas delimita o ponto crítico, $\lambda_{c}=3,310(19)$ e $u_{c}=0,196(18)$.

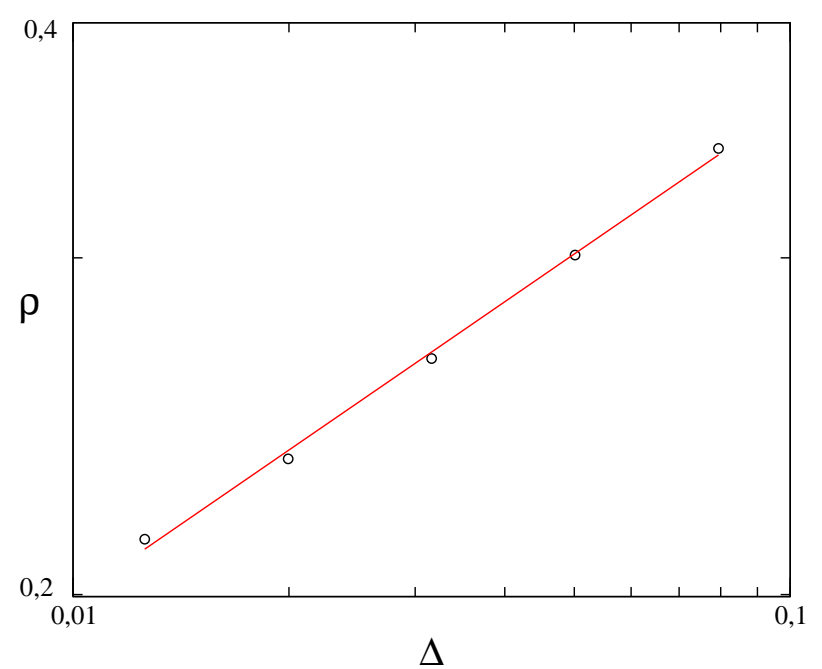

Figura 2.10: Densidade de infectados versus a distância ao ponto crítico $\Delta$. Ajustando uma reta ao pontos obtemos o expoente $\beta=0,26(1)$. As simulações foram executadas para rede de tamanho $L=640$. 
Pela expressão (2.41), conforme exibido na figura 2.11 no ponto crítico, fazendo um gráfico de $\log \rho$ versus $\log L$, em que $L$ é o tamanho da rede, podemos calcular a razão $\beta / \nu_{\perp}$, e tendo calculado $\beta$ previamente, obtemos $\nu_{\perp}$.

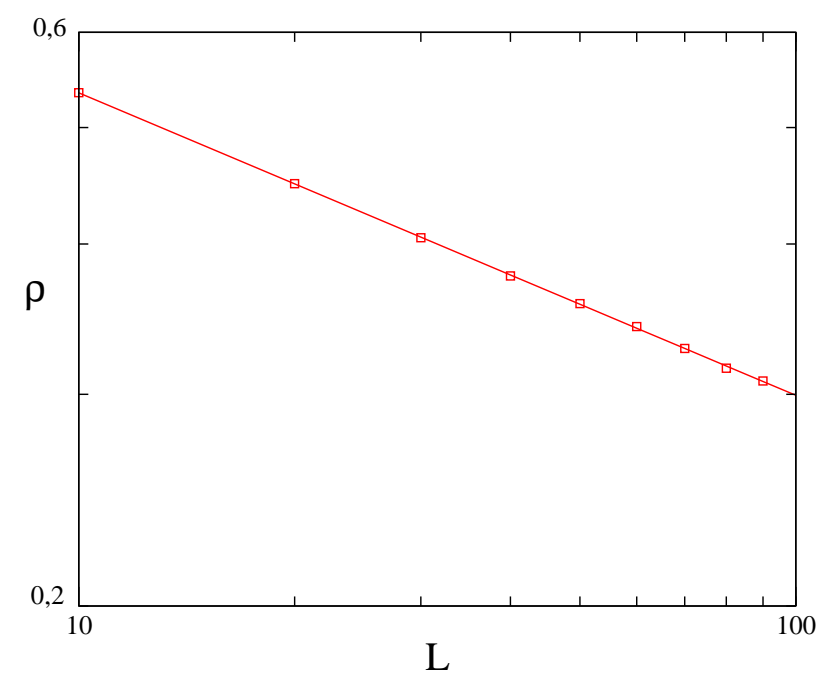

Figura 2.11: Densidade de infectados $\rho$ versus tamanho da rede $L$. Ajustando uma reta aos dados, obtemos o coeficiente linear $\beta / \nu_{\perp}=0,252(3)$.

Para probabilidade de difusão não nula realizamos as simulações estacionárias e determinamos o ponto crítico por meio do cumulante reduzido. Entretanto não foram calculados os expoentes críticos para o modelo difusivo. Na figura 2.12 mostramos gráficos dos cumulantes para duas probabilidades distintas de difusão. Nestes gráficos vemos que o aumento da probabilidade de difusão provoca a redução no limiar de infecção. 

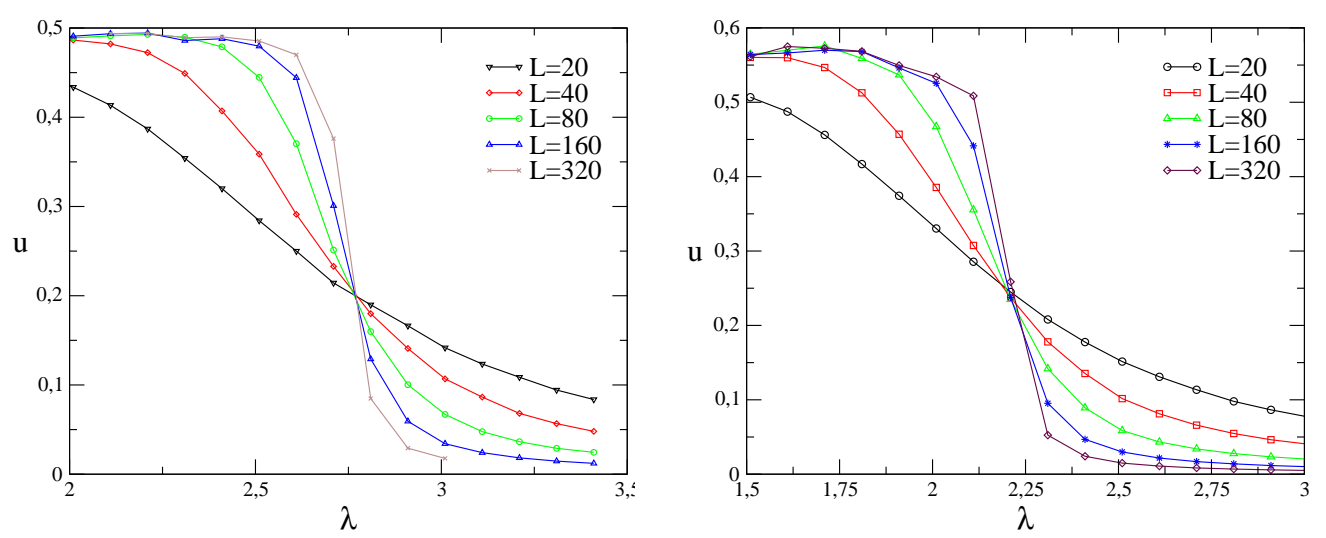

Figura 2.12: Cumulantes em função do parâmetro de controle $\lambda$, para diferentes tamanhos de rede. À esquerda a probabilidade de difusão é $d=0.2$ e no gráfico à direita $d=0.5$.

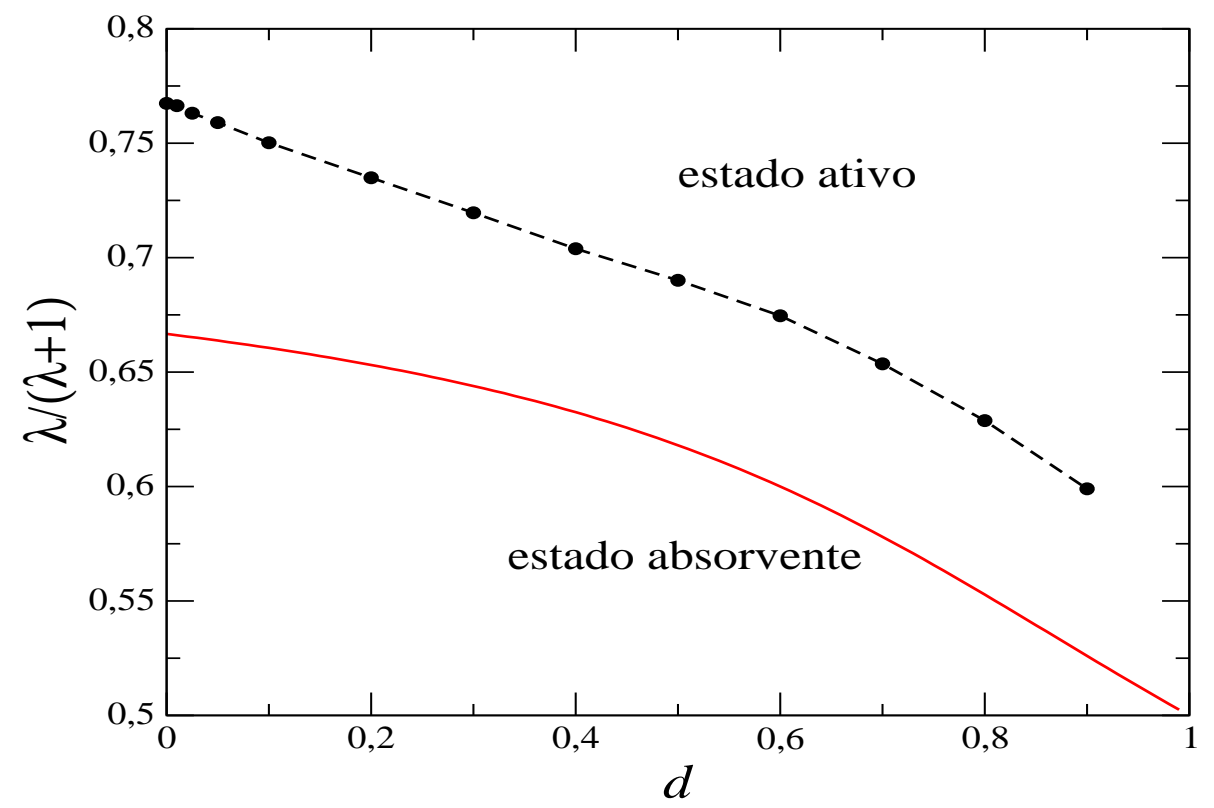

Figura 2.13: Diagrama de fase para o processo de contato difusivo unidimensional. Este gráfico exibe a probabilidade crítica de infecção $\lambda /(\lambda+1)$ em função da probabilidade de difusão $d$. A linha contínua é a solução obtida na aproximação de campo médio com pares (equação 2.37). Cada ponto em destaque na outra curva foi encontrado usando simulações computacionais estacionárias, a linha interlingando-os é um guia para os olhos. Comparando as duas soluções, vemos que a solução de campo médio qualitativamente concorda com os resultados provenientes de simulações computacionais. Para $d \rightarrow 1$ os resultados de simulações de Monte Carlo devem convergir para os resultados de campo médio. Porém, neste limite as simulações tornam-se demasiadamente lentas e não foram realizadas neste trabalho. 


\section{(b) Caso Bidimensional}

Também investigamos o modelo de contato definido em uma rede regular quadrada, com e sem difusão, por meio de simulações computacionais estacionárias. A figura 2.14 exibe a densidade de infectados $\rho$ versus a taxa de infecção $\lambda$ para diferentes tamanhos de rede de lado $L$ para o caso não difusivo. Pela análise do cumulante reduzido de segundo ordem, cujo gráfico é mostrado na figura 2.15, que no ponto crítico apresenta uma intersecção das curvas dos cumulantes calculados para diferentes tamanhos de rede, podemos determinar o ponto crítico.

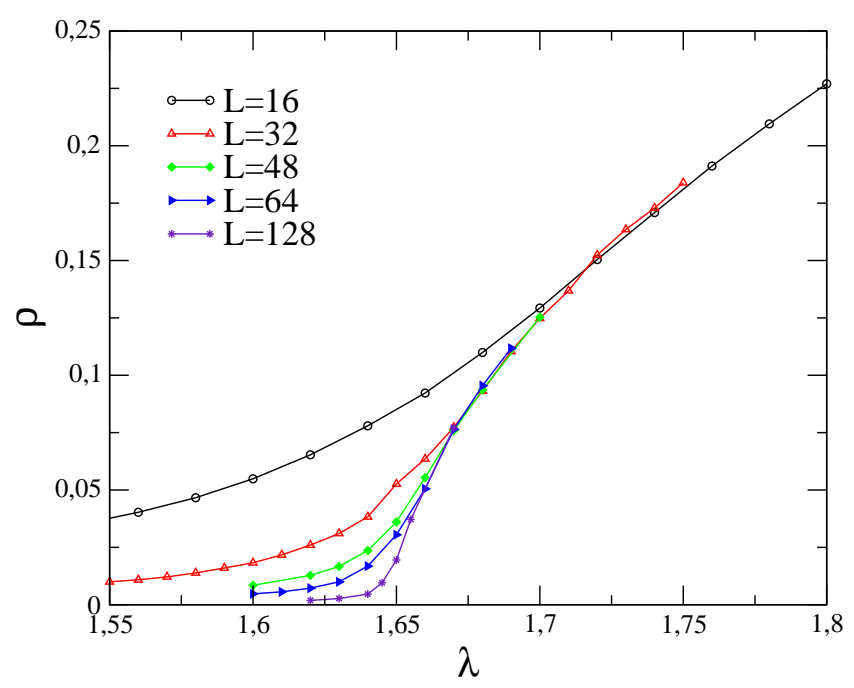

Figura 2.14: Densidade estacionária de infectados versus a taxa de infecção $\lambda$ para vários tamanhos de rede regular quadrada de lado $L$.

Para o modelo de contato difusivo bidimensional, também foram realizadas simulações computacionais estacionárias para diferentes probabilidades de difusão. Como no caso não difusivo, estimamos o ponto crítico a partir da análise gráfica do cumulante reduzido de segunda ordem em função da taxa de infecção.

A figura 2.16] exibe os diagramas de fase do modelo de contato difusivo bidimensional na aproximação de campo médio com pares e por meio de simulações computacionais estacionárias. Neste diagrama vemos que a aproximação de campo médio com pares descreve qualitativamente os resultados encontrados por meio de simulações de Monte Carlo. Além disso, vemos que do mesmo modo que modelo definido em uma rede unidimensional, a fase ativa cresce em função do aumento da probabilidade de difusão. 


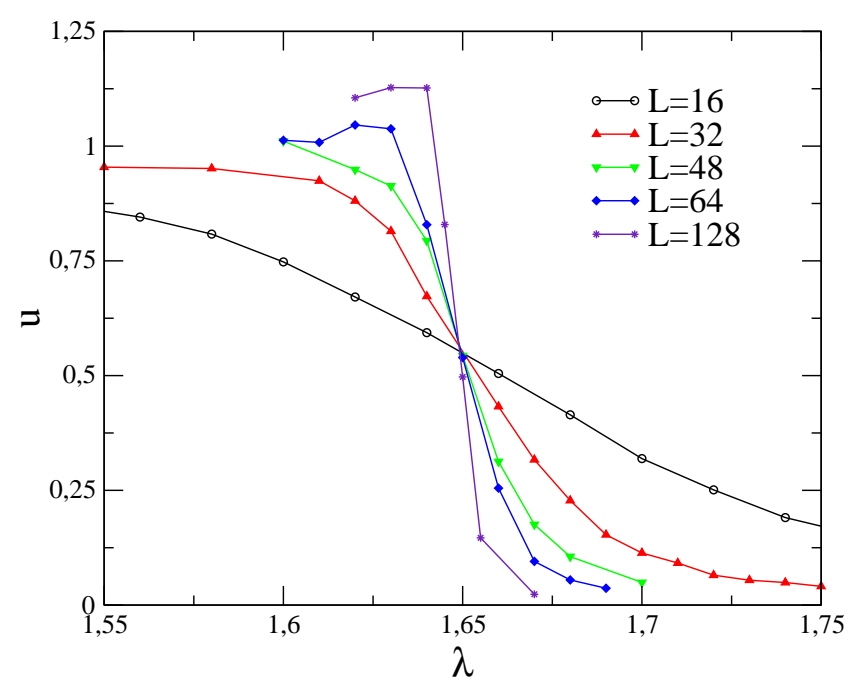

Figura 2.15: Cumulante versus o parâmetro de controle $\lambda$ para diversos tamanhos de rede $L$. O ponto de intersecção das curvas delimita o ponto crítico, o qual estimamos ser $\lambda_{c}=1,6490(5)$ e $u_{c}=0,5680(8)$.

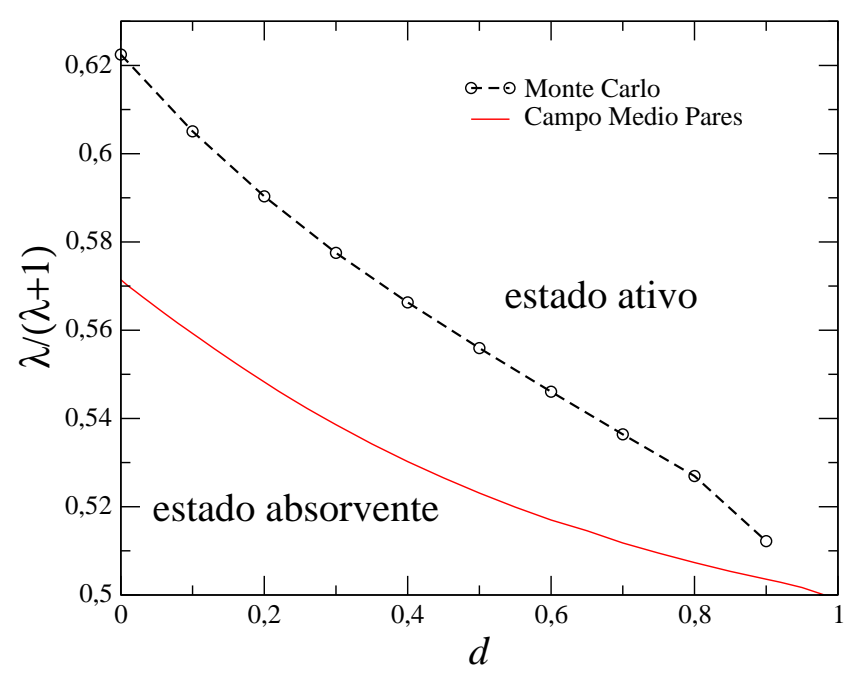

Figura 2.16: Probabilidade crítica de infecção versus a probabilidade de difusão $d$, delimitando o diagrama de fase para o processo difusivo bidimensional. A linha contínua é a solução obtida na aproximação de campo médio com pares (equação 2.39). Cada ponto da outra curva foi determinado usando simulações computacionais estacionárias, a linha tracejada é um guia para os olhos. Para $d \rightarrow 1$ os resultados de simulações de Monte Carlo devem convergir para os resultados de campo médio. Porém, neste limite as simulações tornam-se demasiadamente lentas e não foram realizadas neste trabalho. 
Na tabela 2.2] é apresentada a síntese dos resultados obtidos para o modelo de contato discutidos no presente capítulo.

Tabela 2.2: Parâmetros e expoentes críticos para o modelo não difusivo.

\begin{tabular}{llll}
\hline \hline rede & $\lambda_{c}$ & $\beta$ & $\beta / v_{\perp}$ \\
\hline \hline unidimensional & $3,310(19)$ & $0,26(1)$ & $0,252(3)$ \\
bidimensional & $1,6490(5)$ & & \\
\hline \hline
\end{tabular}

\subsubsection{Simulações Dependentes do Tempo}

Nas simulações dependentes do tempo, usamos o algoritmo descrito na seção 2.3, exluindo o passo $3 . b$ e o passo 5 é modificado: o tempo máximo de evolução é livre, cada simulação termina quando a realização atinge o estado absorvente ou algum infectado atinge a borda da rede; quando isso ocorre iniciamos uma nova realização. A cada passo de tempo calculamos o número de infectados $n(t)$ e o raio quadrático de espalhamento dos infectados $R^{2}(t)$, conforme as seguintes expressões:

$$
n(t)=\sum_{i=1}^{L} \delta\left(\eta_{i}, 1\right)
$$

e a distância quadrática dos indivíduos infectados em relação ao centro da rede,

$$
r^{2}(t)=\sum_{i=1}^{L} \delta\left(\eta_{i}, 1\right)(i-L / 2)^{2} .
$$

O sub-índice $i$ representa a coordenada de cada sítio. Estas expressões referem-se à uma rede unidimensional, para o caso bidimensional as somatórias precisam de mais um sub-índice para percorrer toda a rede.

Após simular um conjunto de $N_{a}$ realizações, calcula-se o número médio de infectados $N(t)$, o raio quadrático médio dos infectados $R^{2}(t)$ e a probabilidade de sobrevivência do processo epidêmico $P_{s}(t)$ conforme as expressões

$$
\begin{gathered}
N(t)=\frac{1}{N_{a}} \sum_{k=1}^{N a} n(t), \\
R^{2}(t)=\frac{1}{N_{a s}(t)} \sum_{t} r^{2}(t) \quad \mathrm{e}
\end{gathered}
$$




$$
P_{s}(t)=\frac{1}{N_{a}} \sum_{k=1}^{N a} H(t) .
$$

Na equação (2.45) $N_{a s}(t)$ é o número de realizações que apresentam infectados no instante $t$, e na equação (2.46) $H(t)$ é a função degrau e assume o valor 1 se ainda há infectado no instante $t$ ou zero caso contrário.

Conforme Grassberger e de la Torre [21], no ponto crítico estas grandezas comportam-se de acordo com as seguintes leis de potência,

$$
\begin{array}{r}
N(t) \sim t^{\eta} \\
R^{2}(t) \sim t^{z} \\
\text { e } \quad P_{s}(t) \sim t^{-\delta},
\end{array}
$$

em que os expoentes críticos dinâmicos $\eta, z$ e $\delta$, satisfazem a relação de hiperescala $2 \eta+4 \delta=d z$, sendo $d$ a dimensão espacial, e juntamente com os expoentes críticos estáticos caracterizam a classe de universalidade do modelo.

Construindo os gráficos de $\log N(t), \log R^{2}(t)$ e $\log P_{s}(t)$ versus $\log t$ no ponto crítico devemos obter retas, onde o coeficiente linear é o expoente dinâmico associado. Fora do ponto crítico obteremos curvas convexas no regime supercrítico e côncavas no regime subcrítico. Deste modo podemos determinar o ponto crítico com elevada precisão.

Efeitos de tamanho finito tornam-se expressivos neste tipo de simulação, na prática deve-se usar tamanhos de rede suficientemente grandes, para se obter um amplo intervalo de tempo. Como descrito por [35], podemos estimar um limite para o tempo máximo a ser usado na linearização dos dados fazendo uma análise mais detalhada dos efeitos de borda, o que na prática nos habilita a usar redes de tamanho não necessariamente muito grande.

A seguir apresentamos resultados de simulações dependentes do tempo para o processo de contato unidimensional sem difusão. Neste trabalho não calculamos os expoentes críticos para o modelo difusivo.

\section{(a) Caso Unidimensional}

Por meio de simulações dependentes do tempo, obtemos que a transição de fase para o processo de contato definido em uma dimensão ocorre em $\lambda_{c}=3,2980(5)$. Algumas curvas para o número de infectados, probabilidade de sobrevivência e raio quadrático são mostradas nas figuras 2.17 2.18 e 2.19. respectivamente, para diferentes valores do parâmetro $\lambda$. Para obter boa precisão númerica na determinação do ponto crítico é necessário que se 
faça muitas simulações para cada valor do parâmetro, aqui foi empregado um total de $10^{5}$ realizações. Curvas com taxa de infecção muito próximas não serão mostradas a fim de facilitar a visualização.

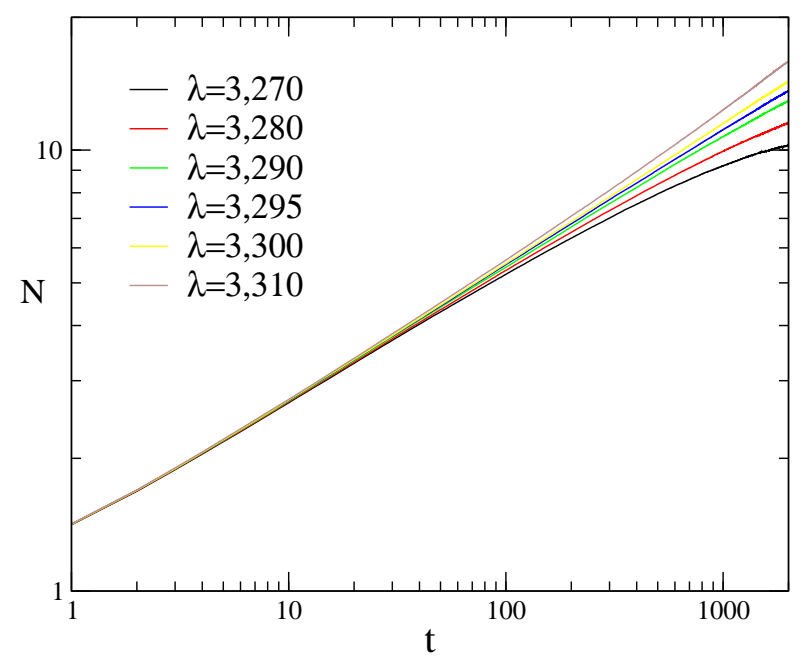

Figura 2.17: Número de infectados versus tempo para diferentes valores de $\lambda$. Percebe-se que $\lambda=3,100$ pertence à fase ativa equanto $\lambda=3,270$ está na fase absorvente. Nossa estimativa para o valor do parâmetro crítico e do expoente $\eta$ são $\lambda_{c}=3,2980(5)$ e $\eta=0,313(3)$.

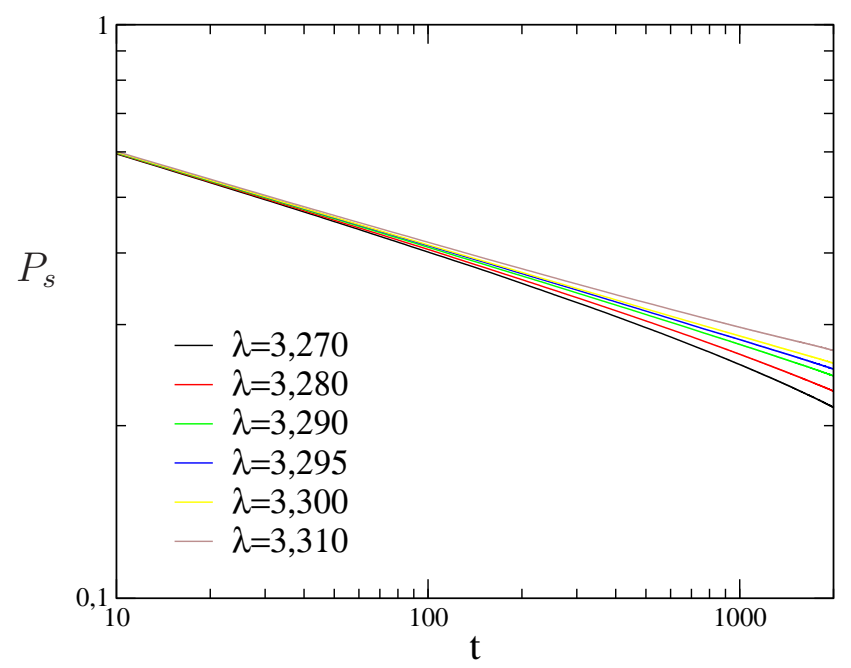

Figura 2.18: Probabilidade de sobrevivência versus tempo para diferentes valores do parâmetro $\lambda$ próximos à transição de fase. No ponto crítico calculamos o expoente $\delta=0,159(3)$. 


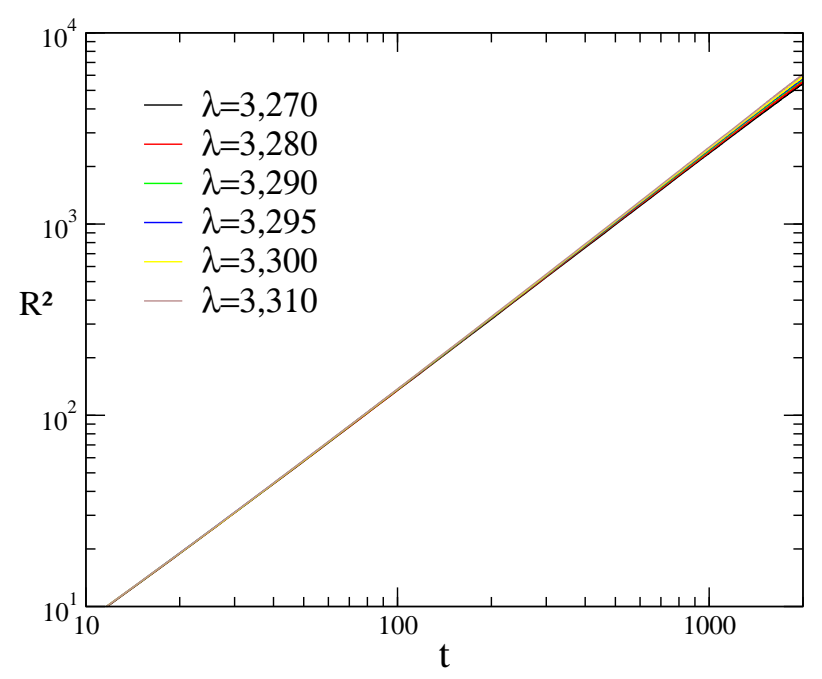

Figura 2.19: Raio quadrático dos infectados em relação ao centro da rede versus tempo. Ajustando uma reta aos dados estimamos $z=1,255(5)$.

Os resultados aqui obtidos concordam com os resultados conhecidos para o modelo de contato [20, 63]. Nosso intuito foi estudar o modelo com difusão, para o qual obtemos o diagrama de fase em uma e duas dimensões. Entretanto não foram determinados os expoentes críticos ao longo da linha de transição. De todo modo, os procedimentos usados servem de base para estudo de outros modelos com transição de fase fora do equilíbrio termodinâmico. Em particular, sabendo que a difusão aumenta a fase ativa, podemos analisar modelos com mais de duas classes de indivíduos, aplicando o processo difusivo para apenas duas classes. 


\section{Capítulo 3}

\section{Modelo SIR}

\subsection{Descrição do Modelo}

Kermarck e McKendrick em 1927 [2] propuseram um modelo para descrever a dinâmica de doenças infecto-contagiosas, em que cada indivíduo da população (suposta constante) é classificado conforme seu estado de saúde, podendo estar suscetível (S), infectado (I) ou recuperado/imune (R). Uma hipótese implícita no modelo, é que o tempo de vida do hospedeiro seja muito maior que o tempo de incubação.

O processo de contaminação é autocatalíco enquanto o processo de recuperação é espontâneo, como ilustrado na figura 3.1. Assim, indivíduos suscetíveis tornam-se infectados devido à população infectada, e indivíduos infectados podem se recuperar, adquirindo imunidade. Dessa forma o modelo inclui os mecanismos básicos necessários para descrever um processo de espalhamento epidêmico com imunização [5, 6, 7, 10, 11, 12, 13, 30, 32, 47, 48, 64].

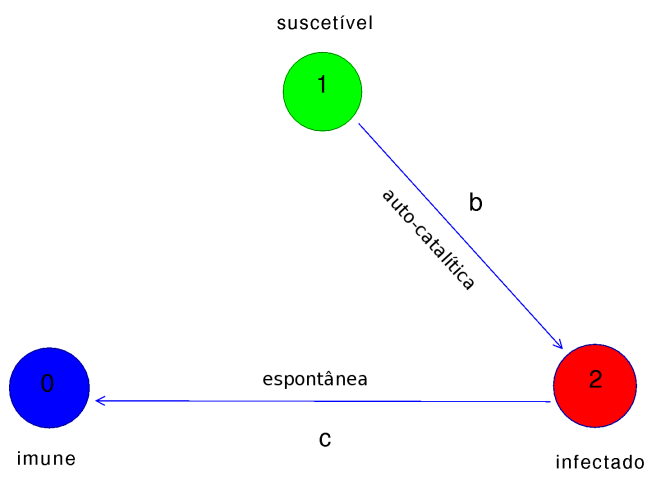

Figura 3.1: Esboço das transições entre os estados para o modelo SIR. 
Examinamos aqui um modelo estocástico espacialmente estruturado definido em uma rede quadrada regular com $N$ sítios. A cada sítio associamos

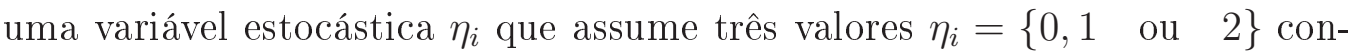
forme o sítio esteja ocupado por um único indivíduo imune, um único indivíduo suscetível ou um único indivíduo infectado, respectivamente. A dinâmica que consideramos é assíncrona e os estados de cada sítio são atualizados conforme as seguintes regras locais:

i) um indivíduo suscetível pode-se infectar com probabilidade $b$ se pelo menos um de seus primeiros vizinhos estiver infectado. Sendo a rede de coordenação $\zeta$, então esse processo ocorre com probabilidade $\frac{b}{\zeta} n$, em que $n$ é o número de primeiros vizinhos infectados.

ii) O processo de imunização é espontâneo, ocorrendo com probabilidade c. Consideramos a condição

$$
b+c=1 .
$$

Isto implica que temos somente um parâmetro externo independente. Esta condição não implica em perda de generalidade. De fato, o modelo que estamos considerando compreende um processo markoviano a tempo contínuo descrito por uma equação mestra. Portanto, podemos reescalar convenientemente o tempo nesta equação para que a condição (3.1) seja observada.

As regras $(i)$ e $(i i)$ podem ser explicitadas por meio da probabilidade de transição por sítio, através da qual o i-ésimo sítio tem seu estado $\eta_{i}$ atualizado de acordo com a expressão

$$
\omega_{i}(\eta)=c \delta\left(\eta_{i}, 2\right)+\frac{1}{\zeta} b \delta\left(\eta_{i}, 1\right) \sum_{j} \delta\left(\eta_{j}, 2\right),
$$

em que a somatória no segundo termo desta equação diz respeito aos primeiros vizinhos $j$ do sítio $i$.

Este modelo exibe uma transição de fase contínua entre uma fase $A \mathrm{em}$ uma fase $B$, pertencente a classe de universalidade da percolação dinâmica. Em ambas fases $(A$ e $B)$ a atividade epidêmica é interrompida, pois em um dado instante, não restará nenhum indivíduo infectado. A diferença entre as fases é que em uma a atividade se encerra após um curto intervalo de tempo, e por isso, no limite termodinâmico apresenta densidade nula de indivíduos imunes (fase $A$ ). Por outro lado, a outra fase apresenta densidade não nula de imunes (fase $B$ ). Esta última fase exibe infinitos estados absorventes, pois em cada realização atinge um estado cuja configuração absorvenete será diferente de uma outra. 


\subsection{Aproximação de Campo Médio Simples}

Seguindo o formalismo e a notação análoga aos usados para o modelo de contato (capítulo 2), escrevemos as equações de evolução dos primeiros momentos da distribuição:

$$
\begin{array}{r}
\frac{d P_{i}(1)}{d t}=-\frac{b}{\zeta} \sum_{\delta} P_{i, i+\delta}(12) \\
\frac{d P_{i}(2)}{d t}=\frac{b}{\zeta} \sum_{\delta} P_{i, i+\delta}(12)-c P_{i}(2) \quad \mathrm{e} \\
\frac{d P_{i}(0)}{d t}=c P_{i}(2),
\end{array}
$$

obtidas a partir da equação mestra para esta dinâmica e considerando a probabilidade de transição dada na equação (3.2).

Aplicando a aproximação de campo médio simples e considerando o espaço homogêneo e isotrópico este sistema de equações assume a forma

$$
\begin{gathered}
\dot{x}=-b x y, \\
\text { e } \\
\dot{y}=b x y-c y .
\end{gathered}
$$

Neste sistema de equações, substituimos $P(1)=x, P(2)=y$ e $P(0)=z$ que representam a densidade de suscetíveis, infectados e imunes, respectivamente. O ponto super-escrito representa a derivação em relação ao tempo. Como a população é considerada constante, não há nascimento ou mortalidade, a equação (3.5) torna-se desnecessária pois

$$
x(t)+z(t)+y(t)=1 .
$$

Portanto o parâmetro crítico $\rho_{o}=\frac{c}{b}$ separa as duas fases, e define o limiar de infectados necessários para desencadear uma epidemia. Podemos interpretar $\rho_{o}$ como a taxa básica de reprodução da infecção, a partir de uma população totalmente saudável [7, 48, 65.

O sistema de equações (3.6)-(3.7) tem como pontos fixos o estado absorvente de suscetíveis $\left(x^{*}, y^{*}\right)=(1,0)$ o qual é estável se $c>b$ e instável caso contrário. O estado absorvente de removidos $\left(x^{*}, y^{*}\right)=(0,0)$ também é solução, sendo sempre estável.

A figura 3.2 exibe as curvas de evolução para a densidade de suscetíveis, infectados e imunes para o modelo SIR, na aproximação de campo médio simples. Vemos que mesmo quando há espalhamento da epidêmia, como é o caso mostrado, para tempos longo, a densidade de infectados se anula e a epidemia cessa em razão da imunização de todos os indivíduos infectados. 


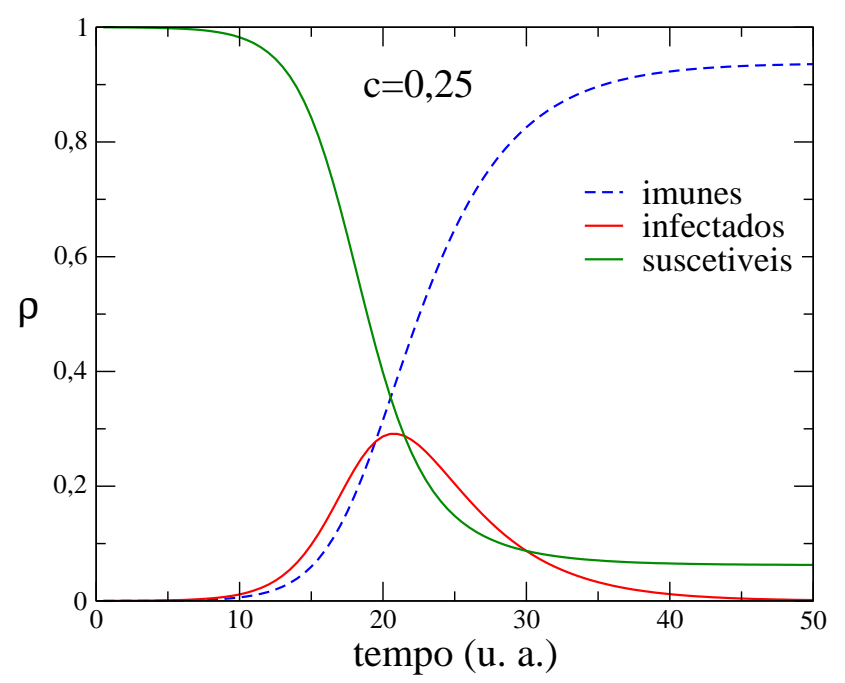

Figura 3.2: Evolução da densidade de suscetíveis, infectados e imunes, na aproximação de campo médio simples, para probabilidade de imunização $c=0,25$. As curvas foram obtidas pela iteração das equações (3.6) e (3.7).

\subsection{Aproximação de Campo Médio por Pares}

Analisamos também o modelo SIR estocástico e espacialmente estruturado utilizando uma aproximação de pares. Neste caso consideramos que correlações de dois ou mais sítios são escritas em termos de correlações de dois e um sítio. Demais correlações são desprezadas. Dentro desta aproximação as equações para os momentos da distribuição são:

$$
\begin{gathered}
\frac{P_{i}(1)}{d t}=-\frac{b}{\zeta} \sum_{\delta} P_{i, i+\delta}(12) \\
\frac{P_{i}(2)}{d t}=\frac{b}{\zeta} \sum_{\delta} P_{i, i+\delta}(12)-c P_{i}(2) \\
\frac{P_{i, j}(01)}{d t}=-\frac{b}{\zeta} \sum_{\substack{\delta \neq i+\delta) \\
j(j)}} P_{i, j, i+\delta}(012)+c P_{i, j}(21) \\
\frac{P_{i, j}(12)}{d t}=\frac{b}{\zeta}\left\{\sum_{\substack{\delta \\
(j \neq i+\delta)}} P_{i, j, i+\delta}(112)-\sum_{\substack{\delta \\
(i \neq i+\delta)}} P_{i, j, i+\delta}(212)\right\}-\left(\frac{b}{\zeta}+c\right) P_{i, j}(12)
\end{gathered}
$$




$$
\frac{P_{i, j}(02)}{d t}=\frac{b}{\zeta} \sum_{\substack{\delta \\(j \neq i+\delta)}} P_{i, j, i+\delta}(012)+c\left(P_{i, j}(22)-P_{i, j}(02)\right) .
$$

Considerando isotropia e homogeneidade espacial, como na seção (3.2), definimos $x=P(1), y=P(2), u=P(01), v=P(12)$ e $w=P(02)$. Fazendo a aproximação de pares, as correlações de trios que aparecem do lado direito das equações (3.11)-(3.13) passam a ser escritas em termos das variáveis $x, y, u, v$ e $w$. Reescrevendo as equações (3.9)-(3.13) temos:

$$
\begin{array}{r}
\dot{x}=-b v, \\
\dot{y}=b v-c y, \\
\dot{u}=b \frac{\zeta-1}{\zeta} \frac{u v}{x}+c v, \\
\dot{v}=b \frac{\zeta-1}{\zeta} \frac{x-u-2 v}{x}-\left(\frac{b}{\zeta}+c\right) v, \\
\text { e } \dot{w}=b \frac{\zeta-1}{\zeta} \frac{u v}{x}+c(y-v-2 w) .
\end{array}
$$

Esse sistema de equações apresenta o ponto fixo $(x=1, y=0, u=0, v=0, w=0)$, que corresponde ao estado absorvente de suscetíveis. A análise de estabilidade [66, 67] mostra que este ponto é estável somente se $c<\frac{\zeta-2}{2(\zeta-1)}$.

$\mathrm{Na}$ figura 3.3 é apresentado as curvas de evolução da densidade de suscetíveis, infectados e imunes, na aproximação de campo médio por pares. As curvas foram obtidas pela iteração das equações (3.14)-(3.18), a partir de uma baixa densidade de infectados.

A figura 3.4 exibe os diagramas de fases para o modelo SIR na aproximação de campo médio simples e por pares para o caso de rede regular quadrada $\zeta=4$. 


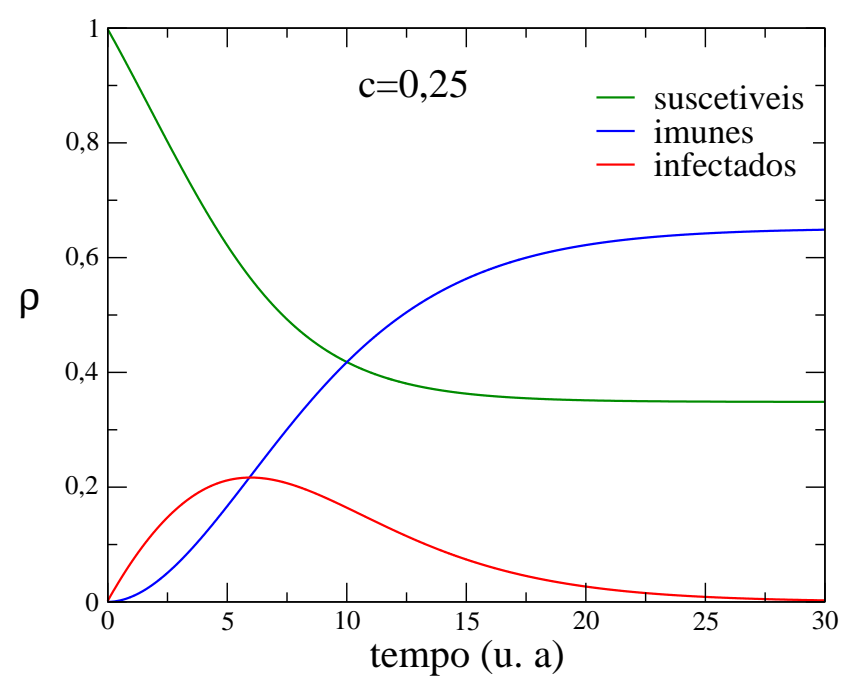

Figura 3.3: Evolução da densidade de suscetíveis, infectados e imunes, na aproximação de campo médio por pares, para probabilidade de imunização $c=0,25$. As curvas foram obtidas pela iteração das equações (3.14)- (3.18) $\operatorname{com} \zeta=4$ correspondente à uma rede regular quadrada.

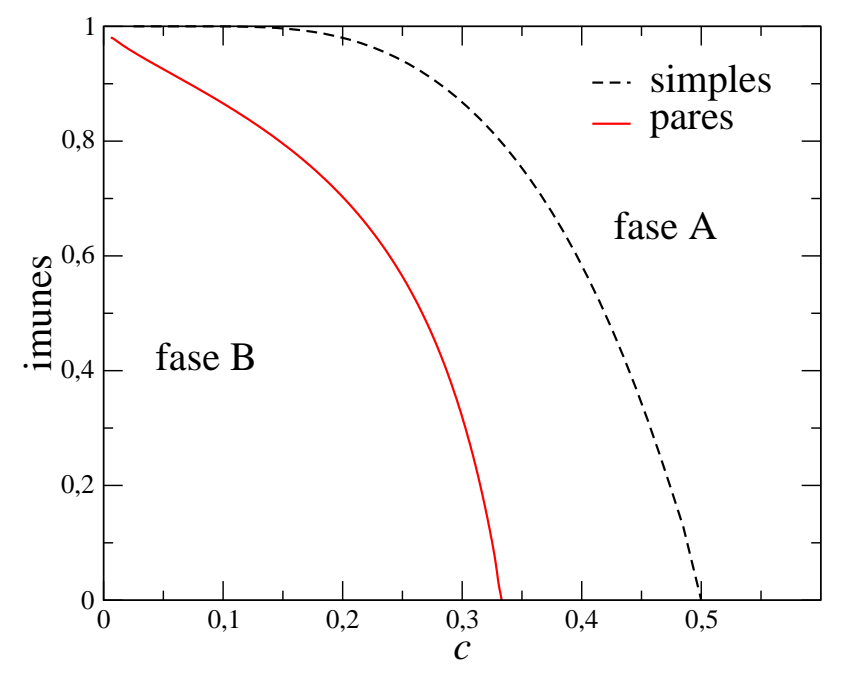

Figura 3.4: Densidade de imunes versus o parâmetro de imunização $c$ obtida por meio de aproximação de campo médio simples (linha tracejada) e por meio de aproximação de pares (linha contínua). A densidade de imunes foi calculada pela iteração das equações (3.6)-(3.7) e (3.9)-(3.13), respectivamentes, usando o método de integração de Runge-Kutta de quarta ordem. Na aproximação de pares fixamos $\zeta=4$ que corresponde a uma rede quadrada. 


\subsection{Simulações de Monte Carlo}

Usamos simulações de Monte Carlo para determinar o ponto crítico para o modelo SIR estocástico definido em uma rede regular bidimensional. Foram realizadas simulações estacionárias e dependentes do tempo com as quais calculamos alguns dos expoentes críticos do modelo.

Em simulações estacionárias, o fato do modelo SIR apresentar infinitos estados absorventes representa um grande problema quando se deseja calcular médias estacionárias. A hipótese que é usada para modelos com um estado absorvente não se aplica a este modelo. Além disso, o parâmetro de ordem, que é a densidade de imunes, é uma função estritamente crecente do tempo e que atinge um valor estacionário assintoticamente.

Entretanto, em simulações dependentes do tempo, os estados absorventes não representam problema algum, e mostraram-se de grande eficiência para determinação do ponto crítico [49].

Nas próximas seções descreveremos detalhadamente como foram realizadas as simulações computacionais de Monte Carlo estacionárias e as dependentes do tempo. Posteriomente mostraremos o estudo do modelo SIR estocástico, espacialmente estruturado e com difusão entre as classes de indivíduos.

\subsubsection{Simulações Estacionárias}

Nas simulações estacionárias do modelo, empregamos o seguinte algoritmo:

1. Inicializa-se uma rede regular quadrada bidimensional, com $L^{2}$ sítios, e condições periódicas de contorno. Todos o sítios estão inicialmente no estado suceptível, exceto o sítio central, disposto no estado infectado.

2. Sorteia-se um sítio da rede, e um número aleatório $\alpha$. Efetua-se o cálculo da probabilidade de transição do sítio $\omega_{i}(\eta)$ usando a equação (3.2). Se $\alpha \leqslant \omega_{i}(\eta)$ então o sítio assume seu próximo estado cíclico.

3. O passo 2 é repetido até que o último infectado torne-se recuperado. A cada $L^{2}$ sítios sorteados o tempo é incrementado de um passo de Monte Carlo e a densidade de imunes é armazenada em uma lista.

O fato do parâmetro de ordem ser uma função estritamente crescente no tempo evidencia que não podemos fazer uma média no tempo para cada amostra. Além disso, cada realização atinge um estado absorvente com certa quantidade de indivíduos imunizados. Na figura 3.5 mostramos histogramas 
das distribuições de probabilidades para diferentes probabilidades de imunização e tamanhos de rede. Notamos que há duas distribuições distintas. Uma ocorre para baixa concentração de imunes e está associada às realizações que atingem o estado absorvente em um curto intervalo de tempo. A segunda é correspondente às realizações que apresentam espalhamento da doença. Isto nos mostra que para calcular a densidade média de imunes, não podemos considerar que cada realização entre com igual peso, pois uma grande quantidade delas estarão contribuindo com uma densidade baixíssima pois atingiram o estado absorvente sem que houvesse propagação da doença.

O que podemos adotar, é que a média de imunizados seja calculada apenas sobre as realizações que apresentam atividade, ou seja, selecionar entre um conjunto de $N_{a}$ realizações somente as $N_{a s}$ que exibiram espalhamento epidêmico. Definimos que uma realização $N a_{i}$ apresenta espalhamento se no instante de máxima atividade de propagação da doença (calculado sobre várias realizações) ela ainda não caiu em um estado absorvente.

Na figura 3.6 mostramos como obtemos o tempo de máxima atividade $t_{s}$. Encontrado este tempo verificamos, dentre todas as realizações, quais que no instante $t=t_{s}$ apresentavam um número não nulo de infectados. Somente para as realizações sobreviventes (que denominamos $N_{a s}$ ) foi computada a densidade de recuperados no estado absorvente conforme a expressão:

$$
z_{s}=\sum_{\substack{n=1 \\\left(t_{n}>t_{s}\right)}}^{N_{a}} z_{n}\left(z_{o}, t_{n}\right) / N_{a s} .
$$

Nesta expressão, $z_{n}$ é um vetor de dimensão $2 \times N_{a}$, que armazena a densidade de imunizados da n-ésima realização quando ela atinge um estado absorvente no instante $t_{n}$. Na figura 3.7 mostramos as diferenças entre a média de imunizados quando calculada sobre todas as realizações e quando o cálculo é efetuado contabilizando apenas as realizações que apresentam atividade epidêmica. Devemos ressaltar que se o valor do parâmetro $c$ estiver próximo ao do ponto crítico e se o tamanho da rede for muito grande então a densidade de imunizados calculada usando todas as realizações tende a zero para $t \rightarrow \infty$. Isto ocorre tanto na fase em que há espalhamento como na fase em que não há espalhamento. 

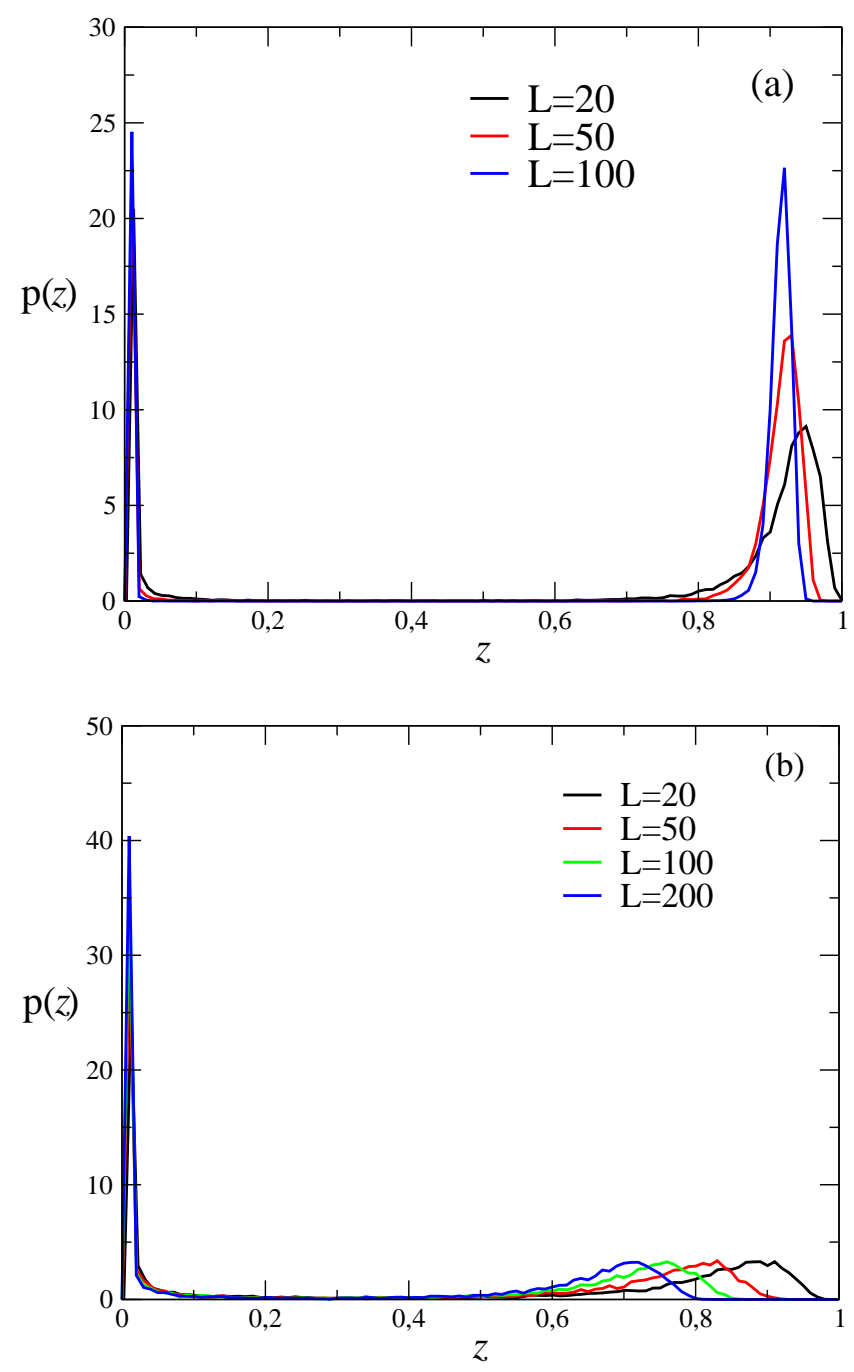

Figura 3.5: Probabilidade que uma realização no estado absorvente apresente a densidade $z$ de recuperados. $\operatorname{Em}(a)$ a probabilidade de imunização $c=0,1500$ e em $(b), c=0,1750$. Nestes gráficos vemos que a probabilidade de encontrar uma realização que exibe baixa densidade de imunizados é uma distribuição extremamente aguda, cujo pico cresce em função da redução da probabilidade de imunização. Por outro lado, a probabilidade de encontrar realizações com alta densidade de imunizados é uma distribuição aguda para baixa probabilidade de imunização, mas que vai se espalhando em razão do aumento desta probabilidade. 


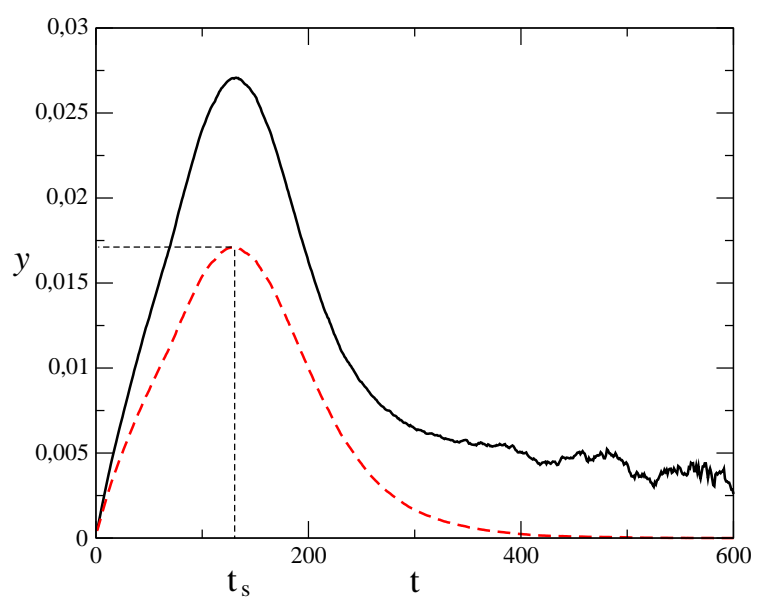

Figura 3.6: Densidade de infectados em função do tempo para rede de tamanho $L=64$ com o parâmetro $c=0,1700$. Exibimos a média realizada sobre todas as realizações (linha tracejada), e a média efetuada somente sobre as realizações que apresentaram espalhamento da doença (linha contínua). Definimos $t_{s}$ como o tempo de máxima atividade de contaminação, calculado a partir da densidade de infectados sobre todas as realizações.

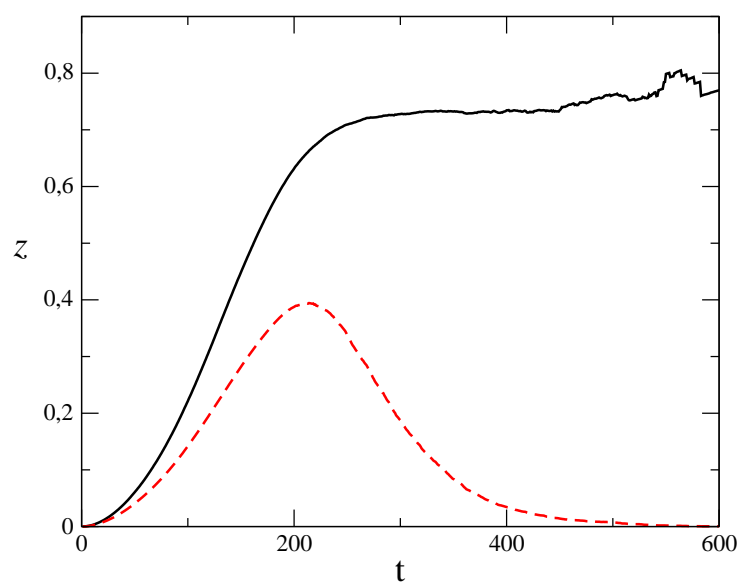

Figura 3.7: Densidade de imunes em função do tempo para uma rede quadrada de lado $L=64$ com o parâmetro $c=0,1700$ e total de $N a=5000$ realizações. Nesta figura exibimos a média realizada sobre todas as realizações (linha tracejada), e a média efetuada somente sobre as realizações que apresentaram espalhamento da doença (linha contínua). 
A figura 3.8 exibe a densidade média de imunes versus a probabilidade de imunização $c$, para diferentes tamanhos de rede quadrada de lado $L$. Entretanto as curvas desta figura não nos possibilitam determinar precisamente o ponto crítico, pois as simulações são efetuadas para redes de tamanho finito, e somente no limite termodinâmico é que o parâmetro de ordem apresentará um comportamento singular.

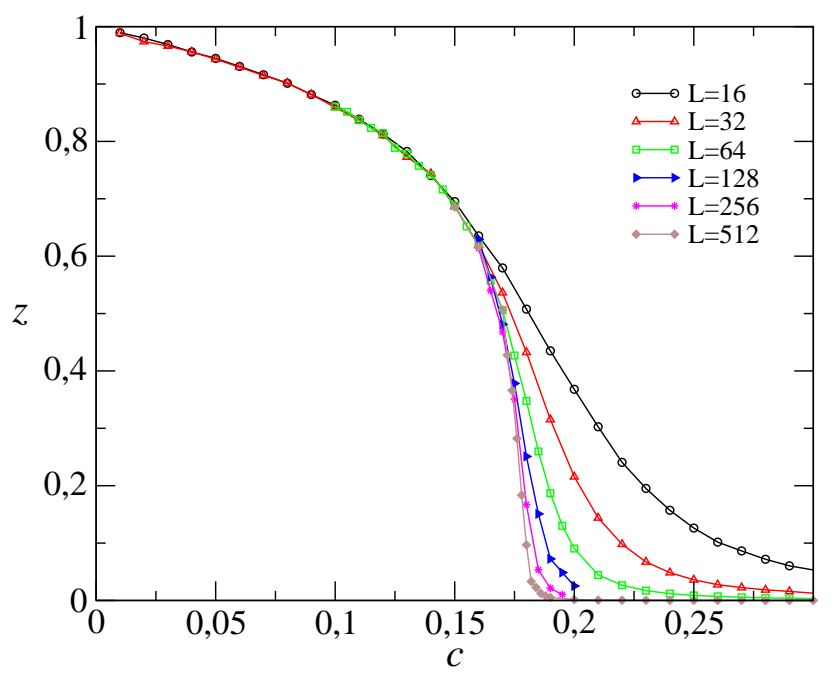

Figura 3.8: Densidade de imunes versus a probabilidade de imunização para diferentes tamanhos de redes quadradas de lado $L$.

No ponto crítico $c=c_{c}$, o parâmetro de ordem obedece a lei de escala,

$$
z_{s}(c)=L^{-\beta / \nu_{\perp}} g\left(\left(c-c_{c}\right) L^{1 / \nu_{\perp}}\right)
$$

em que $g(x)$ é uma função universal e para um sistema infinito se comporta de acordo com

$$
z_{s} \sim\left(c_{c}-c\right)^{\beta}
$$

$\beta$ e $\nu_{\perp}$ são expoentes críticos associados ao parâmetro de ordem e ao comprimento de correlação espacial. A figura 3.9 mostra a densidade de imunes versus o tamanho da rede para probabilidades próximas à crítica. A partir da equação (3.20) pode-se determinar o ponto crítico e calcular $\beta / \nu_{\perp}$.

Para uma rede suficientemente grande obtivemos o comportamento da densidade de imunes em função da distância ao ponto crítico $\left(\Delta=c_{c}-c\right)$. Ajustando uma reta aos dados obtidos por simulações computacionais estimamos o expoente $\beta=0,129(10)$, como exibido na figura 3.10.

Como os expoentes estáticos da percolação dinâmica, da qual este modelo pertence, são conhecidos exatamente [63], então podemos usar o valor exato 


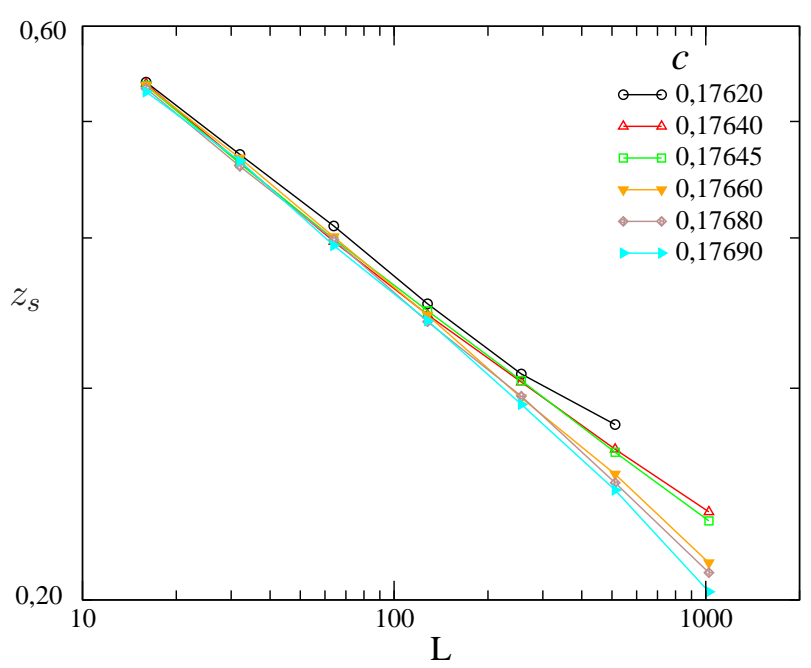

Figura 3.9: Densidade de imunes versus o tamanhos da rede $L$ para diferentes probabilidades de imunização. No ponto crítico $c=c_{c}$ a densidade decai conforme a equação (3.20); probabilidades maiores (regime subcrítico) geram curvas convexas e probabilidades inferiores (regime supercrítico) apresentam curvas côncavas. Por meio de simulações realizadas para probabilidades de imunização espaçadas em intervalos menores estimamos que $c_{c}=0,17650(5)$ e a razão entre os expoentes estáticos seja $\beta / \nu_{\perp}=0,096(7)$.

do expoente $\beta$ para encontrar o ponto crítico. Na figura 3.11 mostramos a densidade de imunes reescalada com $\beta$. A extrapolação para $z_{c} \rightarrow 0$ nos fornece o valor para $c$ crítico. Este resultado está em concordância com o ponto crítico que obtivemos usando simulações estacionárias mostrado na figura 3.9 


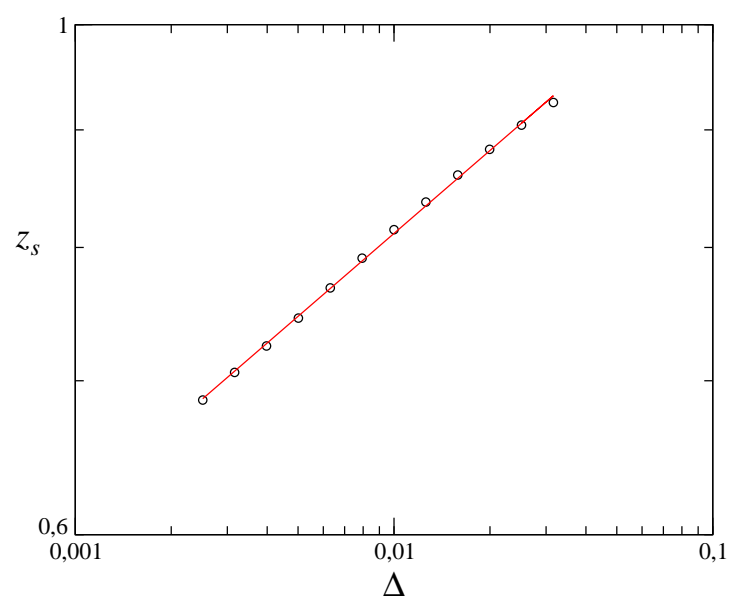

Figura 3.10: Densidade de imunes versus a distância ao ponto crítico $\left(\Delta=c_{c}-c\right)$, para a fase ativa. Ajustando uma reta aos dados relativos à $L=512$, estimamos $\beta=0,129(10)$.

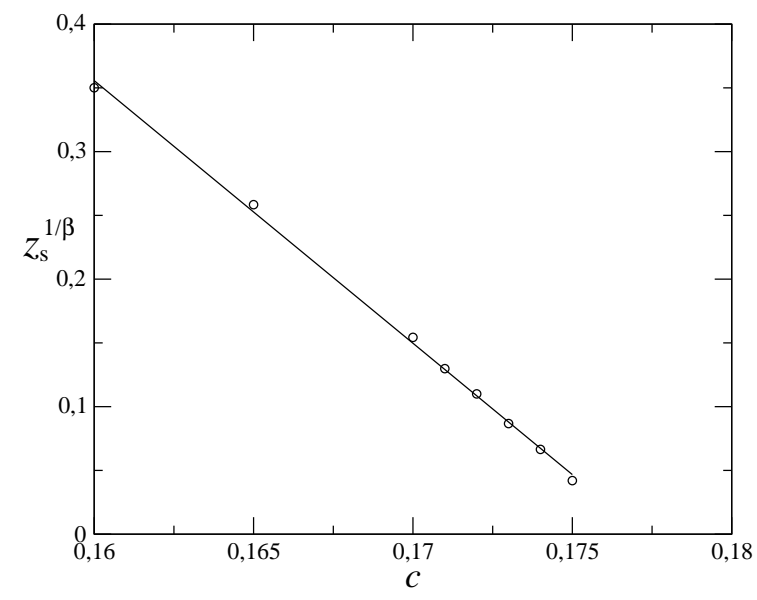

Figura 3.11: Densidade de imunes reescalada com o expoente $1 / \beta$ em função da probabilidade de imunização (resultados para uma rede quadrada de lado $L=512$ ). O ajuste de uma reta aos dados e a extrapolação para $z_{s}^{1 / \beta}=0$, em que $\beta=5 / 36$ leva a obtenção de uma estimativa para a probabilidade crítica $c_{c}=0,177(1)$. 


\subsubsection{Simulações Dependentes do Tempo}

Nas simulações dependentes do tempo para o este modelo, usamos o algoritmo descrito abaixo:

1. Inicializa-se uma rede regular quadrada bidimensional, com $L^{2}$ sítios. Todos o sítios estão inicialmente no estado suceptível, exceto o sítio central, disposto no estado infectado.

2. Sorteia-se um sítio da rede, e um número aleatório $\alpha$. Efetua-se o cálculo da probabilidade de transição do sítio $\omega_{i}(\eta)$ usando a equação (3.2). Se $\alpha \leqslant \omega_{i}(\eta)$ então o sítio assume seu próximo estado cíclico. Caso o último indivíduo infectado se recupere, ou se algum sítio da fronteira da rede tornar-se infectado a simulação é interrompida

3. O passo 2 é repetido até que o último infectado torne-se recuperado. A cada $L^{2}$ sítios sorteados o tempo é incrementado de um passo de Monte Carlo e são computados o número de infectados,

$$
n(t)=\sum_{i, j=1}^{L} \delta\left(\eta_{i, j}, 2\right),
$$

e a distância quadrática dos indivíduos infectados em relação ao centro da rede,

$$
r^{2}(t)=\sum_{i, j=1}^{L} \delta\left(\eta_{i, j}, 2\right)\left[(i-L / 2)^{2}+(j-L / 2)^{2}\right] .
$$

Os sub-índices $i, j$ representam as coordenadas de cada sítio.

Após simular um conjunto de $N a$ realizações, calcula-se o número médio de infectados $N(t)$, o raio quadrático dos infectados $R^{2}(t)$ e a probabilidade de sobrevivência do processo epidêmico $P_{s}(t)$ conforme as expressões

$$
\begin{gathered}
N(t)=\frac{1}{N_{a}} \sum_{k=1}^{N a} n(t), \\
R^{2}(t)=\frac{1}{N_{a s}(t)} \sum_{t} r^{2}(t) \quad \mathrm{e} \\
P_{s}(t)=\frac{1}{N_{a}} \sum_{k=1}^{N a} H(t),
\end{gathered}
$$

em que $N_{a s}(t)$ é o número de realizações que ainda não atingiram o estado absorvente no instante $t$ e a função $H(t)$ assume o valor 1 se ainda há infectado no instante $t$ ou zero caso contrário. 


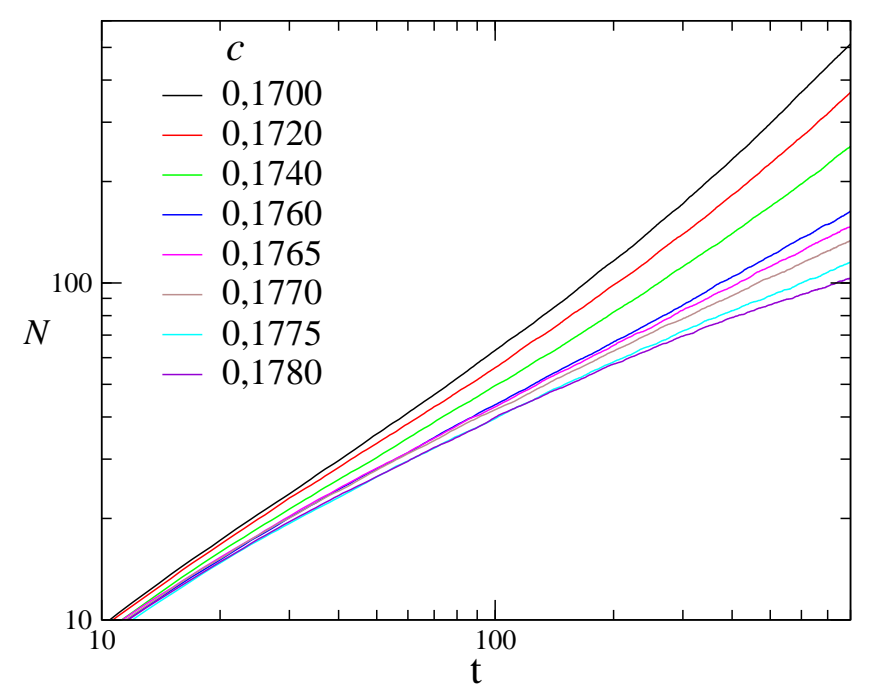

Figura 3.12: Número de infectados versus tempo para diferentes probabilidades de imunização. De acordo com a equação a (2.45) na criticalidade o número de infectados cresce com expoente $\eta$, assim no ponto crítico devemos observar uma reta quando fazemos um gráfico de $\log N(t)$ versus $\log$. Estimamos o ponto crítico $c_{c}=0,1765(5)$ e $\eta=0,586(1)$.

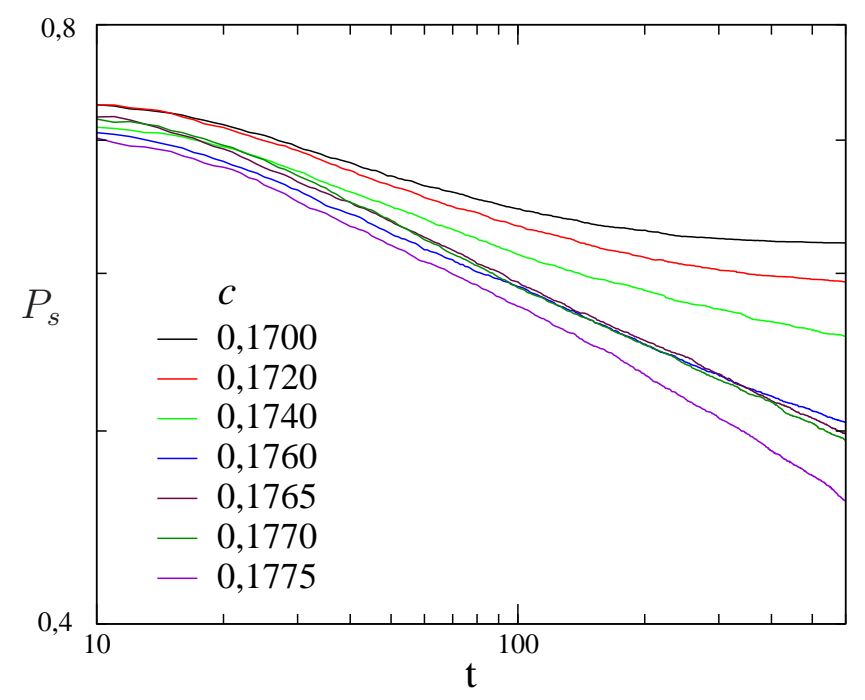

Figura 3.13: Probabilidade de sobrevivência versus tempo para diversas probabilidades de imunização. É esperado que a probabilidade de sobrevivência, no ponto crítico decresca com o expoente $\delta$ (equação (2.47)). Ajustando uma reta aos dados obtidos para $c_{c}=0,1765$ estimamos $\delta=0,094(3)$. 


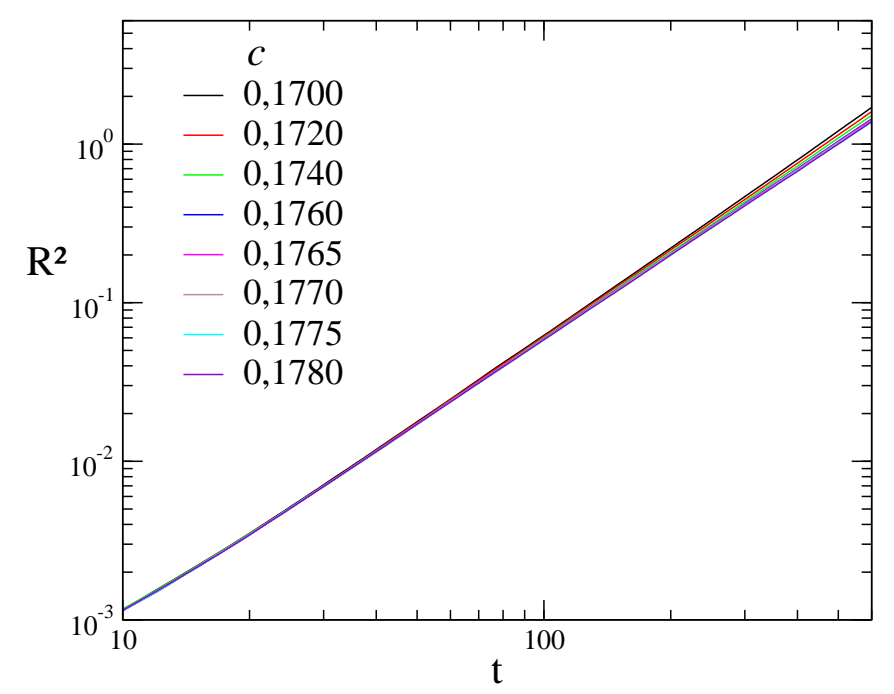

Figura 3.14: Raio quadrático versus tempo para diferentes probabilidades de imunizaçao. No ponto crítico, seguindo a equação (2.46), o raio quadrático cresce no tempo com o expoente $z$, o qual a partir do ajuste de uma reta aos dados obtidos leva a estimativa $z=1,773(1)$. 


\subsection{Modelo SIR com Difusão}

Tal qual realizado para o processo de contato, estudamos o modelo SIR estocástico com difusão. Por meio do processo difusivo uma partícula pode permutar sua posição na rede com uma partícula em um sítio adjacente. Como o modelo SIR apresenta três classes distintas de indivíduos, analisamos as diferentes possibilidades de difusão em que indivíduos de uma das classes não sofrem o processo de difusão explícita. Também consideramos o caso de difusão isotrópica, na qual indivíduos de qualquer umas das classes sofrem difusão com a mesma probabilidade.

A figura 3.15 exibe retratos em diferentes instantes para uma realização do modelo SIR sem difusão, a qual será usada para fins de comparação com os casos difusivos.
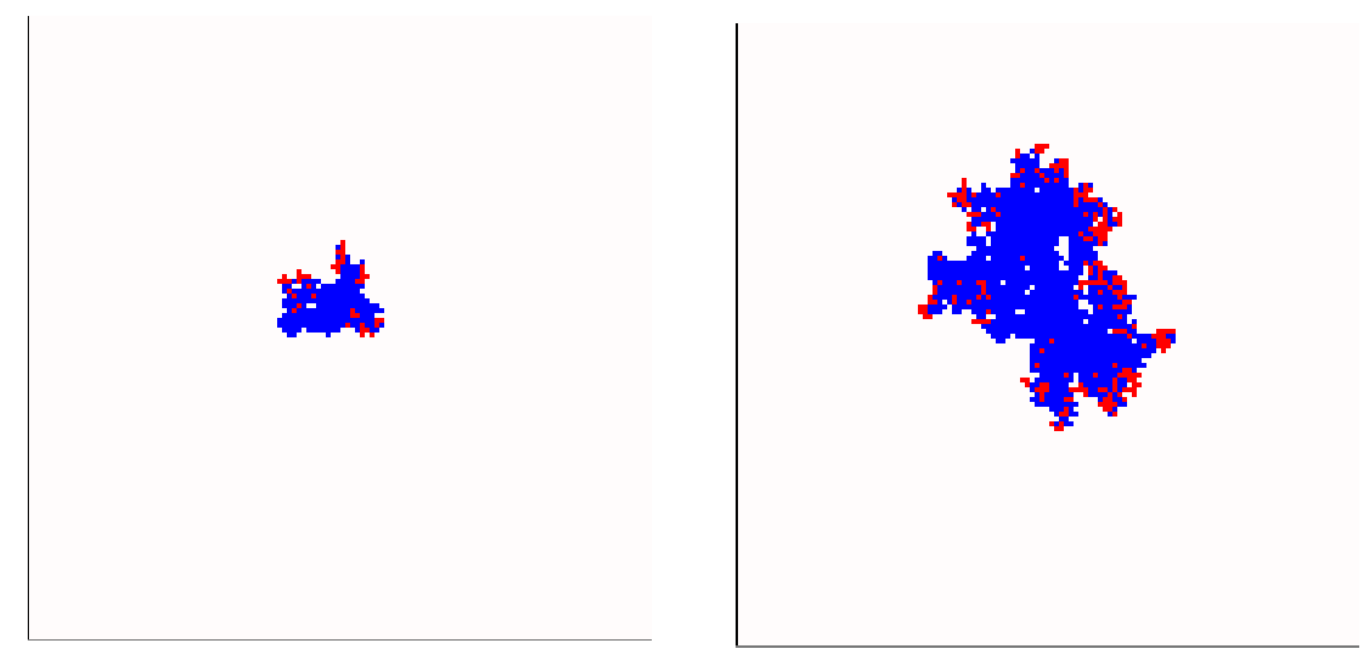

Figura 3.15: Retratos das simulações nos instantes $t=50$ (à esquerda) e $t=100$ (à direita) passos de Monte Carlo. A rede tem tamanho $L=128$ e a probabilidade de imunização é $c=0,15$ e não há difusão $d=0,00$. Denotamos por pontos azuis os indivíduos imunes, por vermelhos (infectados) e brancos (suscetíveis). 
A seguir discutimos cada um dos processos difusivos que investigamos:

\section{(a) Difusão entre infectados e suscetíveis}

Se o processo de difusão ocorre somente entre infectados e suscetíveis, conforme mostrado na figura 3.16, vemos que como o indivíduo suscetível que participa do par central (que com probabilidade $d$ sofre a permutação de posições) se mantém vizinho do infectado e ainda pode tornar-se vizinho de outros infectados, aumentando a probabilidade dele tornar-se infectado. Em decorrência do processo difusivo, percebe-se que o indivíduo infectado envolvido no processo acaba sendo imerso em locais parcial ou totalmente circundado de suscetíveis originando novos focos epidêmicos.

Figura 3.16: Diagrama exemplificando como a difusão entre suscetíveis e infectados favorece a propagação da epidemia. Neste diagrama consideramos um "cluster" de oito sítios composto por dois sítios centrais e seus primeiros vizinhos. Representamos um indivíduo suscetível por $\circ$, um infectado por - Neste caso particular, na permutação entre os estados dos dois sítios centrais, o indivíduo infectado passa a ter contato somente com suscetíveis, enquanto o suscetível que já era seu vizinho ganha mais um vizinho infectado, aumentando a probabilidade de adquirir a doença.

Na figura 3.17 temos alguns retratos da rede em diferentes instantes para uma realização em que há difusão entre suscetíveis e infectados. Como a maioria dos pares (suscetível-infectado) estão na fronteira de propagação epidêmica, a dinâmica de criação de novos focos epidêmicos, discutida previamente, favorece o espalhamento da doença e quando comparado ao caso não difusivo vemos também que isto aumenta a velocidade de expansão da fronteira. 
(a)

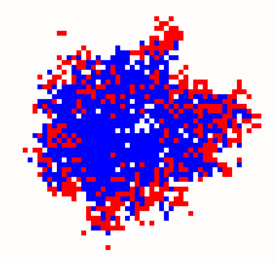

(b)

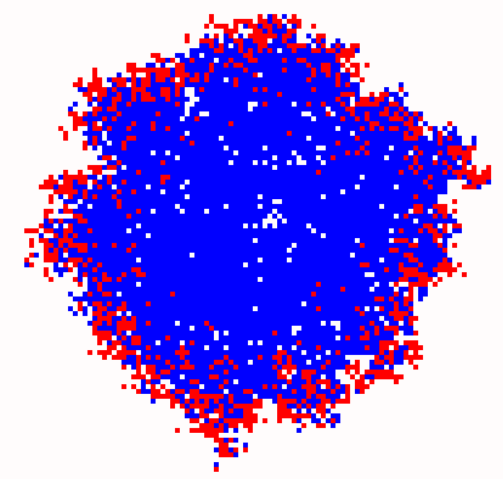

Figura 3.17: Retratos das simulações nos instantes $t=50$ (à esquerda) e $t=100$ (à direita) passos de Monte Carlo. A rede tem tamanho $L=128$ e a probabilidade de imunização é $c=0,15$, a probabilidade de difusão é $d=0,40$. Neste processo, a difusão ocorre apenas entre suscetíveis e infectados. Denotamos por pontos azuis os indivíduos imunes, por vermelhos (infectados) e brancos (suscetíveis). 


\section{(b) Difusão entre infectados e imunes}

Se somente o processo de difusão entre infectados e imunes, conforme mostrado nas figuras 3.18, verifica-se que esta dinâmica difusiva contribui, predominantemente, para o isolamento de um foco epidêmico. Por haver uma grande quantidade de pares (infectado-imune) na interface de propagação epidêmica, em decorrência do processo difusivo, origina uma barreira natural de imunes que contribui para o impedimento do avanço da epidemia.

Figura 3.18: Diagrama exemplificando como a dinâmica entre imunes e infectados inibe a propagação da epidemia. Usamos os símbolos $\circ$ para denotar um indivíduo suscetível, • para infectado e $\bullet$ para imune. Devido a permutação entre os dois sítios centrais do "cluster", o indivíduo infectado fica isolado, impedindo que os suscetíveis que antes eram seus vizinhos tornem-se infectados.

Neste tipo de difusão também pode ocorrer o processo mostrado na figura 3.19, que ilustra a possibilidade de infecção de suscetíveis pertencentes a ilhas que "escaparam" da epidemia. Neste processo, indivíduos infectados, por difusão, podem sair da fronteira de propagação e imergir em ilhas de suscetíveis. Por este mecanismo, notamos que ao cessar a epidemia, o número de "ilhas" de suscetíveis é menor, se comparado ao caso não difusivo.

Figura 3.19: Diagrama exemplificando como a dinâmica entre infectados e imunes pode causar a imersão de um infectado numa "ilha" de suscetíveis. Ao permutar as posições dos indivíduos centrais do "cluster", os três indivíduos à esquerda, pertencentes a uma "ilha" de suscetíveis ficam expostos a epidemia. Usamos os símbolos $\circ$ para denotar um indivíduo suscetível, • para infectado e $\bullet$ para imune. 
Na figura 3.20 é apresentado retratos da rede em diferentes instantes para uma realização na qual há difusão entre infectados e imunes. Quando comparamos estas imagens com as exibidas na figura 3.15 (caso não difusivo) percebemos que há uma considerável redução na quantidade e tamanho das "ilhas" de suscetíveis e na fronteira de propagação percebe-se o isolamento de indivíduos infectados, processo este que contribui para erradicação da doença.

(a)

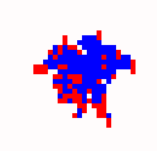

(c)

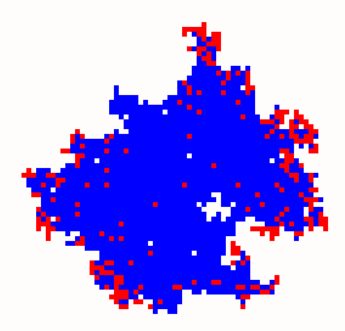

(b)

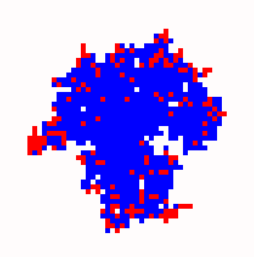

(d)

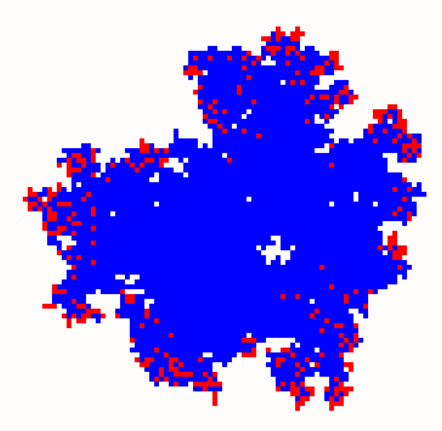

Figura 3.20: Retratos das simulações nos instantes $t=50$ (a), $t=100$ (b), $t=150$ (c) e $t=200$ (d) passos de Monte Carlo. A rede tem tamanho $L=$ 128 e a probabilidade de imunização é $c=0,15$, o processo de difusão ocorre somente entre infectados e imunes com probabilidade $d=0,40$. Denotamos por pontos azuis os indivíduos imunes, por vermelhos (infectados) e brancos (suscetíveis). 


\section{(c) Difusão entre suscetíveis e imunes}

Se suscetíveis difundem com imunes, notamos dois efeitos principais. Um é a fragmentação das "ilhas" de suscetíveis mostrado na figura 3.21. E o outro é o isolamento de suscetíveis em agregados de imunes, como ilustrado na figura 3.22. Note que estes efeitos tem consequências distintas. A fragmentação de uma "ilha" de suscetíveis ocorre pela saída de um indivíduo suscetível, isto de algum modo faz com que ele torne-se mais vulnerável pois tende a aproximálo de indivíduos infectados. Entretanto, a inserção de um indivíduo suscetível em um agregado de imunes, favorece o isolamento do mesmo, afastando-o de indivíduos infectados.

Figura 3.21: Diagrama exemplificando a dinâmica de exposição de um indivíduo suscetível de uma ilha ao processo epidêmico devido ao processo de difusão entre imunes e suscetíveis. Por difusão um indivíduo suscetível do "cluster" permuta de posição com um indivíduo imune, tornando-se vizinho de dois infectados. Usamos os símbolos o para denotar um indivíduo suscetível, • para infectado e • para imune.

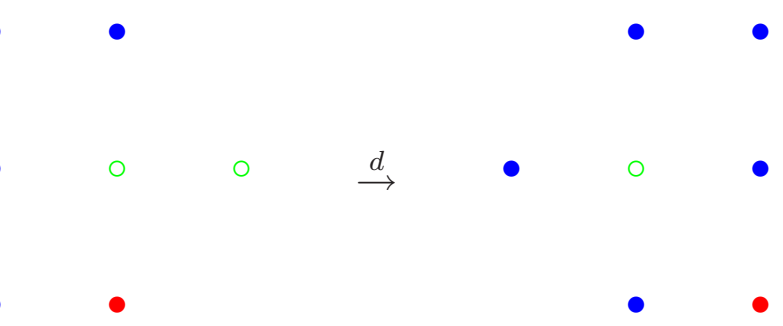

Figura 3.22: Diagrama exemplificando a dinâmica de isolamento de um indivíduo suscetível em detrimento do processo de difusão entre imunes e suscetíveis. Por difusão um indivíduo suscetível permuta de posição com um indivíduo imune, evitando assim que um dos suscetíveis do "cluster" continue tendo como vizinho um infectado. Processos deste tipo devem ocorrer predominante na fronteira de propagação da epidemia. Usamos os símbolos $\circ$ para denotar um indivíduo suscetível, • para infectado e • para imune. 
Pela observação de retratos da rede figura 3.23 para uma realização com difusão entre suscetíveis e imunes notamos que as "ilhas" de suscetíveis que escaparam da epidemia apresentam uma grande dinâmica, sofrendo rupturas. E na fronteira de propagação da epidemia há imunes espalhados entre infectados e suscetíveis, formando "barreiras" que inibem a proliferação da doença.

(a)

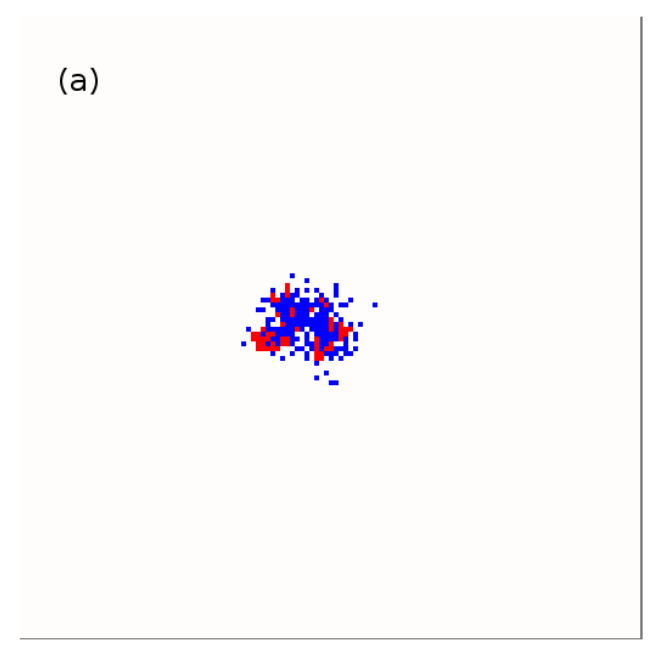

(b)

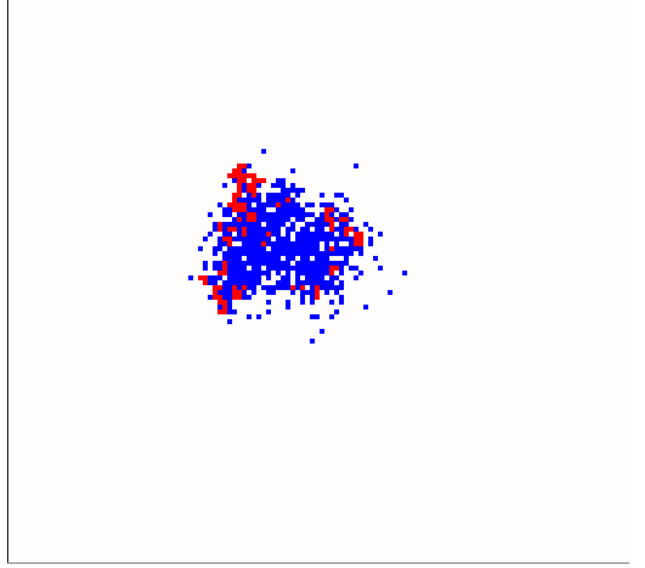

(c)

(d)
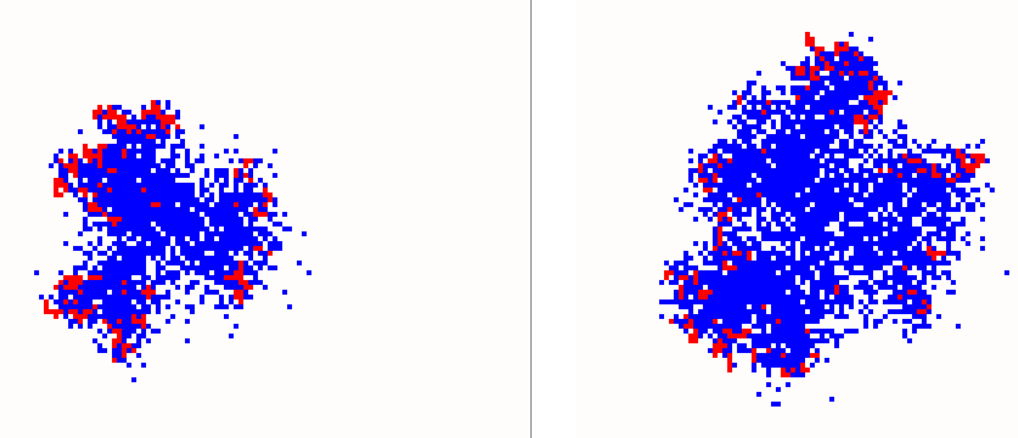

Figura 3.23: Retratos das simulações nos instantes $t=100$ (a), $t=200$, $t=150$ (c) e $t=200$ (d) passos de Monte Carlo. A rede tem tamanho $L=128$ e a probabilidade de imunização é $c=0,15$, neste caso o processo de difusão ocorre entre suscetíveis e imunes com probabilidade $d=0,40$. Denotamos por pontos azuis os indivíduos imunes, por vermelhos (infectados) e brancos (suscetíveis). 


\section{(d) Difusão isotrópica}

Quando indivíduos de todas as diferentes classes sofrem difusão com mesma probabilidade, os processos difusivos discutidos (a), (b) e (c) competem entre si e assim há uma superposição de todos os efeitos decorrentes da difusão. Analisando uma sequência de retratos da rede (figura 3.24), percebemos que há uma grande redução no tamanho das ilhas de suscetíveis (fica menos provável uma certa região não ser afetada pela epidemia). Na fronteira de propagação há infectados distribuídos por quase toda a interface, o que causa uma expansão mais homogênea da fronteira. Além disso, há a formação de novos focos epidêmicos e "ilhas" de imunes ao longo da fronteira. Os focos favorecem e aceleram a propagação da epidemia, enquanto as ilhas de imunes apresentam efeito contrário.

(a)

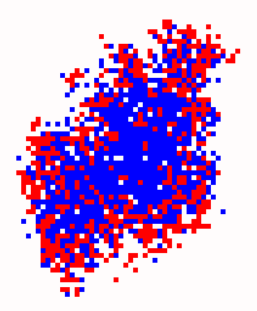

(b)

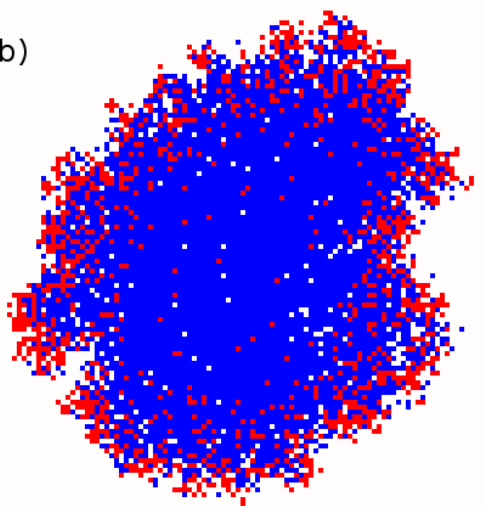

Figura 3.24: Retratos das simulações nos instantes $t=50$ (a), $t=100$, $t=150$ passos de Monte Carlo. A rede tem tamanho $L=128$ e a probabilidade de imunização é $c=0,15$, neste caso o processo de difusão ocorre entre de qualquer uma das classes com probabilidade $d=0,40$. Denotamos por pontos azuis os indivíduos imunes, por vermelhos (infectados) e brancos (suscetíveis). 
Pelos diagramas de fase para os diferentes processos difusivos investigados, apresentado na figura 3.25. notamos que na difusão isotrópica, há a prevalência ao favorecimento da propagação da epidemia, quando comparamos aos demais processos difusivos isoladamente, apresenta limiar epidêmico superior à todos os outros para uma mesma probabilidade de difusão. Esta diferença advém da não formação de domínios bem definidos, pois se indivíduos de todas as classes podem migrar não há a formação de um "cluster" bem definido de imunes, capaz de isolar indivíduos suscetíveis, e os poucos indivíduos imunes na fronteira, que se interpõe entre infectados e suscetíveis, ficam nessa situação por pouco tempo, não tendo eficiência em inibir o espalhamento da doença.

Para os processos difusivos isolados (a), (b) e (c) é mais fácil compreender o motivo que causa a redução do limiar de imunização na ordem (a), (b) e (c). A razão é: havendo difusão somente entre infectados e suscetíveis (caso (a)), não existe nenhum mecanismo que favoreca o isolamento dos suscetíveis, e, portanto, o limiar de imunização cresce em função do aumento da probabilidade de difusão.

Por outro lado, tanto na difusão entre infectados e imunes (caso (b)) quanto na difusão entre suscetíveis e imunes (caso (c)), há mecanismos de inibição à propagação da epidemia e por isso o limiar de imunização abaixa em função do aumento da probabilidade de difusão. Esta redução é mais acentuada para a difusão entre suscetíveis e imunes porque neste caso a não mobilidade de infectados impede a formação de novos focos epidêmicos. 


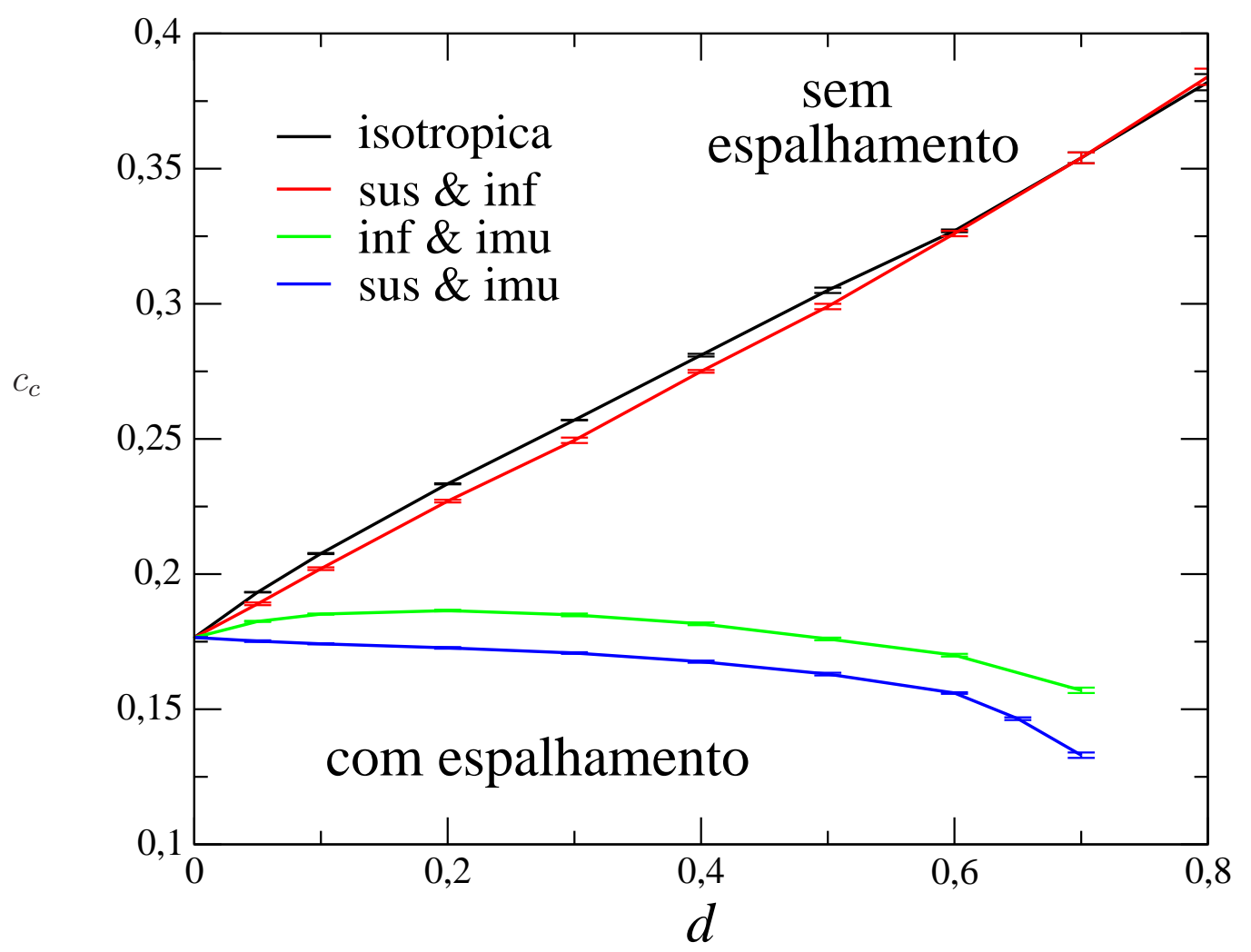

Figura 3.25: Diagramas de fase no plano $d-c_{c}$ para os processos SIR difusivo com os diferentes tipos de difusão considerados. $d$ é a probabilidade de difusão e $c_{c}$ é a probabilidade crítica (obtida via simulações dependentes do tempo). A difusão isotrópica significa que indivíduos de qualquer uma das classes podem permutar de posição com um vizinho de classe diferente com probabilidade $d$ e com probabilidade $1-d$ o sítio sofre um processo de infecção ou imunização conforme a equação (3.2). Vemos que tanto a difusão isotrópica quanto a difusão entre suscetíveis e infectados favorem o espalhamento da epidemia. Por outro lado, tanto os processos de difusão entre suscetíveis e imunes como o processo de difusão entre infectados e imunes provocam uma inibição na disseminação da doença. 


\section{Capítulo 4}

\section{Modelo SIRS}

\subsection{Descrição do Modelo}

O modelo SIRS pode ser entendido como uma generalização do modelo SIR, no qual considera-se que a imunidade aquirida não seja permanente. Isto é, um indivíduo pode perder sua resistência ficando novamente suscetível ao processo de contaminação. Nesse caso podemos esboçar o processo de evolução nas etapas $S \rightarrow I \rightarrow R \rightarrow S$ como mostrado na figura 4.1. As regras dinâmicas do modelo são as regras estocásticas do modelo SIR (definido no capítulo 3), devendo-se adicionar o processo de perda de imunidade através do qual indivíduos imunes sofrem perda espontânea de imunidade com probabilidade $a$ tornando-se suscetíveis novamente.

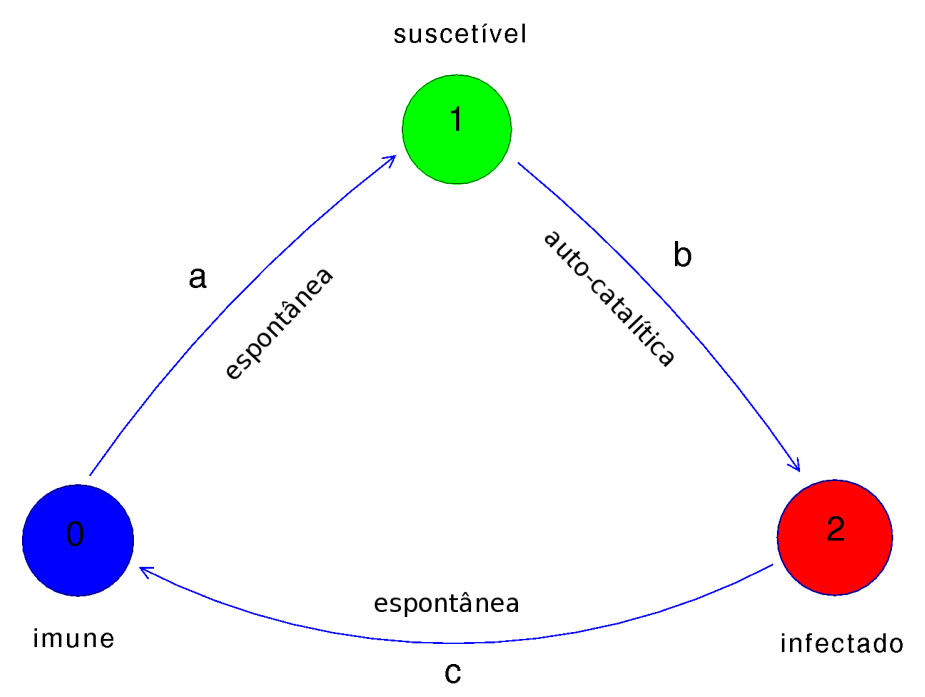

Figura 4.1: Esboço das transições entre os estados para o modelo SIRS. 
Assim o modelo SIRS agrega os processos essenciais necessários para descrever a propagação de uma epidemia com perda de imunidade [?, [3, 5, 6, 68, 69. e que serve como modelo introdutório ao estudo de disseminação de doenças com dinâmica populacional [53, 56, 70] e gerenciamento de políticas públicas de controle como vacinação [18, 45, 46, 47, 71]. Considerando que indivíduos de três classes: suscetíveis $(\mathrm{S})$, infectados $(\mathrm{I})$ e recuperados $(\mathrm{R})$ ocupam os sítios de uma rede hipercúbica. As regras de transição do modelo podem ser escritas em termos da probabilidade de transição por sítio:

$$
\omega_{i}(\eta)=a \delta\left(\eta_{i}, 0\right)+c \delta\left(\eta_{i}, 2\right)+\frac{1}{\zeta} b \delta\left(\eta_{i}, 1\right) \sum_{j}\left(\eta_{j}, 2\right),
$$

através da qual o sítio $i$ tem sua variável estocástica $\eta_{i}$ atualizada. A soma do lado direito da equação é feita sobre os primeiros vizinhos do sítio $i$. A variável $\eta_{i}$ denota o estado do sítio $i$ e pode assumir três valores $\eta_{i}=1,2,0$ correspondendo ao sítio estar ocupado por um indivíduo suscetível, infectado ou imunizado, respectivamente. O parâmetro $\zeta$ é o número de sítios vizinhos do sítio $i$.

Os dois primeiros termos no lado direito da equação (4.1) representam os processos de perda de imunidade e imunização, respectivamente, enquanto o terceiro termo descreve o processo de contaminação, por meio do qual o i-ésimo sítio que se encontra suscetível pode adquirir a doença por contato com um primeiro vizinho $j$ infectado. A somatória contabiliza o total de primeiros vizinhos do sítio $i$ que se encontram infectados.

Analisando a dinâmica deste modelo verifica-se que ela se mapeia na dinâmica do modelo SIR definida na equação (3.2) para $a \rightarrow 0$.

\subsubsection{Aproximação de Campo Médio Simples}

Adotaremos aqui o formalismo e a notação similar aos utilizada para o modelo de contato definido no capítulo (2) e modelo SIR (seção 3.2). Levando em conta a probabilidade de transição dada na equação (4.1) podemos escrever a equação mestra para o modelo e a partir dessa podemos deduzir as equações de evolução para os primeiros momentos da distribuição de probabilidades:

$$
\begin{array}{r}
\frac{d P_{i}(1)}{d t}=-\frac{b}{\zeta} \sum_{\delta} P_{i, i+\delta}(12)+a P_{i}(0) \\
\frac{d P_{i}(2)}{d t}=\frac{b}{\zeta} \sum_{\delta} P_{i, i+\delta}(12)-c P_{i}(2) \quad \mathrm{e} \\
\frac{d P_{i}(0)}{d t}=c P(2)-a P(0)
\end{array}
$$


Aplicando a aproximação de campo médio simples às equações (4.2)-(4.3) e considerando o espaço homogêneo e isotrópico obtemos o conjunto de equações

$$
\dot{x}=-b x y+a(1-x-y)
$$

e

$$
\dot{y}=b x y-c y .
$$

em que $x=P(1), y=P(2)$ e $z=1-x-y=P(0)$.

Uma vez que as equações (4.5) e (4.6) são obtidas a partir de uma equação mestra, a qual nos permite reescalar convenientemente o tempo através de de uma transformação $a \rightarrow \tau a, b \rightarrow \tau b, c \rightarrow \tau c$, em que $\tau$ é uma constante positiva, podemos em particular escolher $\tau$ de modo que a satisfazer a seguinte condição:

$$
a+b+c=1 .
$$

Esta condição é satisfeita através da transformação $a=(1-c) / 2-p$, $b=(1-c) / 2+p, c=c$; em que o parâmetro $p=(b-a) / 2$ está definido no intervalo $[-1 / 2,1 / 2]$. A figura 4.2 mostra o espaço de parâmetros do modelo. Podemos entender a transformação realizada com sendo uma projeção do espaço de parâmetros definido em uma superfície $\Re^{3}$ sobre o plano pc. Portanto, embora ao realizar a transformação o número de parâmetros seja reduzido para duas variáveis independentes $(p$ e $c$ ) elas conservam todas as propriedades do modelo. Os resultados a serem obtidos serão apresentados em termos dos parâmetros $p$ e $c$.

$$
\begin{gathered}
\dot{x}=-\left(\frac{1-c}{2}+p\right) x y+\left(\frac{1-c}{2}-p\right)(1-x-y), \\
\dot{y}=\left(\frac{1-c}{2}+p\right) x y-c y .
\end{gathered}
$$

Este sistema de equações diferenciais apresenta os seguintes pontos fixos:

$$
\left(x^{*}, y^{*}\right)=(1,0)
$$

e

$$
\left(x^{*}, y^{*}\right)=\left(\frac{c}{b}, \frac{a}{b} \frac{b-c}{a+c}\right), \quad \text { com } \quad b>c .
$$

O primeiro ponto fixo representa o caso de uma população livre de epidemia (estado absorvente de suscetíveis). Contudo, para o segundo ponto fixo a densidade de infectados e imunes é não nula e, portanto, haverá persistência da doença (fase ativa). 


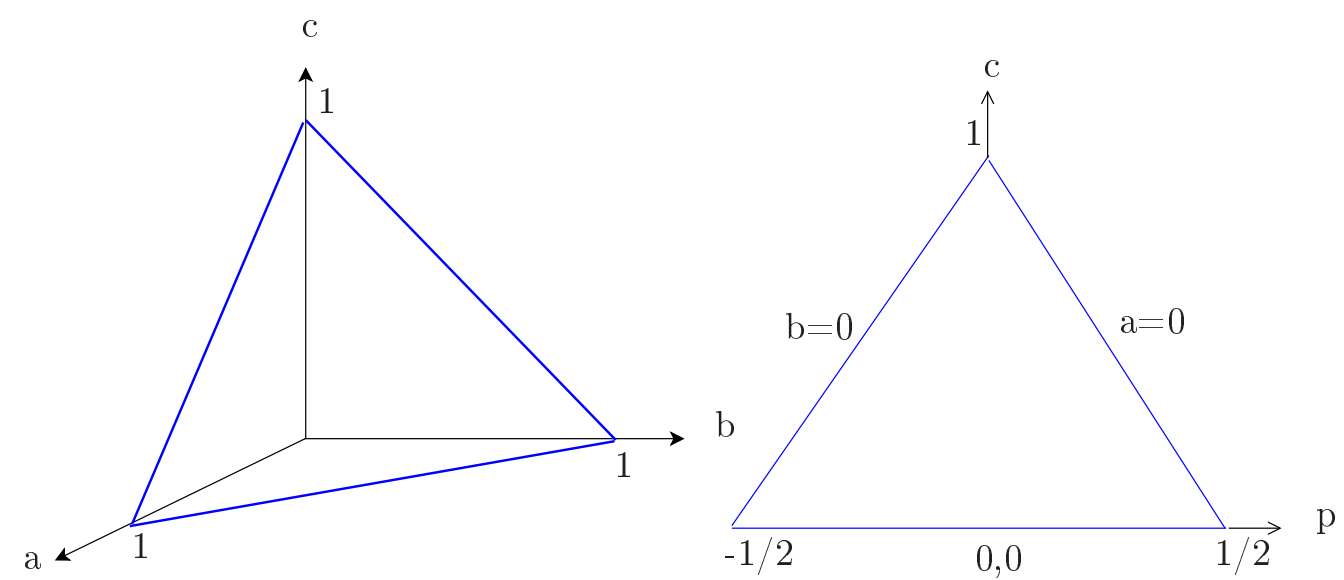

Figura 4.2: O triângulo definido pelas linhas em azul na figura à esquerda delimita o espaço dos parâmetros $(a, b$ e $c)$ do modelo. Por uma mudança conveniente de variável podemos redefinir este espaço tornando-o uma superfície definida no plano $p-c$ (figura à direita), e que, portanto, necessita apenas dois parâmetros para descrever completamente as probabilidades de transição do modelo.

Realizando a análise de estabilidade [66, 67] das soluções deste sistema de equações por meio da matriz jacobiana:

$$
J=\left(\begin{array}{cc}
a-b y^{*} & -a-b x^{*} \\
b y^{*} & -c+b x^{*}
\end{array}\right),
$$

verifica-se que a solução trivial possui os autovalores $\lambda_{1}=-a$ e $\lambda_{2}=b-c$ e, portanto, esta solução é estável para $b<c$. Ademais, nota-se que a transição de fase ocorre na linha $b=c$, que em termos da variáveis $p$ e $c$ se escreve: $c=(1+2 p) / 3$. Por outro lado, para a fase ativa, os autovalores são as raízes da equação

$$
\lambda=\frac{1}{2}\left(-\frac{a(a+b)}{a+c} \pm \sqrt{\Delta}\right),
$$

em que o discriminante é

$$
\Delta=a^{2}\left(\frac{a+b}{a+c}\right)^{2}-4 a(b-c) .
$$

Para $\Delta>0$ os autovalores são reais e negativos e assim a solução é um nó. Contudo, se $\Delta<0$ os autovalores são complexos e o ponto fixo torna-se um foco. Ambas soluções são estáveis, e a transição de nó para foco ocorre quando $\Delta=0$, ou seja

$$
a^{2}(a+b)^{2}-4 a(b-c)(a+c)^{2}=0 .
$$


Resolvendo a equação (4.10), construimos o diagrama de fase do modelo, na aproximação de campo médio simples, conforme mostrado na figura 4.3. Para a fase ativa apresentamos na figura 4.5 como evolui a densidade de imunes na região oscilante e não-oscilante. Percebe-se que após o transiente em que a densidade de imunes é estritamente crescente (o que ocorre às espensas da recuperação e imunização de indivíduos infectados) a densidade decai devido à perda de imunidade. Contudo os processos de infecção, imunização e perda de imunidade competem entre si, levando à flutuações que vão assintoticamente para o valor estacionário. Portanto este comportamento é totalmente diferente aos descritos nas referências [70, 172, 173, 174, 75] nos quais há oscilações que podem ser consequentes

de sazonalidade ou mutação do agente transmissor da doença. Vale ressaltar que ao longo da linha $a=0,0$ o modelo SIRS torna-se SIR o qual não apresenta oscilação alguma nas densidades. A medida que $a$ se aproxima de zero, o tempo que um indivíduo recuperado leva para perder a imunidade $(\tau \sim 1 / a)$ torna-se muito longo e consequentemente as oscilações desaparecem.

A figura 4.4 mostra a evolução das densidades de suscetíveis, infectados e imunes (na aproximação de campo médio simples) com a probabilidade de imunização $c=0,12$ para dois diferentes parâmetros $p$. Por esta figura vemos, mantendo $c$ fixo e aumentando a probabilidade de contaminação $b$, há uma redução no tempo transiente, e obviamente, o acréscimo na densidade de infectados e imunes com a respectiva redução na densidade de suscetíveis.

Na figura 4.5] é exibido a evolução da densidade de imunes para o regime oscilante e não-oscilante. O mesmo comportamento ocorre para a densidade de suscetíveis e infectados, mas as curvas não são mostradas a fim de evidenciar esta diferença de regimes. 


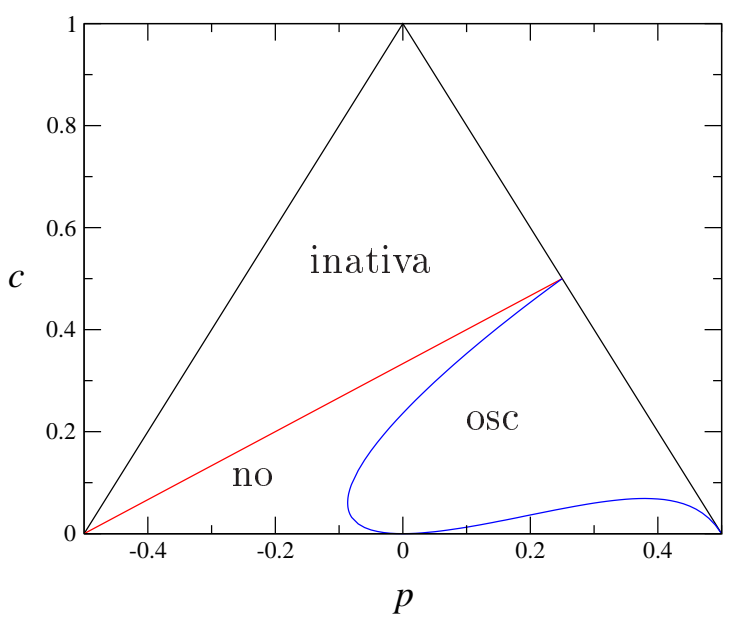

Figura 4.3: Diagrama do modelo SIRS na aproximação de campo médio simples. Na fase inativa toda a população encontra-se suscetível e portanto não há disseminação da doença. A fase ativa (no e osc) é caracterizada por apresentar densidade não nula de infectados e imunes, havendo uma coexistência entre suscetíveis, infectados e imunes.

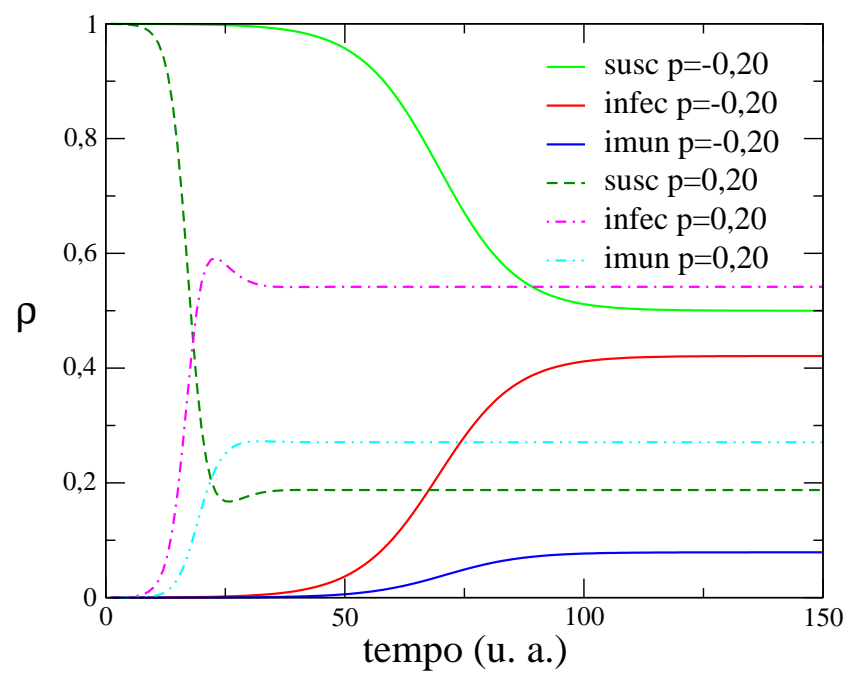

Figura 4.4: Evolução da densidades de suscetíveis, infectados e imunes com probababilidade de imunização $c=0,12$, para $p=-0,20$ (caso $a>b$ ) e $p=0,20($ caso $b>a)$. As curvas foram obtidas pela iteração das equações (4.8) e (4.9). 


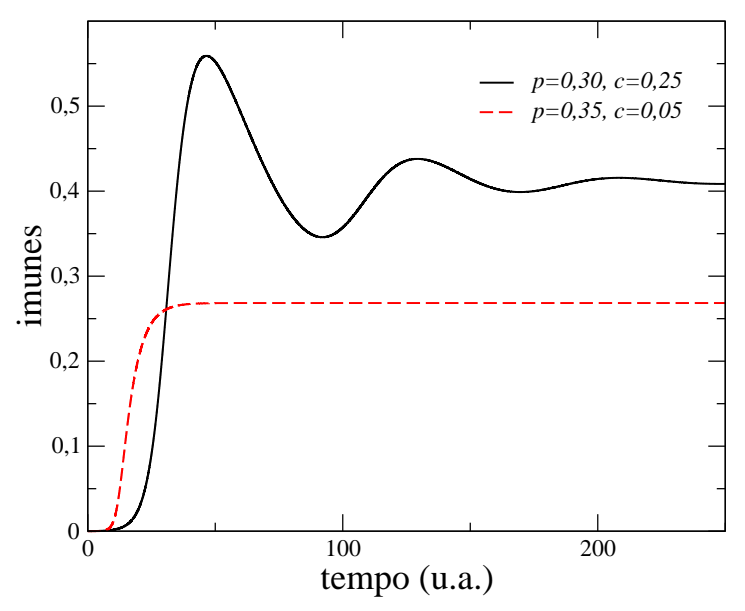

Figura 4.5: Evolução da densidade de imunes obtida pela iteração das equações (4.8) e (4.9). Ambas as curvas foram obtidas para uma região em que a probabilidade de perda de imunidade $a$ é maior que probabilidade de contaminação $b$. Os parâmetros relativos à curva contínua $(p=0,30, c=0,35)$ pertencentem ao domínio da fase oscilante (osc) enquanto os da curva tracejada $(p=0,35, c=0,05)$ estão no domínio da fase não-oscilante (no).

\subsubsection{Aproximação de Campo Médio por Pares}

Seguindo o formalismo e a notação idênticas às utilizadas na seção (3.3), analisamos o modelo SIRS por meio da aproximação de campo médio por pares. Dentro desta aproximação, usando a equação mestra deste problema juntamente com a equação (4.1) para a probabilidade de transição entre os estados, obtemos as equações de evolução para os momentos da distribuição:

$$
\begin{gathered}
\frac{d P_{i}(1)}{d t}=-\frac{b}{\zeta} \sum_{\delta} P_{i, i+\delta}(12)+a P_{i}(0) \\
\frac{d P_{i}(2)}{d t}=\frac{b}{\zeta} \sum_{\delta} P_{i, i+\delta}(12)-c P_{i}(2) \\
\frac{d P_{i, j}(01)}{d t}=-\frac{b}{\zeta} \sum_{\substack{\delta \\
i+\delta \neq j}} P_{i+\delta, i, j}(012)+c P_{i, j}(21)-a P_{i j}(01) \\
\frac{d P_{i, j}(02)}{d t}=\frac{b}{\zeta} \sum_{\substack{\delta \\
i \neq j+\delta}} P_{i, j, j+\delta}(012)+c P_{i, j}(22)-c P_{i, j}(02)-a P_{i j}(02) \quad \text { e }
\end{gathered}
$$




$$
\begin{array}{r}
\frac{d P_{i, j}(12)}{d t}=\frac{b}{\zeta}\left\{\sum_{\substack{\delta \\
i \neq j+\delta}} P_{i, j, j+\delta}(112)-\sum_{\substack{\delta \\
i \neq j+\delta}} P_{i, j, j+\delta}(212)\right\}- \\
\frac{b}{\zeta} P_{i, j}(12)-c P_{i, j}(12)+a P_{i j}(02) .
\end{array}
$$

Como na seção (3.3), consideramos isotropia e homogeneidade espacial e definimos $x=P(1), y=P(2), u=P(01), v=P(12)$ e $w=P(02)$. Em função destas variáveis e empregando a aproximação de campo médio por pares para descorrelacionar os trios que aparecem no lado direito das equações (4.13)-(4.16), as equações (4.11)-(4.16) passam a ser escritas como:

$$
\begin{array}{r}
\dot{x}=-b v+a(1-x-y), \\
\dot{y}=b v-c y, \\
\dot{u}=-b \frac{\zeta-1}{\zeta} \frac{u v}{x}+c v-a u, \\
\dot{v}=b \frac{\zeta-1}{\zeta} \frac{v}{x}(x-u-2 v)-\left(\frac{b}{\zeta}+c\right) v+a w, \quad \mathrm{e} \\
\dot{w}=b \frac{\zeta-1}{\zeta} \frac{u v}{x}+c(y-v-2 w)-a w .
\end{array}
$$

Este sistema de equações apresenta somente um ponto fixo trivial, $\left(x^{*}, y^{*}, u^{*}, v^{*}, w^{*}\right)=(1,0,0,0,0,0)$, que se refere ao estado absorvente de suscetíveis. Para efetuar a análise de estabilidade deste ponto, escrevemos a matriz jacobiana

$$
J=\left(\begin{array}{ccccc}
-a & -a & 0 & -b & 0 \\
0 & -c & 0 & b & 0 \\
0 & 0 & -a & c & 0 \\
0 & 0 & 0 & b \frac{\zeta-2}{\zeta}-c & a \\
0 & c & 0 & -c & -(a+2 c)
\end{array}\right) .
$$

Verifica-se que dois dos autovalores de $J$ são: $\lambda_{1,2}=-a$ e os demais são as raízes da equação

$$
\begin{array}{r}
(c+\lambda)\left\{\left[(1-c+2 p) \frac{\zeta-2}{2 \zeta}-c-\lambda\right]\left(\frac{1-c-2 p}{2}+2 c+\lambda\right)-\right. \\
\left.\frac{c}{2}(1-c-2 p)\right\}+\frac{c}{4}(1-c)^{2}-p^{2}=0 .
\end{array}
$$

O ponto fixo é estável desde que ambos autovalores sejam negativos. Na transição de fase os autovalores se anulam e neste caso a equação (4.21), para o caso de uma rede com coordenação $\zeta=4$, se escreve:

$$
c\left[(1-5 c+2 p)(2+6 c-4 p)-2 c(1-c-2 p)+(1-c)^{2}-4 p^{2}\right]=0 .
$$


As raízes da equação (4.22) são

$$
c=0
$$

e

$$
c_{\mp}=-\frac{1}{18}\left[10-24 p \pm \sqrt{(10-24 p)^{2}+108\left(1-4 p^{2}\right)}\right] .
$$

Como o parâmetro $c$ está restrito ao intervalo [0,1], a equação para a transição de fase corresponde à solução $c_{+}$, visto que uma das raízes é nula e outra é negativa.

Nesta aproximação também ocorre um regime oscilante cuja linha de transição para o regime não-oscilante deve ser diferente da curva encontrada na aproximação de campo médio simples. Contudo, na aproximação de pares a determinação desta linha é muito mais difícil e não foi obtida aqui.

Na figura 4.23 apresentamos o diagrama de fase do modelo SIRS, segundo os diferentes métodos empregados neste trabalho. A transição de fase na aproximação de campo médio por pares, dada pela equação (4.24) apresenta grande concordância com a aproximação de campo médio simples no limite de transmição de infecção com probabilidade unitária. Neste caso o modelo SIRS pode ser mapeado no modelo de contato, discutido no capítulo (2), no qual o processo de infecção ocorre com taxa $\lambda=b / c$.

\subsection{Processo "Birth and Death"}

Um método alternativo para estudo do modelo SIRS é aplicar o processo markoviano de tempo contínuo conhecido como "birth and death" [7, 36, 76], também denominado "one-step process" [20, 28, 29, 68]. Este método é similar ao modelo das urnas de Ehrenfest [77], mas no presente caso há 3 estados distintos e as regras de transição são diferentes das adotadas para o modelo da urna.

Consideramos uma população de $N$ indivíduos, em que cada um deles pertence a uma das três classes, suscetível, infectado ou recuperado. As variáveis estocásticas são: o número de suscetíveis,

$$
n=\sum_{i=1}^{N} \delta\left(\eta_{i}, 1\right)
$$

e o número de infectados,

$$
m=\sum_{i=1}^{N} \delta\left(\eta_{i}, 2\right)
$$


A equação mestra que descreve a evolução da probabilidade $P(n, m, t)$ é

$$
\begin{array}{r}
\frac{d}{d t} P(n, m, t)=N \sum_{\sigma=-1}^{1} \sum_{\tau=-1}^{1}\left\{A_{\sigma \tau}(n-\sigma, m-\tau) P(n-\sigma, m-\tau, t)-\right. \\
\left.A_{\sigma \tau}(n, m) P(n, m, t)\right\} .
\end{array}
$$

As probabilidades de transições possíveis são estabelecidas conforme os seguintes processos:

\section{- processo de infecção}

Neste processo, com probabilidade $b$, e proporcionalmente à quantidade de infectados $(m)$, um indivíduo suscetível torna-se infectado, e, portanto, o número de suscetíveis decai $(n \rightarrow n-1)$ enquanto o número de infectados é acrescido $(m \rightarrow m+1)$, neste caso a probabilidade de transição é escrita como

$$
A_{-+}(n+1, m-1)=w(n \rightarrow n-1, m \rightarrow m+1)=b x y .
$$

\section{- imunização espontânea}

Uma vez infectado, um indivíduo pode recuperar, adquirindo momentaneamente uma resistência natural à contaminação. Uma vez que este processo é espontâneo, a probabilidade de transição depende apenas da quantidade de indivíduos infectados $(n)$, e o decaimento de $(n)$ resulta no acréscimo da população imunizada $(N-n-m)$. Podemos escrever a probabilidade de imunização da forma

$$
A_{0-}(n, m-1)=w(n \rightarrow n, m \rightarrow m-1)=c y .
$$

\section{- perda espontânea de imunidade}

Considerando que a imunidade aquirida expire após algum tempo, deixando o indivíduo novamente suscetível à contaminação, podemos escrever esta transição como

$$
A_{+0}(n-1, m)=w(n \rightarrow n+1, m \rightarrow m)=a z .
$$

Nas equações (4.28)-(4.30), $x=n / N, y=m / N$ e $z=1-x-y$ são as densidades de suscetíveis, infectados e imunes respectivamente. A figura 4.6 mostra como as probabilidades (4.28)-(4.30) atuam no espaço $\mathrm{nm}$ formado pelo número de susceptíves e infectados. Para o modelo SIR temos $A_{+0}=0$, neste caso, como exibido na figura 4.7, há, no limite termodinâmico, infinitos estados absorventes. 
Em termos destas probabilidades, a equação mestra (4.27) torna-se

$$
\begin{aligned}
\frac{d P}{d t}(n, m, t)= & A_{-+}(n+1, m-1) P(n+1, m-1)-A_{-+}(n, m) P(n, m)+ \\
& A_{+0}(n-1, m) P(n-1, m)-A_{+0}(n, m) P(n, m)+ \\
& A_{0_{-}}(n, m+1) P(n, m+1)-A_{0-}(n, m) P(n, m) .
\end{aligned}
$$

$N$

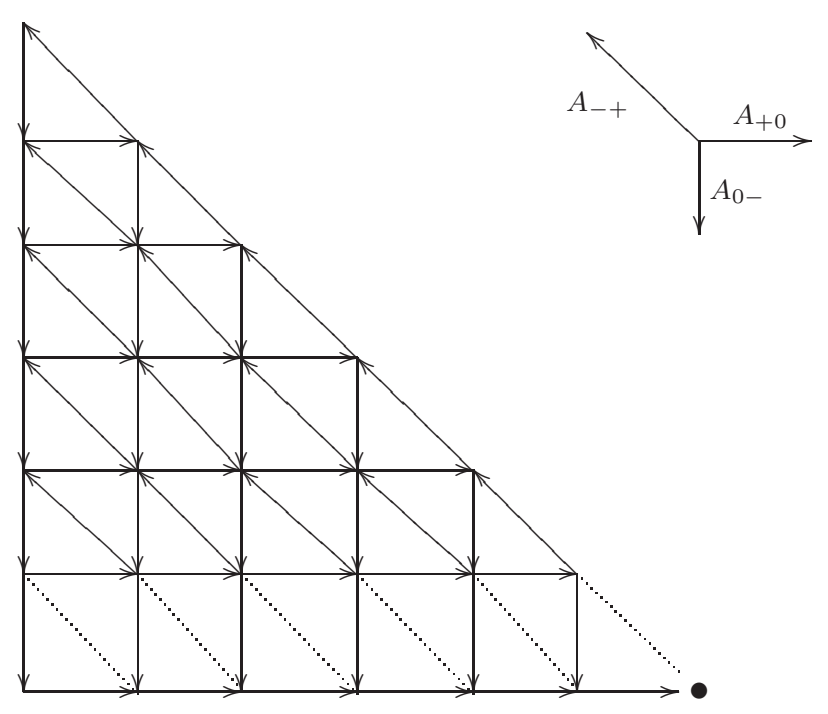

$m$

0

0

$n$

$N$

Figura 4.6: Transições do processo "birth and death" no espaço de suscetíveis $(n)$ e infectados $(m)$. As setas diagonais representam a transição $A_{-+}$através da qual um indivíduo suscetível torna-se infectado. As setas verticais representam o processo de imunização que ocorre segundo a transição $A_{0-}$, e as setas horizontais representam o processo de perda de imunidade que obedece a transição $A_{+0}$. As ligações pontilhadas são transições proibidas uma vez que para criar um novo infectado é necessário a existência de pelo menos um indivíduo infectado no agregado. O ponto à direita do diagrama representa o estado absorvente de suscetíveis. 


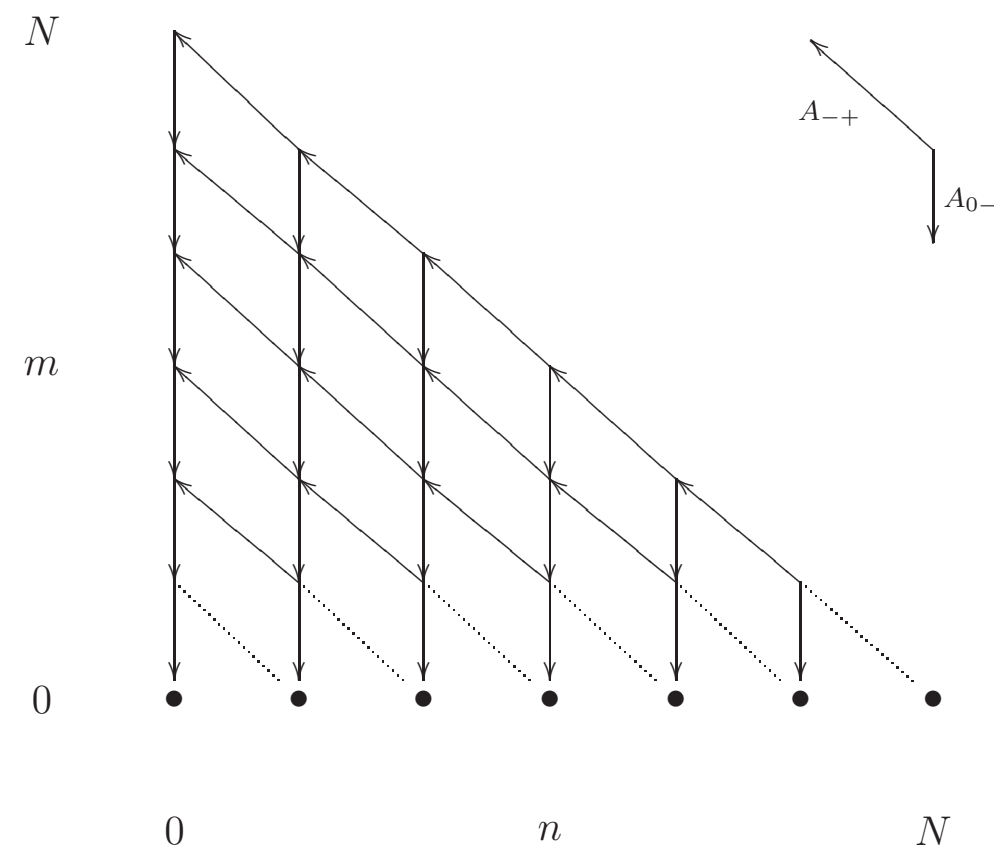

Figura 4.7: Transições do processo "birth and death" para o modelo SIR no espaço de suscetíveis $(n)$ e infectados $(m)$. Neste caso não há a transição $A_{+0}$, isto origina, no limite termodinâmico $N \rightarrow \infty$, infinitos estados absorventes os quais estão representados no diagrama (com número finito de estados) por

\section{Cálculo da média de uma grandeza de estado}

Para calcular a média de uma grandeza de estado, que a princípio pode depender da densidade de suscetíveis e/ou da densidade de infectados, $<f(n, m)>$, emprega-se a equação equação mestra (4.31) como segue,

$$
\begin{aligned}
<f(n, m)>= & \frac{d}{d t} \sum_{n, m} f(n, m) P(n, m)=\sum_{n, m} \frac{d}{d t} P(n, m) \\
& =\sum_{n, m} f(n, m)\left\{A_{-+}(n+1, m-1) P(n+1, m-1)-\right. \\
& A_{-+}(n, m) P(n, m)+A_{+0}(n-1, m) P(n-1, m)- \\
& A_{+0}(n, m) P(n, m)+A_{0-}(n, m+1) P(n, m+1)- \\
& \left.A_{0-}(n, m) P(n, m)\right\}
\end{aligned}
$$


ou seja

$$
\begin{aligned}
<f(n, m)>= & \sum_{n, m}\left\{f(n-1, m+1) A_{-+} P(n, m)-\right. \\
& f(n, m) A_{-+}(n, m) P(n, m)+f(n+1, m) A_{+0}(n, m) P(n, m)- \\
& f(n, m) A_{+0}(n, m) P(n, m)+f(n, m-1) A_{0-}(n, m) P(n, m)- \\
& \left.f(n, m) A_{0-}(n, m) P(n, m)\right\} \\
& =\sum_{n, m}\left\{[f(n-1, m+1)-f(n, m)] A_{-+}(n, m) P(n, m)+\right. \\
& {[f(n+1, m)-f(n, m)] A_{+0}(n, m) P(n, m)+} \\
& {\left.[f(n, m+1)-f(n, m)] A_{0-}(n, m) P(n, m)\right\} . }
\end{aligned}
$$

Uma vez obtida uma expressão genérica para se calcular a média de uma grandeza de estado, podemos determinar a densidade média de suscetíveis,

$$
\begin{aligned}
\frac{d}{d t}<x>= & \frac{d}{d t}<\frac{n}{m}>=\frac{d}{d t}<f(n)> \\
& =N \sum_{n, m}\left(\frac{n-1}{N}-\frac{n}{N}\right) b \frac{n}{N} \frac{m}{N} P(n, m)+ \\
& \left(\frac{n+1}{N}-\frac{n}{N}\right) a\left(\frac{N-n-m}{N}\right) P(n, m)+\left(\frac{n}{N}-\frac{n}{N}\right) c \frac{m}{N} P(n, m)
\end{aligned}
$$

que resulta em

$$
\frac{d}{d t}<x>=-b<x y>+a<z>\text {. }
$$

E de forma similar calcula-se a densidade de infectados,

$$
\begin{aligned}
\frac{d}{d t}<y>= & \frac{d}{d t}<\frac{m}{N}>=\frac{d}{d t}<f(m)> \\
& =N \sum_{n, m}\left\{\left(\frac{m+1}{N}-\frac{m}{N}\right) b \frac{n}{N} \frac{m}{N} P(n, m)+\right. \\
& \left(\frac{m}{N}-\frac{m}{N}\right) a \frac{N-m-n}{N} P(n, m)+ \\
& \left(\frac{m+1}{N}-\frac{m}{N}\right) c \frac{m}{N} P(n, m) \\
& =b<x y>-c<y>.
\end{aligned}
$$

Entretanto, as equações (4.34) e (4.35) estão acopladas de forma que não conseguimos obter $<x(t)>\mathrm{e}<y(t)>$ exatamente. 


\section{Simulação do processo "birth and death"}

Além da abordagem analítica, o processo "birth and death" pode ser simulado computacionalmente e assim tornar-se uma ferramenta auxiliar à aproximação de campo médio, possibilitando investigar algumas propriedades do modelo que tenham sido detectadas. Em particular podemos encontrar a linha de transição, que separa a fase ativa da inativa, e também analisar a região da fase ativa que apresenta oscilações.

Empregando o processo "birth and death", foram efetuadas simulações computacionais empregando um conjunto de $N=5000$ partículas, cuja transição entre as classes ocorre com as probabilidades (4.28)-(4.30).

A simulação do modelo SIRS por meio do processo "birth and death" segue o seguinte algoritmo:

1. cria-se um a lista de lista de $N$ partículas, que representa os $N$ indivíduos de uma população. À cada partícula está associada uma variável estocástica $\eta_{i}$ que pode assumir os valores $\eta_{i}=\{0,1$ ou 2$\}$ conforme o estado seja, suscetível, infectado ou imune. No instante inicial há $N-1$ suscetíveis e apenas um indíviduo infectado, o qual é sorteado entre as $N$ partículas.

2. Sorteia-se uma partícula e um número aleatório $\gamma$. Calcula-se a probabilidade de transição $\omega_{i}$ conforme as equações (4.28), (4.29) ou (4.30), caso o indivíduo esteja suscetível, infectado ou imune respectivamente. Se $\gamma \leq \omega_{i}$ então a partícula assume seu próximo estado cíclico $(0 \rightarrow 1 \rightarrow 2 \rightarrow 0)$.

3. Repete-se o passo 2 até um tempo máximo, definido previamente. Para cada $N$ partículas sorteadas o tempo é incrementado em um passo de Monte Carlo, e se o tempo for maior que o tempo transiente, aquiva-se o valor das densidades para que se calcule posteriormente o valor médio ou fazer estudos das séries temporais das densidades.

A figura 4.8 ilustra como evoluem as densidades de suscetíveis, infectados e removidos. Após um tempo transiente, que próximo da linha $a \rightarrow 1$ é curto mas torna-se longo a medida que se aproxima de $a \rightarrow 0 \quad$ com $\quad b \rightarrow 1$, as densidades apresentam um ruído que pode ser consequência da estocasticidade agregada ao processo de evolução; mas, nos casos em que o ruído apresenta correlação, verifica-se que há flutuações inerentes ao processo em questão.

Na figura 4.9 vemos a dependência do parâmetro de ordem em relação ao tamanho do sistema. Para determinar o ponto crítico, em cada valor do 


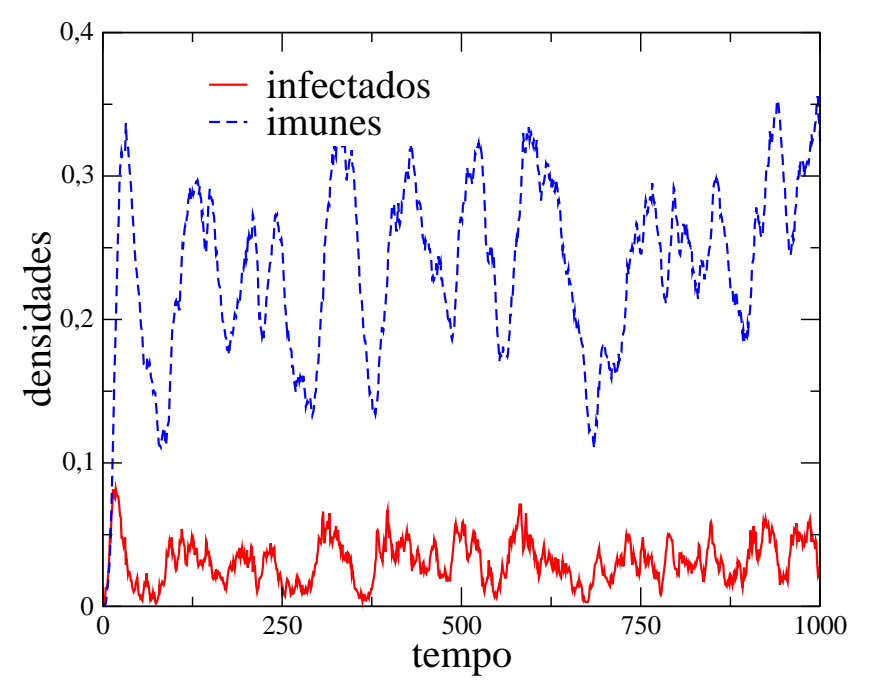

Figura 4.8: Evolução das densidades de suscetíveis, infectados e imunes para os parâmetros $p=0,24$ e $c=0,40$, com um total de $N=5000$ partículas.

parâmetro $p$ é necessário que a quantidade de partículas seja suficientemente grande para tornar as flutuações nas densidades desprezíveis. Para encontrar a linha de transição, varia-se o parâmetro $p$ e a partir dele, uma vez que a probabilidade $a$ é fixada, calcula-se $c$, a fim de determinar cada ponto da linha, e assim construir o diagrama de fase, o qual é exibido na figura 4.10.

Pode-se avaliar a estabilidade das densidades, analisando o desvio padrão $\sigma=\sqrt{\left\langle x^{2}\right\rangle-\langle x\rangle^{2}}$, onde $x$ representa uma das densidades (suceptíveis, infectados ou imunes). A figura 4.11 mostra a dependência de $\sigma$ em relação ao tamanho da população. Percebe-se que mesmo na região que apresenta oscilações, as flutuações decaem com o inverso do tamanho populacional. Portanto, estas oscilações só existem para sistema de tamanho finito, e no limite termodinâmico não deve existir oscilações.

Além disso, conforme [35, 33] podemos determinar a separação entre as fases oscilante e não-oscilante a partir da função auto-correlação temporal. A auto-correlação de uma função $f(k)$ é definida como

$$
c(t)=<f(0) f(t)>=\lim _{T \rightarrow \infty} \frac{1}{T} \int_{0}^{T} f(k) f(k+t) d k,
$$

em que $f(k)$ é uma função contínua e $t$ é o intervalo de tempo. Analogamente, define-se a auto-correlação cruzada entre as funções $f(k)$ e $g(k)$ como

$$
c_{f g}(t)=\lim _{T \rightarrow \infty} \frac{1}{T} \int_{0}^{T} f(k) g(k+t) d k .
$$




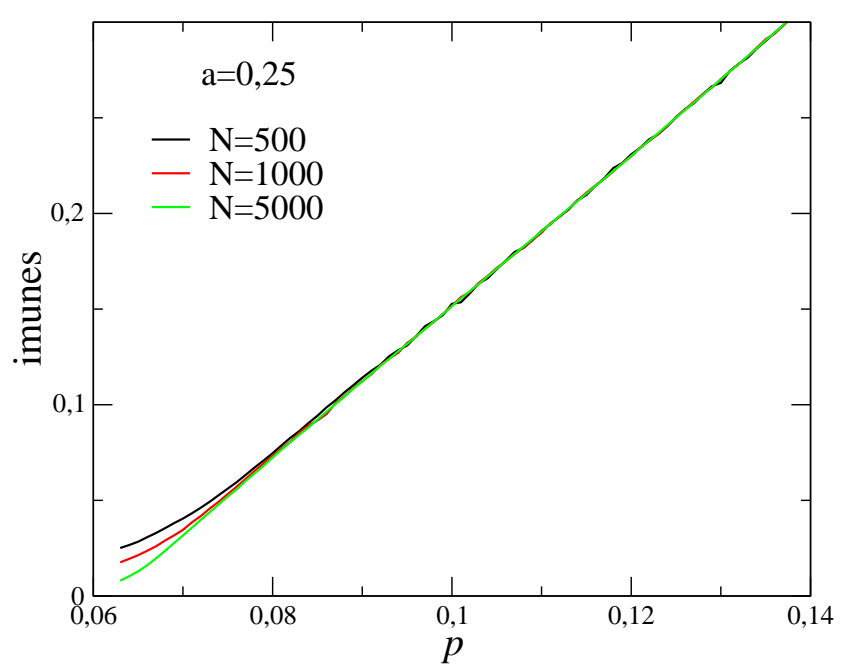

Figura 4.9: Densidade estacionária de infectados em função do parâmetro $p$ para diferentes tamanhos populacionais $N$. A probabilidade de perda de imunidade é constante $(a=0,25)$. A transição de fase é determinada fazendo a extrapolação para densidade de infectados nula. Percebe-se que próximo à transição de fase a densidade de infectados apresenta uma dependencia em relação ao tamanho do sistema, a qual deve desaparecer no limite $N \rightarrow \infty$.

Para uma série de dados da forma $x=\left\{x_{1}, x_{2}, \ldots, x_{n}\right\}$, espaçado em intervalos discretos iguais, a auto-correlação é calculada conforme a expressão

$$
c(t)=\frac{1}{(n-t) \sigma^{2}} \sum_{m=1}^{n-t}\left(x_{m}-\bar{x}\right)\left(x_{m+t}-\bar{x}\right),
$$

onde $\sigma$ é o desvio quadrático médio.A auto-correlação para duas séries discretas é definida de modo similar.

Assumindo que na região em que as densidades apresentam oscilações a auto-correlação seja uma função da forma

$$
c(t) \sim e^{-\alpha t} \cos (\omega t)
$$

em que $-\alpha$ e $\omega$ são as partes reais e imaginárias dos autovalores. Enquanto, para a região não-oscilante, sendo os autovalores puramente reais a expressão (4.39) se reduza à

$$
c(t) \sim e^{-\alpha t}
$$

Uma vez que a mudança entre os regimes oscilante para não-oscilante ocorre continuamente em função do período. Podemos convencionar que as 


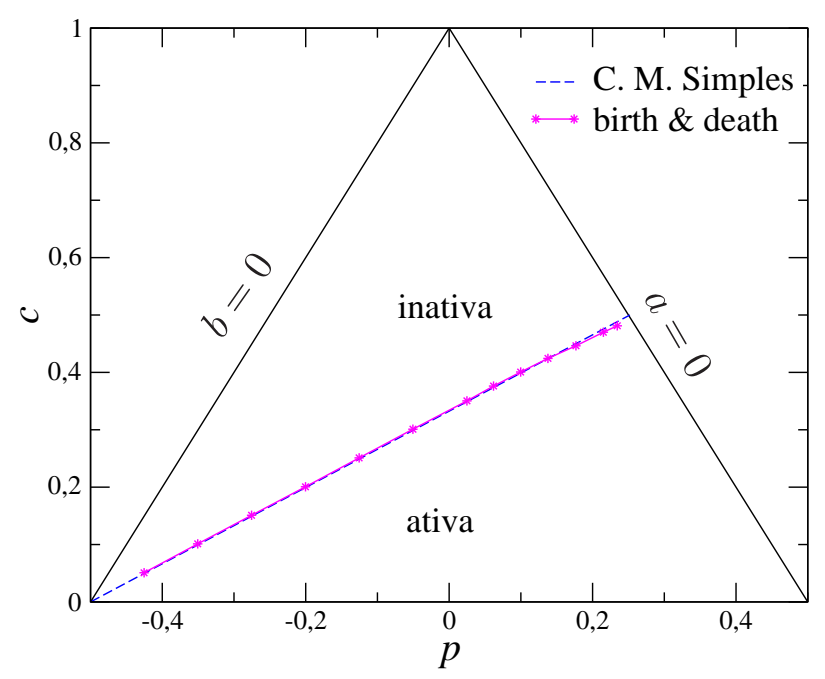

Figura 4.10: Diagrama de fase determinado com a aproximação de campo médio simples (CMS) e por simulações computacionais do processo "birth and death". Vemos que o processo "birth and death" reproduz fielmente os resultados para a linha de transição obtida a partir da aproximação de campo médio simples.

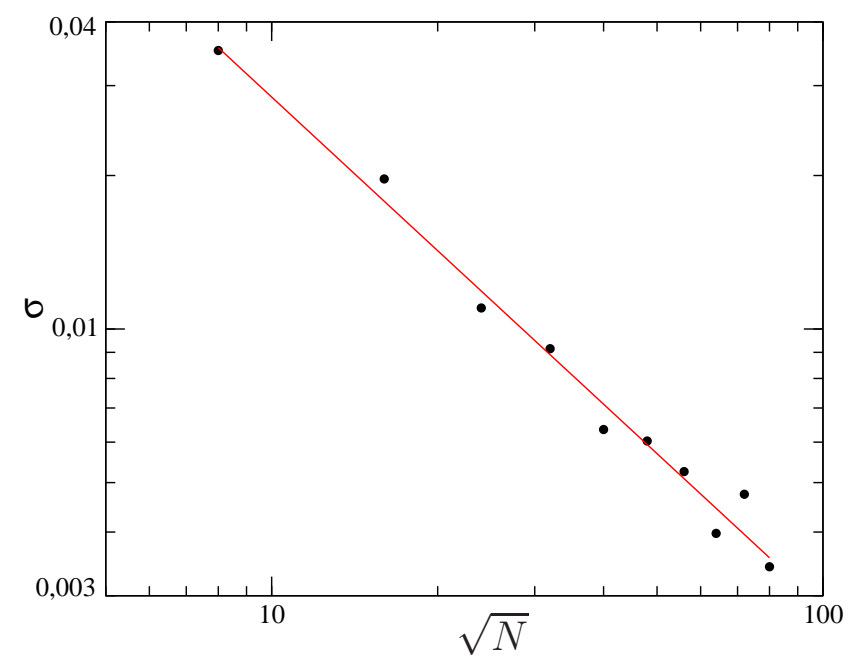

Figura 4.11: Desvio quadrático médio da densidade de imunes em função do tamanho da população, os parâmetros usados nas simulações foram $p=0,20$ e $c=0,02$. Como esperado, $\sigma$ decai com o inverso do tamanho da população $\sigma \sim 1 / N$. Pela linearização, linha contínua, encontramos que o expoente de decaimento é $\alpha=-1$. 
oscilações sejam dadas da forma

$$
c_{n}=(-1)^{n} e^{n \frac{\alpha \tau}{2}}, \quad n=1,2,3, \ldots
$$

nesta equação, $n$ representa a sucessão de vales ( $n$ ímpar) e picos ( $n$ par).

Quando observamos a auto-correlação temporal para a densidade de imunes, mostrada na figura 4.12, ou demais densidades do modelo, vemos que os picos se deslocam em relação ao tempo (mudança de período de oscilação) e a amplitude da auto-correlação possui uma forte dependencia em relação aos parâmetros do modelo. Embora este comportamento seja perceptível para todos os vales e picos, ele é mais evidente para o primeiro vale, pois é o que possui maior amplitude.

Fazendo um gráfico da amplitude da função de auto-correlação temporal do primeiro vale $\left(c_{1}\right)$ em função da probabilidade de imunização $c$, tendo fixado $p$, podemos percorrer o espaço todo o diagrama de fase, e obter a linha que delimita a região com oscilações nas densidades. A figura 4.15 exibe este procedimento, onde foi calculada a correlação para a densidade de imunes, sob a linha com $p=0,25$. Nesta figura nota-se que quando a probabilidade de imunização é muito baixa, $c \lesssim 0,15$, as densidades não apresentam oscilações e portanto a amplitude da função de auto-correlação é nula. Entretanto, na região $0,15 \lesssim c \lesssim 0,5$ as densidades apresentam oscilações periódicas. Conforme $c$ aumenta, o sistema sai da região com oscilações, deixando de apresentar qualquer oscilação, e para valores ainda maiores de $c$ a fase absorvente é atingida. Embora seja difícil de determinar precisamente uma separação destes regimes em simulações computacionais, obtemos resultados coerentes com a previsão de campo médio simples. Do ponto de vista da termodinâmica este tipo de transição não representa uma transição de fase, e sim uma mudança de regime que se percebe na evolução temporal das densidades.

Para encontrar toda a curva de transição de regime, é necessário que se faça a análise para todo o espaço de parâmetros (figura 4.2). Contudo, nosso objetivo é apenas mostrar como é possível obter esta separação a partir das séries temporais advindas de simulações computacionais do modelo SIRS usando o processo birth and death.

Pode-se determinar o período das oscilações através da análise da função de auto-correlação temporal, contudo este procedimento pode resultar causar uma imprecisão grande, visto que apenas os primeiros picos e vales estão bem localizados. Seguindo [78] podemos calcular a transformada de Fourier da correlação temporal, realizada para uma das densidades, ou mesmo da correlação cruzada. Este cálculo é realizado conforme a seguinte expressão

$$
S(\omega)=\int \frac{c(t)}{c(0)} e^{i \omega t} d t
$$


em que $c(t)$ é calculada conforme a equação (4.38). O fator $c(0)$ corresponde à normalização da correlação.

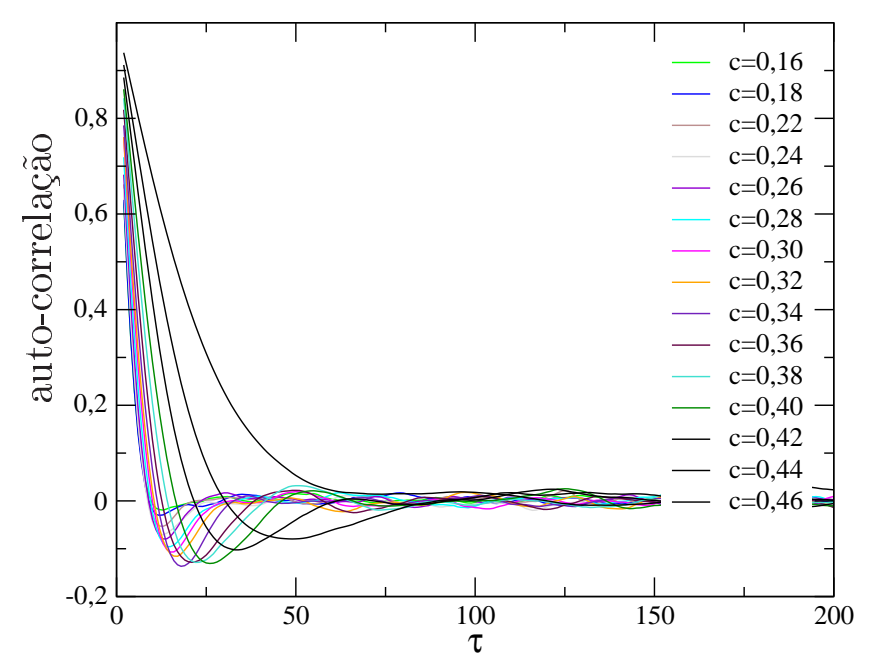

Figura 4.12: Auto-correlação temporal para a densidade de indivíduos imunes quando $p=0,20$. Conforme a probabilidade de imunização aumenta a sistema passa de uma região sem oscilações para um região com oscilações, mas aumentando ainda mais esta probabilidade as oscilações desaparecem. 


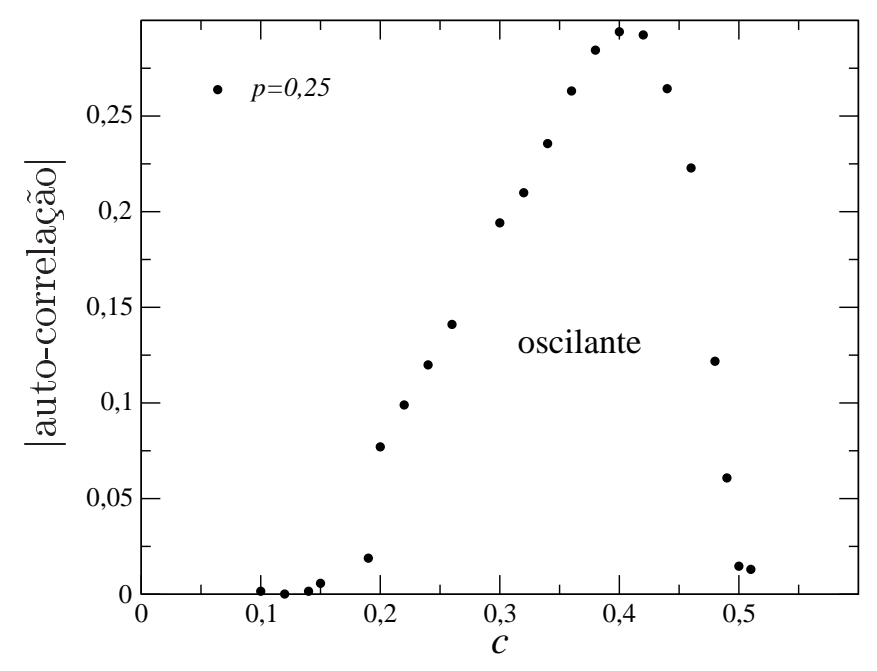

Figura 4.13: Diagrama com a separação entre o regime não-oscilante para o oscilante. Fixado o parâmetro $p=0,25$ varia-se a probabilidade de imunização até atingir a fase inativa. Ao fazer o gráfico da amplitude do primeiro vale da função de auto-correlação temporal versus o parâmetro $c$ podemos aferir os limiares de imunização que levam à densidades populacionais de suscetíveis, infectados e imunes oscilantes ou não oscilantes.

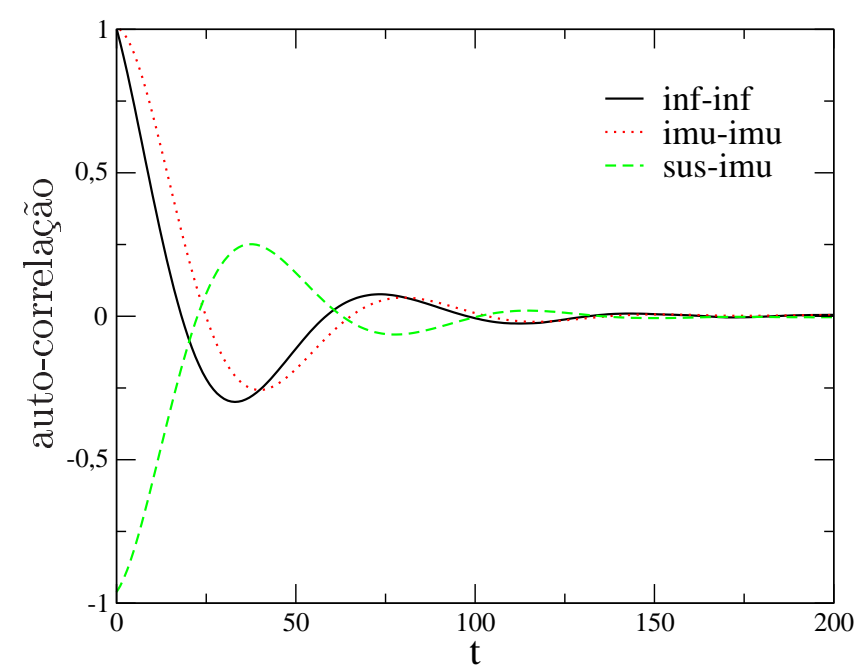

Figura 4.14: Auto-orrelação temporal para a densidade de infectados (infinf), imunes (imu-imu) e a correlação cruzada entre susceptíves e imunes (susimu) versus tempo. As densidades são resultados de simulações do processo "birth and death" com os parâmetros $p=0,25$ e $c=0,40$. 


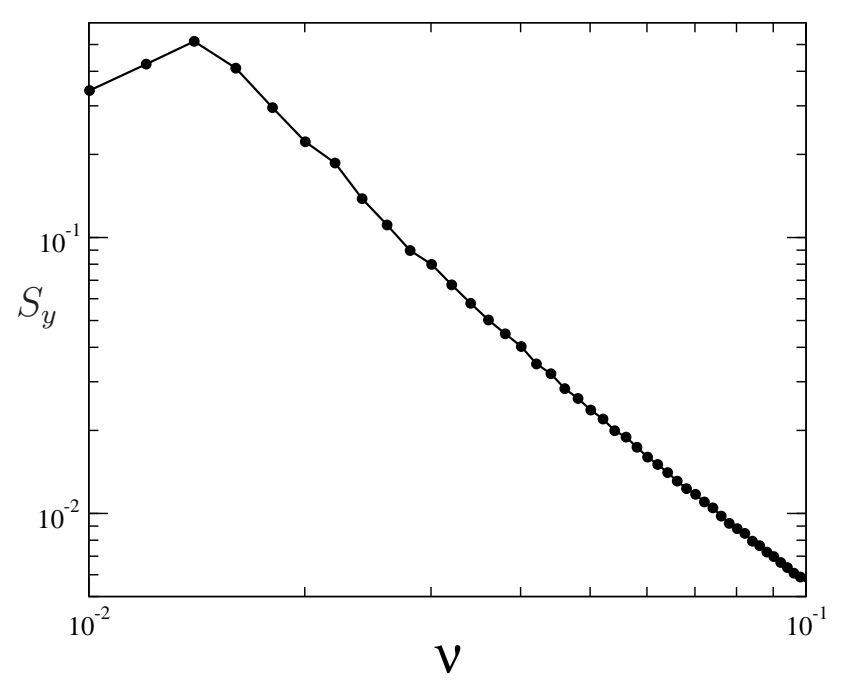

Figura 4.15: Transformada de Fourier da correlação temporal de infectados, $\nu=\omega / 2 \pi$ é a frequência. Neste gráfico vemos que há apenas um pico que ocorre para frequência $\nu=0,013(3)$ que corresponde ao período $\tau=72(3)$ passos de Monte Carlo.

\subsection{Simulações de Monte Carlo}

Empregando o método de Monte Carlo, analisamos o modelo SIRS em redes regulares quadradas com coordenação $\zeta=4$, com o intuito de determinar a linha de transição de fase bem como alguns dos expoentes críticos do modelo.

Em detrimento do tempo computacional exigido, usamos simulações dependentes do tempo para determinar a transição de fase ao longo do espaço de parâmetros do modelo. Uma vez determinado o ponto crítico com a precisão desejada, calculamos os expoentes críticos desejados realizando o tipo simulação apropriada.

\subsubsection{Simulações Dependentes do Tempo}

Por ser uma generalização do modelo SIR, nas simulações dependentes do tempo para o modelo SIRS, podemos empregar o mesmo algoritmo descrito na sessão (3.4.2), exceto que no segundo passo é necessário que se use a regra de transição (4.1) a qual contém o termo que descreve o processo de perda de imunidade.

Dado o espaço de parâmetros exibido na figura 4.2. executamos as simulações ao longo de superfícies com probabilidade de perda de imunidade constante, que são linhas paralelas à $a=0$. Uma exceção é o ponto $p=0$, 
que representa o caso em que a probabilidade de infecção e perda de imunidade são iguais $(a=b)$. Em ambos os casos, fixa-se um dos parâmetros, $a$ ou $p$, e varia $c$ até encontrar o ponto crítico.

As figuras 4.16, 4.19 mostram retratos da rede referentes à realizações para diferentes

parâmetros. Em todas as figuras a simulação inicia com o sistema na iminência de cair no estado absorvente, ou seja, todos os indivíduos da rede encontram-se susceptíves, com exceção do sítio central que é ocupado por um infectado. Pelas figuras 4.16, 4.17 e 4.19, as quais possuem a mesma probabilidade de imunização, vemos que o acréscimo na probabilidade de perda de imunidade causa redução na quantidade de indivíduos imunes, conforme esperado. Além disso, mesmo sem fazer o cálculo apropriado, nota-se que a velocidade de espalhamento da doença também diminui em função do aumento da probabilidade de perda de imunidade. Esta redução na velocidade pode ser compreendida diretamente pela condição (4.7), pois se $c$ é constante e $a$ está descrescendo, então a probabilidade de infecção $b$ deve reduzir e consequentemente desacelerar o processo de espalhamento da doença. As figuras 4.17 e 4.18 mostram realizações efetuadas para a mesma probabilidade de perda de imunidade $a=0,30$ mas com diferente probabilidade de imunização, na primeira $c=0,15$ enquanto a segunda possui $c=0,19 \mathrm{e}$ que, conforme a previsão de campo médio, está mais próxima da transição de fase. Nestas figuras vemos que conforme se aproxima da transição de fase a velocidade de espalhamento epidêmico diminui e que a região afetada pela doença apresenta menor densidade de indivíduos infectados e imunizados.

Nas figuras 4.20 4.22 são exibidos gráficos para a evolução do número de infectados $N(t)$, o raio quadrático médio $R^{2}(t)$ e a probabilidade de persistência da doença $P_{s}(t)$ para diferentes parâmetros do modelo. Nas simulações uma das probabilidades entra como parâmetro, e varia-se uma segunda até que seja possível determinar o ponto crítico associado. 

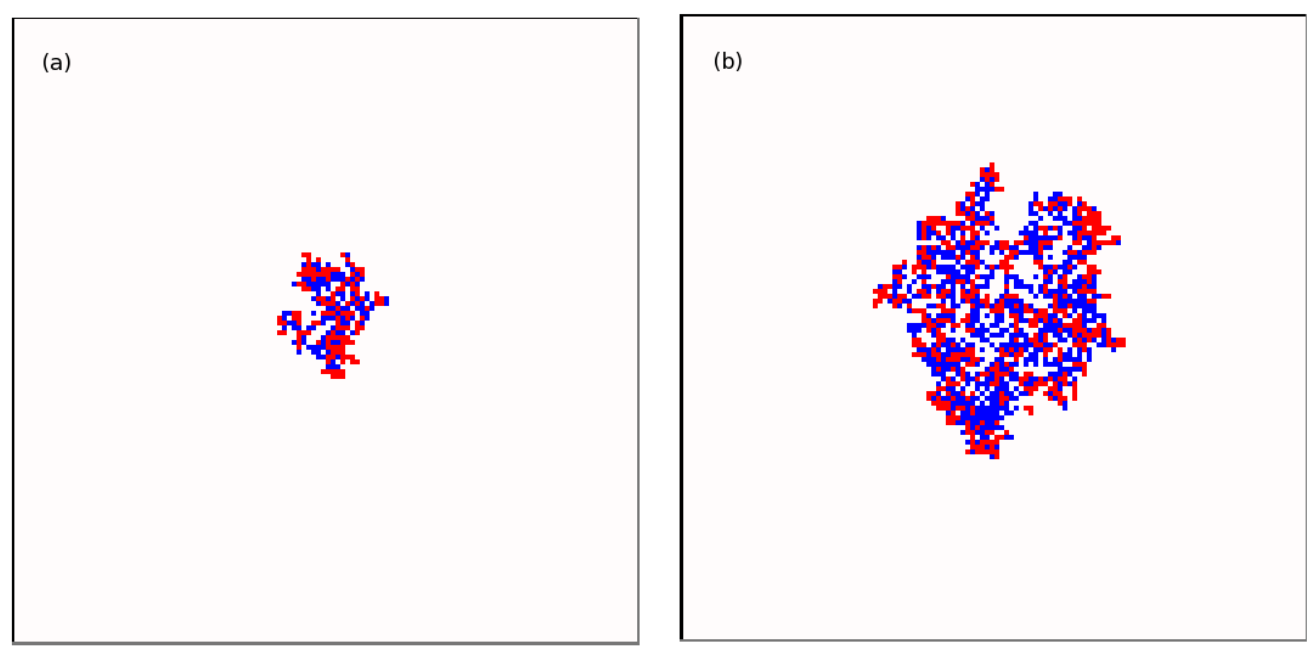

(c)

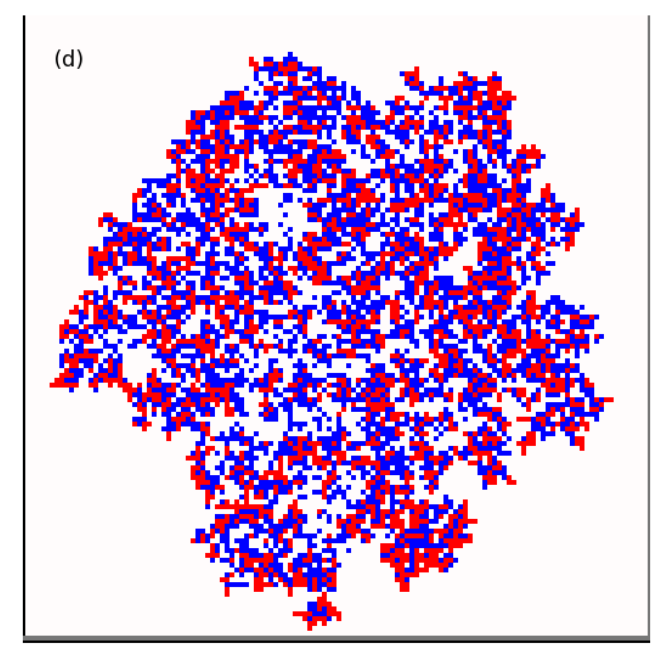

Figura 4.16: Retratos da evolução de uma realização executada para os parâmetros $a=0,10 ; c=0,15$ e $L=128$. As figuras exibem fotografias da rede nos instantes $(a),(b),(c)$ e $(d)$ equivalentes à $t=50,100,150$ e 200 passos de Monte Carlo, respectivamente. As cores dos sítios correspondem: branco (suscetível), vermelho (infectado) e azul (imune). 

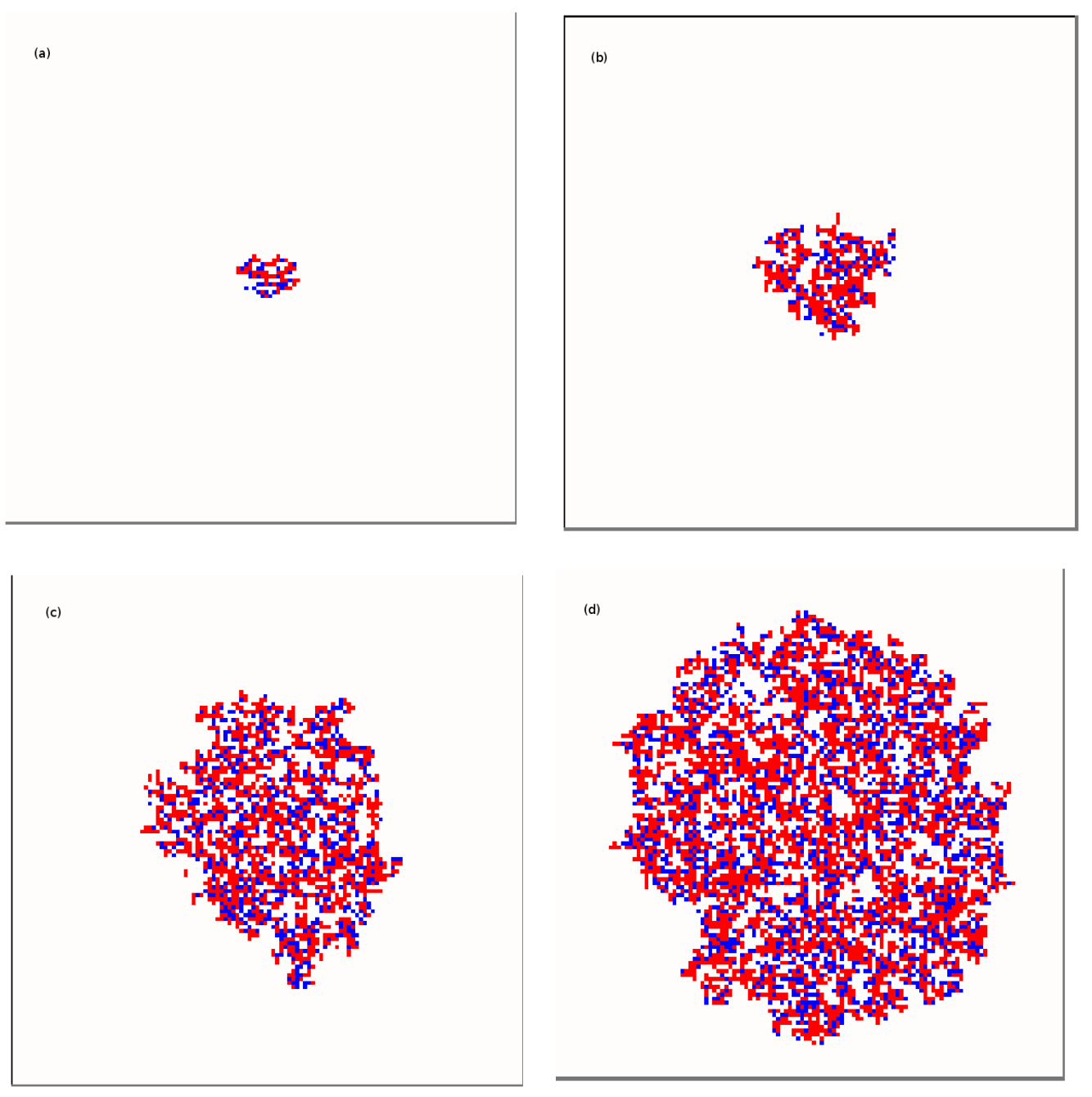

Figura 4.17: Retratos da evolução de uma realização executada para os parâmetros $a=0,30 ; c=0,15$ e $L=128$. As figuras exibem fotografias da rede nos instantes $(a),(b),(c)$ e $(d)$ equivalentes à $t=50,100,200$ e 300 passos de Monte Carlo, respectivamente. As cores dos sítios correspondem: branco (suscetível), vermelho (infectado) e azul (imune). 
(a)

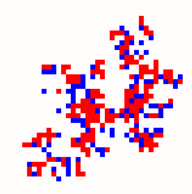

(c)

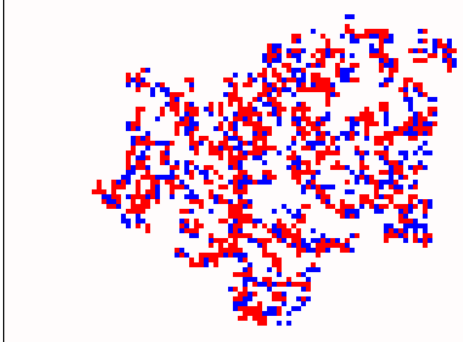

(b)

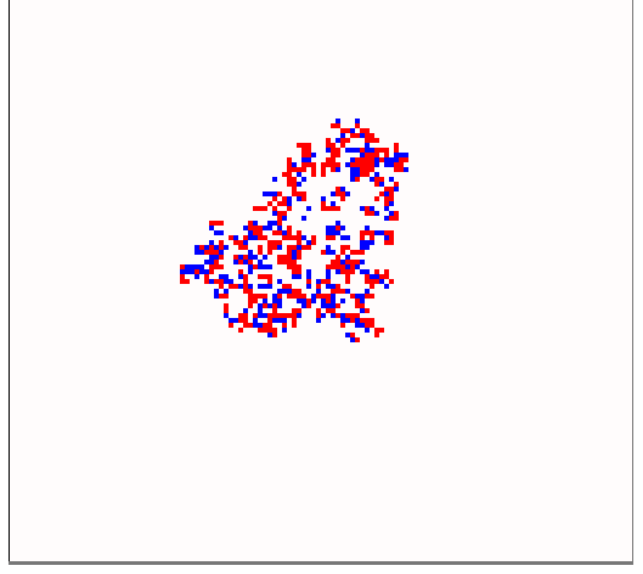

(d)

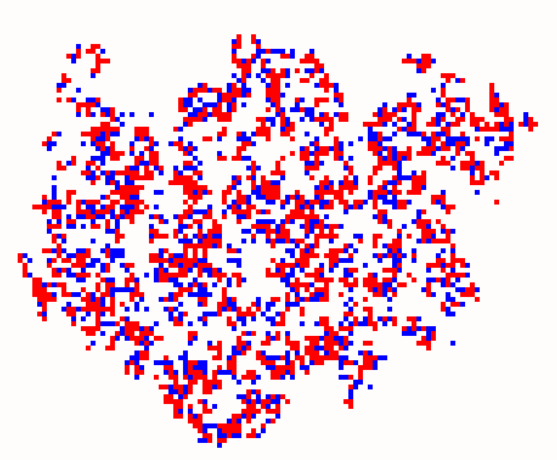

Figura 4.18: Retratos da evolução de uma realização executada para os parâmetros $a=0,30 ; c=0,19$ e $L=128$. As figuras exibem fotografias da rede nos instantes $(a),(b),(c)$ e $(d)$ equivalentes à $t=200,300,400$ e 500 passos de Monte Carlo, respectivamente. As cores dos sítios correspondem: branco (suscetível), vermelho (infectado) e azul (imune). 


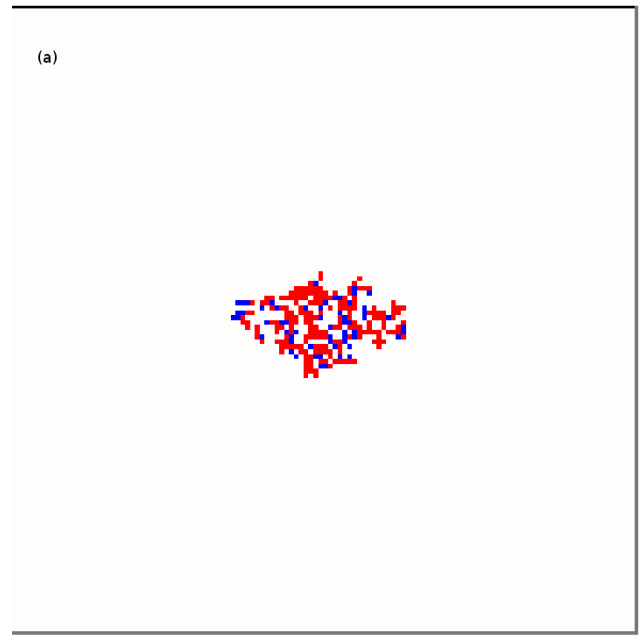

(b)

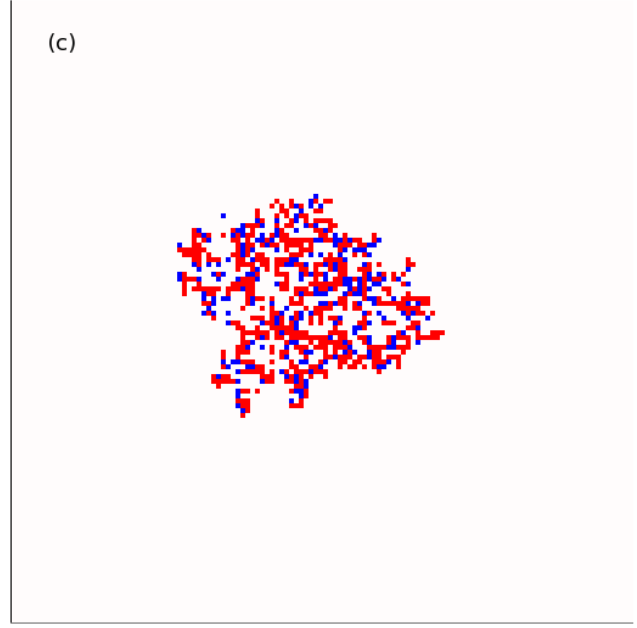

(d)

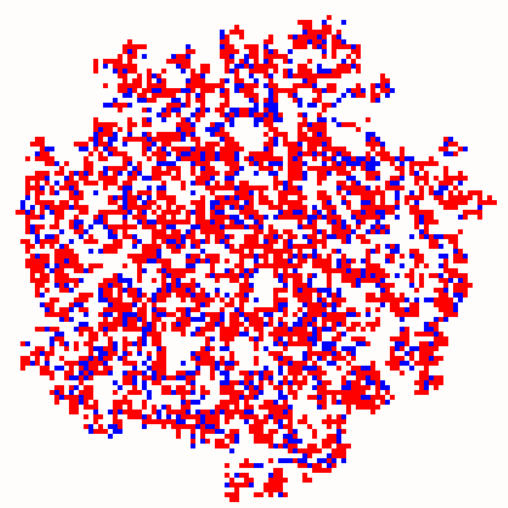

Figura 4.19: Retratos da evolução de uma realização executada para os parâmetros $p=0,00 ; c=0,15$ e $L=128$. As figuras exibem fotografias da rede nos instantes $(a),(b),(c)$ e $(d)$ equivalentes à $t=100,200,300$ e 500 passos de Monte Carlo, respectivamente. As cores dos sítios correspondem: branco (suscetível), vermelho (infectado) e azul (imune). 

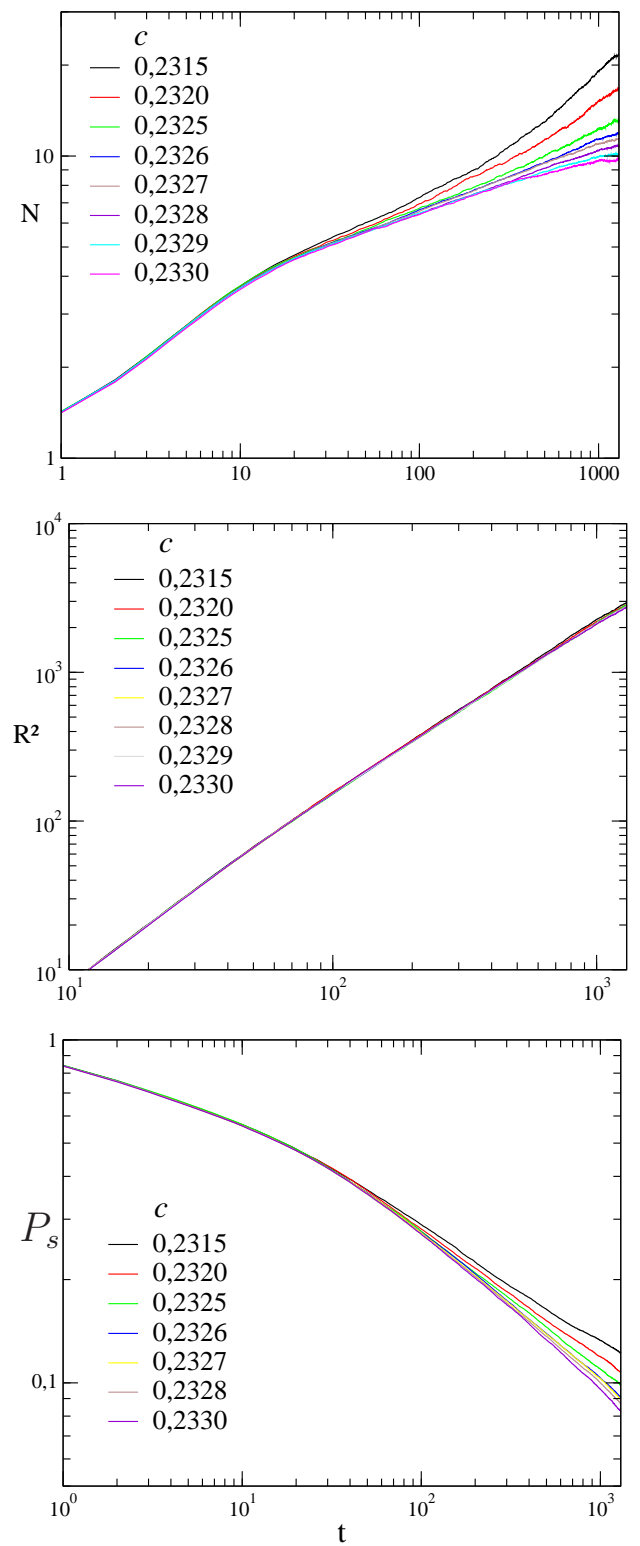

Figura 4.20: Gráficos do número de infectados $N(t)$, do raio quadrático $R^{2}(t)$ e probabilidade de sobrevivência da doença $P_{s}$ em função do tempo. Os parâmetros adotados foram $a=0,10$ e $L=256$. Analisando estes gráficos, obtemos que a transição de fase ocorre em $c_{c}=0,23270(5)$, e para tempos longos, fazendo um ajuste linear verifica-se que $N(t) \sim t^{\eta}$, com $\eta=0,230(8)$; $R^{2}(t) \sim t^{z}$ em que $z=1,126(10)$ e $P_{s}(t) \sim t^{-\delta}$ sendo $\delta=0,435(12)$. 

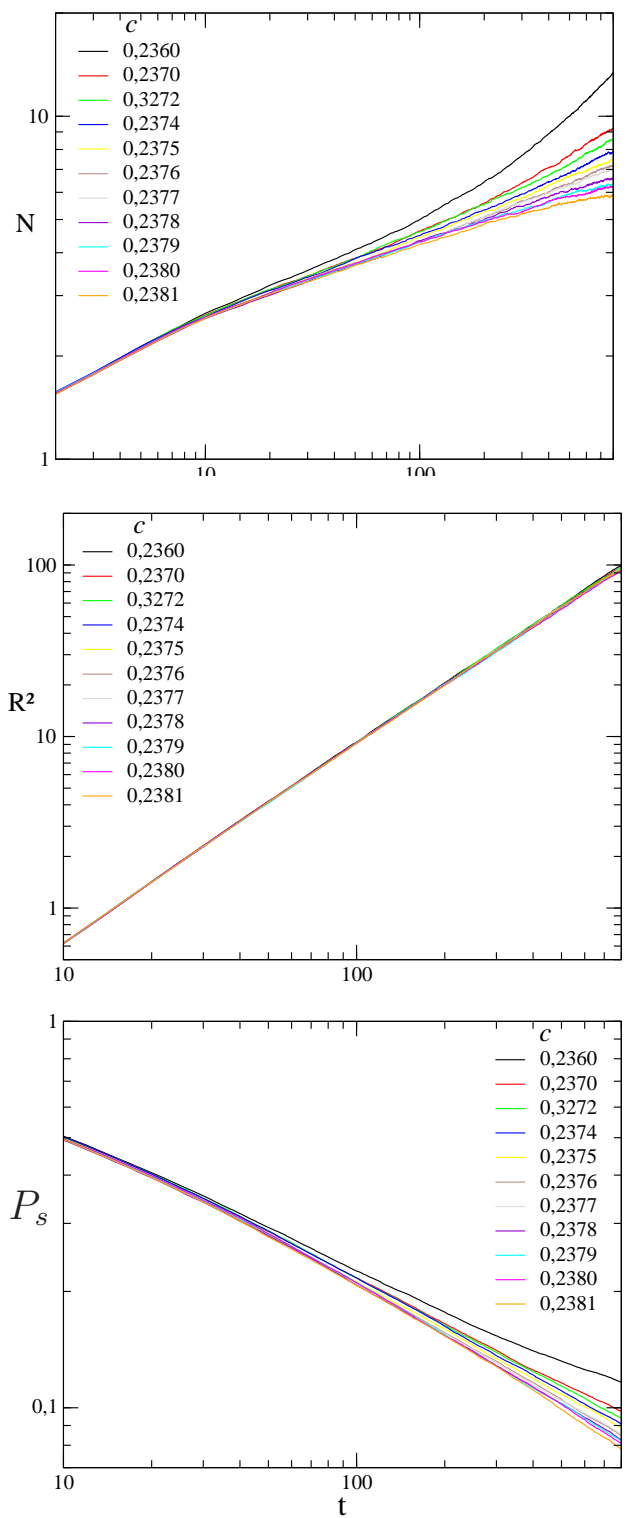

Figura 4.21: Gráficos do número de infectados $N(t)$, do raio quadrático $R^{2}(t)$ e probabilidade de sobrevivência da doença $P_{s}$ em função do tempo. Os parâmetros adotados foram $a=0,20$ e $L=160$. Analisando estes gráficos, obtemos que a transição de fase ocorre em $c_{c}=0,2377(1)$, e para tempos longos, fazendo um ajuste linear verifica-se que $N(t) \sim t^{\eta}$, com $\eta=0,227(2)$; $R^{2}(t) \sim t^{z}$ em que $z=1,132(2)$ e $P_{s}(t) \sim t^{-\delta}$ sendo $\delta=0,446(2)$. 

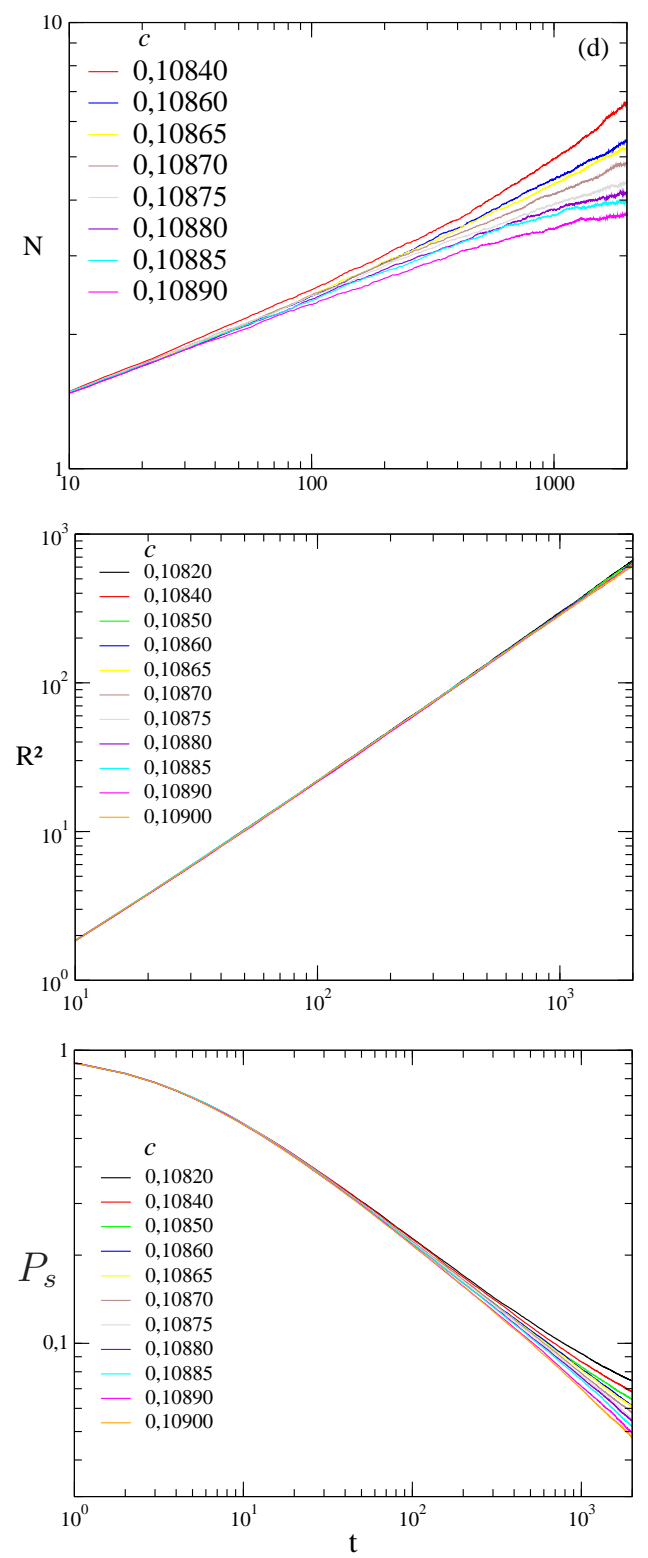

Figura 4.22: Gráficos do número de infectados $N(t)$, do raio quadrático $R^{2}(t)$ e probabilidade de sobrevivência da doença $P_{s}$ em função do tempo. Os parâmetros adotados foram $a=0,70$ e $L=160$. Analisando estes gráficos, obtemos que a transição de fase ocorre em $c_{c}=0,10870(5)$, e para tempos longos, fazendo um ajuste linear verifica-se que $N(t) \sim t^{\eta}$, com $\eta=0,22(1)$; $R^{2}(t) \sim t^{z}$ em que $z=1,12(1)$ e $P_{s}(t) \sim t^{-\delta}$ sendo $\delta=0,46(1)$. 
Realizando simulações dependentes do tempo para diferentes probabilidades de perda de imunidade, obtivemos pontos da linha de transição e calculamos também os expoentes dinâmicos. O conjunto de pontos críticos e expoentes críticos que analisamos está mostrado na tabela 4.1 e o diagrama de fase está mostrado na figura 4.23. Os valores dos expoentes críticos aqui estimados apresentam boa concordância com os melhores valores obtidos para a classe de universalidade da percolação direcionada em $2+1$ dimensões [63]. Portanto, os nossos resultados apontam que o modelo SIRS estocástico definido em uma rede bidimensional está na mesma classe de universalidade da percolação direcionada. Além disso, como mostrado na figura 4.24 vemos que se $a>0$ o modelo exibe expoentes críticos característicos da percolação direcionada, mas se $a=0$ (modelo SIR), ocorre uma mudança abrupta nos expoentes críticos e nesse caso particular, o modelo passa a pertencer à classe da percolação dinâmica. Na figura 4.20 vemos que para tempos curtos, o número de partículas cresce com um determinado expoente diferente do observado para tempos longos. Analisando estes dois regimes separadamente vemos que para tempos curtos, no limite $a \rightarrow 0$, o modelo parece exibir um comportamento compatível com os expoentes críticos da percolação dinâmica, mas passado esse transiente, o modelo passa a exibir os expoentes pertencentes à classe da percolação direcionada.

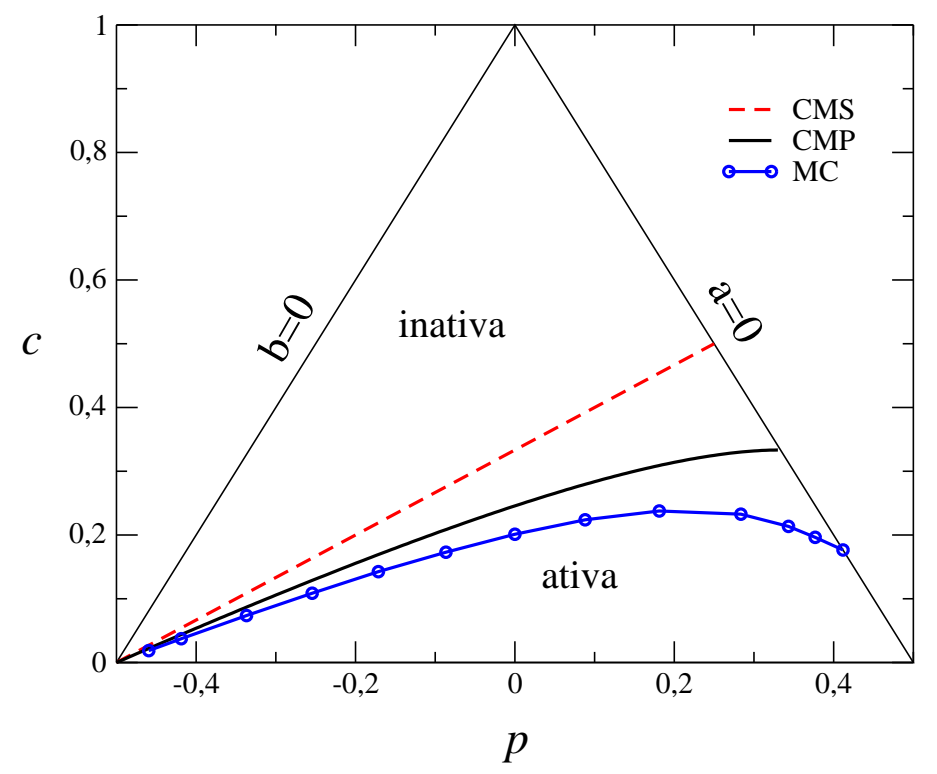

Figura 4.23: Diagrama de fase do modelo SIRS. Neste diagrama é apresentada a linha de transição determinada na aproximação de campo médio simples (CMS) e por pares (CMP) e via simulação de Monte Carlo (MC). 


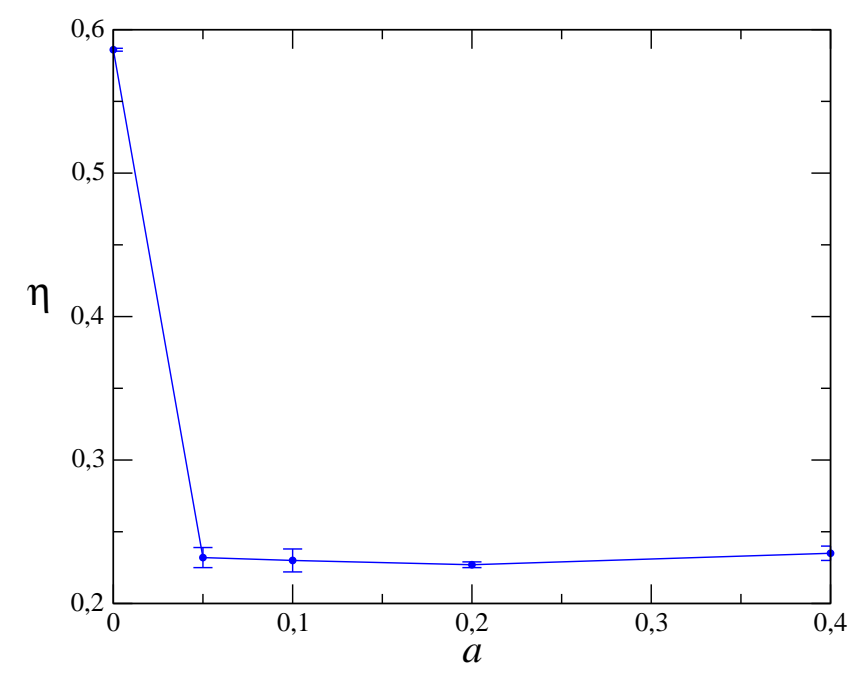

Figura 4.24: Variação do expoente crítico $\eta$ em função da probabilidade de perda de imunidade $a$. ( $\eta$ está definido na equação (2.47).)

\subsubsection{Simulações Computacionais Estacionárias}

Assim como o modelo de contato, o modelo SIRS apresenta um único estado absorvente, e deste modo pode-se empregar, sem perda de confiabilidade, a perturbação que evita que as realizações caiam no estado absorvente [59]. Com esta perturbação o algoritmo usado nas simulações computacionais estacionárias compreende as seguintes etapas:

1 Inicializa-se uma rede quadrada de lado $L$, com um total de $L^{2}$ sítios, e condições periódicas de contorno. Cada sítio da rede é ocupado por um único indivíduo, e no instante inicial, apenas o sítio central é ocupado por um indivíduo infectado, todos os demais sítios da rede são preenchidos por indivíduos suscetíveis.

2-a Sorteia-se um sítio da rede e um número aleatório $\gamma$ contido intervalo $[0,1)$. Calcula-se a probabilidade de transição de estado para o sítio $\omega_{i}(\eta)$ conforme a equação (4.1). Se $\gamma \leq \omega_{i}(\eta)$ então o sítio assume seu novo estado cíclico $(S \rightarrow I \rightarrow R \rightarrow S)$.

2-b No passo $(2-a)$ verifica se o sítio a ser atualizado não corresponde ao último indivíduo infectado, caso seja, impede-se que ele torne-se imune.

3 A cada $L^{2}$ sítios sorteados, contabiliza-se um passo de Monte Carlo, incrementado o tempo em uma unidade. Descarta-se os primeiros passos que dizem respeito ao transiente. A realização é interrompida após 
a execução de um número máximo de passos de Monte Carlo, definido previamente pelo programador, usualmente isto é feito ao definir os parâmetros a serem simulados.

É necessário que se faça uma averiguação prévia do tempo necessário para se atingir o regime estacionário e assim determinar um tempo transiente, a partir do qual deve-se computar as grandezas de estado, que serão utilizadas para calcular as grandezas médias. Sabendo a duração deste transiente escolhe-se o tempo máximo de evolução de cada realização. Uma simulação é composta de várias realizações, em que cada uma delas evolui a partir das mesmas configurações iniciais, mas as séries de números aleatórios usadas para sortear os sítios e probabilidades de transição são diferentes para cada realização.

A título de exemplo, mostramos na figura 4.25 cumulantes para diferentes probabilidades de infecção $a=0,20$. A figura 4.26 exibe curvas para a densidade estacionária de imunes para diferentes tamanhos de redes quadradas regulares de lado $L$. Ambas figuras possibilitam estimar o ponto crítico mas a realização de simulações dependentes do tempo se mostraram mais eficientes para este fim.

Uma vez estabelecido que o modelo pertence à classe de universalidade da percolação direcionada, para a qual foram calculados os expoentes críticos com elevada precisão [63, podemos fazer uso do expoente crítico $\beta$ associado ao parâmetro de ordem para reescalar as densidades conforme a relação de escala (3.21) e fazendo uma extrapolação para $\rho^{1 / \beta} \rightarrow 0$, determinar o ponto crítico. A figura 4.27 exibe as densidades reescaladas com $1 / \beta$ em função da probabilidade $c$, para dados relativos a simulações em redes de lados $L=80$. Ajustando uma reta para as densidades na fase ativa e extrapolando para $\rho^{1 / \beta} \rightarrow 0$ estimamos o ponto crítico $c_{c}=0,2378(1)$, resultado que está em pleno acordo com os obtidos via simulações dependentes do tempo. 


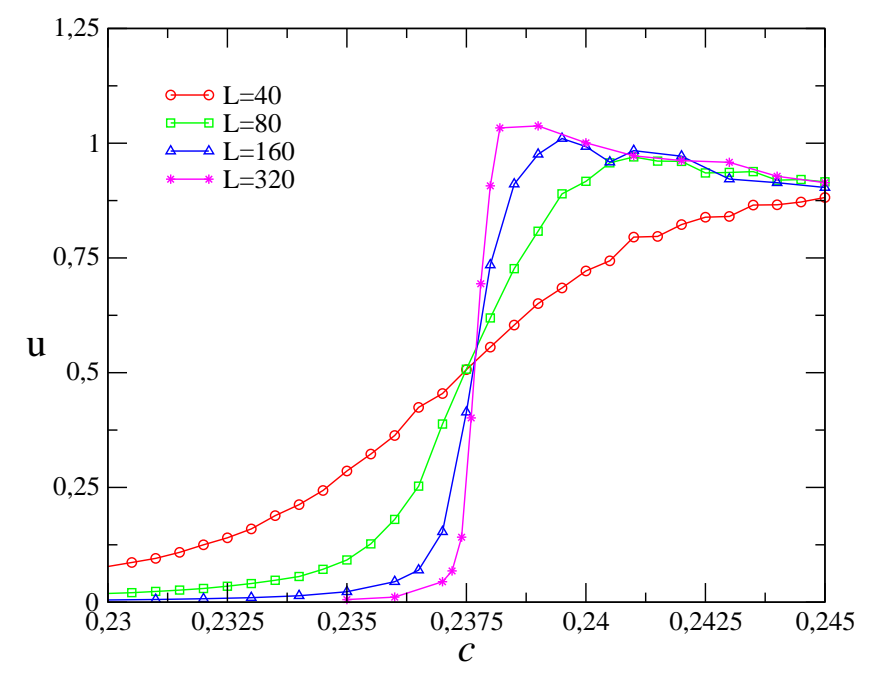

Figura 4.25: Cumulantes versus probabilidade de imunização $c$, para diferentes tamanhos de rede quadrada de lado $L$. A probabilidade de perda de imunidade é $a=0,20$. Na transição de fase o cumulante independe do tamanho da rede, e assim os diferentes cumulantes se colapsam. Neste gráfico estimamos que a transição ocorra no ponto $c_{c}=0,2377(1)$.

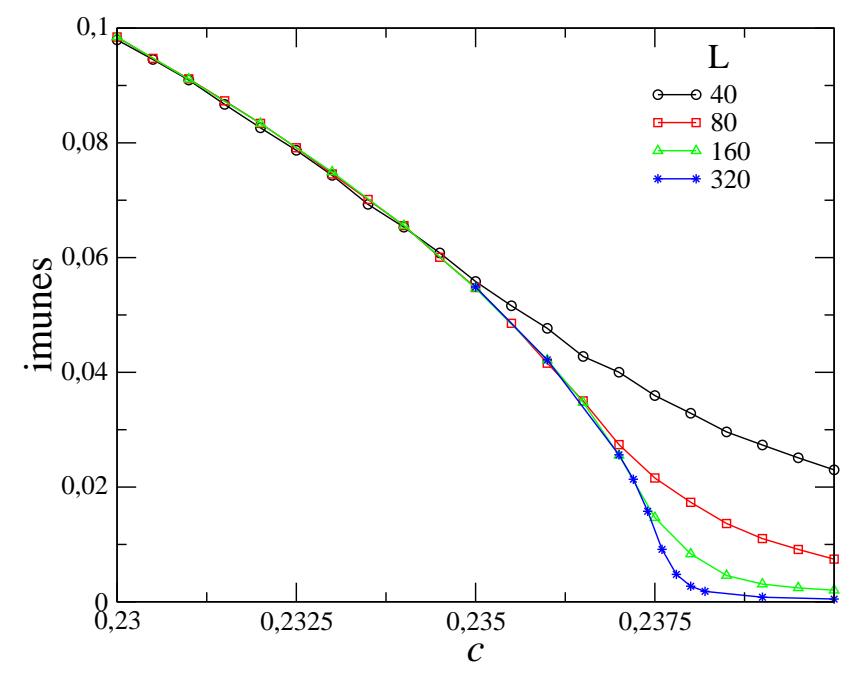

Figura 4.26: Densidade de imunes versus probabilidade de imunização $c$ para diferentes tamanhos de rede quadrada de lado $L$. A probabilidade de perda de imunidade é $a=0,20$. 


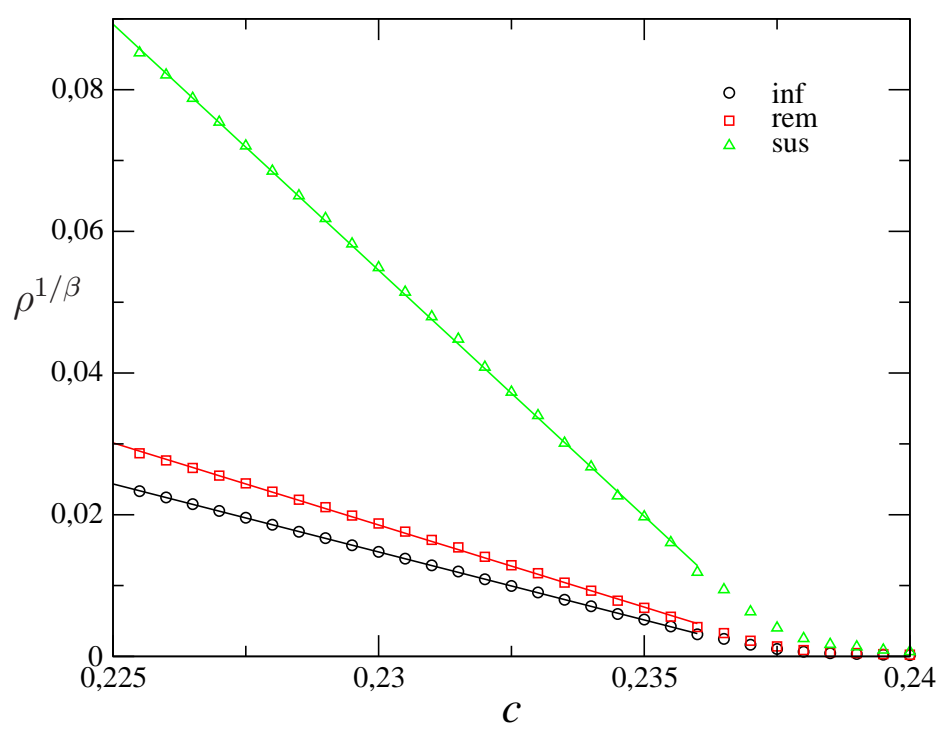

Figura 4.27: Densidades $\rho^{1 / \beta}$ em função da probabilidade de imunização. Para os suscetíveis $\rho=1-x$, em que $x$ é a densidade de suscetíveis. Ajustamos uma reta para os dados correspondentes a simulações para uma rede quadrada de lado $L=80$ e considerando apenas os dados referentes à fase ativa. A extrapolação para $\rho^{1 / \beta} \rightarrow 0$, adotando $\beta=0,583$, leva à estimativa para a probabilidade crítica $c_{c}=0,2378(1)$. 
Na tabela 4.1$]$ é apresentado os parâmetros críticos e expoentes críticos para o modelo SIRS definido em uma rede regular quadrada. Para cada probabilidade de perda de imunidade $a$ realizamos simulações de Monte Carlo dependentes do tempo para determinar a probabilidade crítica de imunização $c$, exceto o ponto $a=b$ no qual a probabilidade de infecção é igual à probabilidade de perda de imunidade, caso em o parâmetro $p$ é nulo. Sabendo o ponto crítico, calculamos os expoentes dinâmicos $\eta, z$ e $\delta$ a partir da evolução do número de infectados, do raio quadrático dos infectados em relação ao centro da rede, e da probabilidade de sobrevivência da epidemia, grandezas estas que no ponto crítico satisfazem às equações (2.47)-(2.49). Os expoentes críticos estáticos foram determinados por meio de simulações de Monte Carlo estacionárias empregando redes de lado $L=256$.

Tabela 4.1: Parâmetros e expoentes críticos relativos à transição para o estado absorvente de suscetíveis para o modelo SIRS.

\begin{tabular}{lllllll}
\hline \hline $\mathrm{a}$ & $c_{c}$ & $\beta$ & $\beta / v_{\perp}$ & $\eta$ & $\mathrm{z}$ & $\delta$ \\
\hline \hline 0 & $0,1765(5)$ & $0,129(10)$ & $0,096(7)$ & $0,586(1)$ & $1,773(1)$ & 0,094 \\
\hline 0,025 & $0,19640(5)$ & $0,575(9)$ & $0,806(11)$ & $0,22(2)$ & $1,2(1)$ & $0,42(3)$ \\
0,050 & $0,21355(5)$ & $0,577(7)$ & $0,805(14)$ & $0,232(7)$ & $1,163(7)$ & $0,424(15)$ \\
0,10 & $0,23270(5)$ & $0,576(8)$ & $0,790(10)$ & $0,230(8)$ & $1,126(10)$ & $0,435(12)$ \\
0,20 & $0,2377(1)$ & $0,576(15)$ & $0,793(10)$ & $0,227(2)$ & $1,132(2)$ & $0,446(2)$ \\
0,30 & $0,2238(2)$ & & & $0,21(3)$ & $1,13(2)$ & $0,46(2)$ \\
$0,3994(5)$ & $0,20115(5)$ & $0,57(2)$ & $0,79(2)$ & $0,235(5)$ & $1,130(2)$ & $0,447(6)$ \\
0,50 & $0,1730(2)$ & & & & & \\
0,60 & $0,1425(5)$ & & & & & \\
0,70 & $0,10870(5)$ & & & $0,22(1)$ & $1,12(1)$ & $0,46(1)$ \\
0,80 & $0,07365(5)$ & & & & & \\
0,90 & $0,03733(1)$ & & & & & \\
0,95 & $0,0187(1)$ & & & & & \\
\hline \hline
\end{tabular}




\section{Capítulo 5}

\section{Conclusão}

Apresentamos neste trabalho três diferentes modelos estocásticos empregados no estudo de propagação epidemias. Na modelagem é considerada a estrutura espacial do ambiente, sobre a qual distribui-se uma população. Cada indivíduo da população é caracterizado conforme sua posição espacial e quanto ao seu estado de saúde, e as interações ocorrem localmente.

Para o modelo de contato e SIR estudamos também o efeito de difusão entre os indivíduos da população. Através do processo difusivo dois vizinhos podem permutar suas posições e assim migrar pela estrutura espacial. No modelo SIR, que apresenta três classes distintas, foi estudado a difusão isotrópica (por meio da qual quaisquer dois indivíduos de classes distintas podem permutar suas posições) e a difusão anisotrópica (onde apenas duas classes específicas podem difundir).

Ambos modelos possuem pelo menos uma probabilidade de transição proibida (o modelo SIR possui duas) e, portanto, são intrinsecamente irreversíveis, pois uma vez que o estado absorvente é atingindo não há como mudar de estado. Além disso estes modelos exibem transição de fase fora do equilíbrio termodinâmico. No caso do modelo SIR todos os estados estacionários são absorventes e a transição de fase está relacionada ao limiar da propagação epidêmica.

Por meio de aproximações de campo médio dinâmico e simulações de Monte Carlo obtivemos os diagramas de fase para os modelos. Em todos os modelos, os resultados da aproximação de campo médio incluindo correlações de dois sítios são qualitativamente concordantes com os resultados obtidos por simulações de Monte Carlo.

Nos modelos de contato e SIR verificamos que a introdução do termo difusivo provoca a ampliação da fase ativa, isto é, se indivíduos infectados podem se mover eles acabam entrando em contato com maior número de indivíduos suscetíveis ampliando a possibilidade de transmissão da doença. 
No modelo SIR verificamos que se a difusão é anisotrópica, ocorrendo apenas entre algumas classes, tanto a difusão entre susceptíveis e imunes quanto entre infectados e imunes causa redução da fase ativa, enquanto a difusão entre susceptíveis e infectados favorece a propagação da epidemia. Portanto, a mobilidade dos indivíduos imunes em conjunto com suscetíveis ou infectados dificulta a propagação epidêmica.

Concluímos também que no limite puramente difusivo $(d \rightarrow 1)$ a linha crítica, obtida na aproximação de campo médio por pares, quanto os resultados de simulações de Monte Carlo, converge para os resultados de campo médio simples. Este resultado é plausível pois espera-se que quando a difusão é muito alta resultados de campo médio simples sejam válidos. Ou seja, os pressupostos do modelo estocástico espacialmente estruturados, em que os indivíduos estão localizados e são discretos, continuam válidos, mas não são relevantes neste limite.

Nossos resultados de campo médio mostram que o modelo SIRS apresenta na fase ativa (a qual apresenta densidade não nula de susceptíveis, infectados e imunes) um regime com oscilações nas densidades que assintoticamente atingem o valor estacionário. Entretanto, estudando o modelo através de um processo estocástico do tipo "birth \& death" constatamos que estas oscilações podem se tornar estáveis. Analisamos também a função de auto-correlação temporal das séries para as densidades de indivíduos. Verificamos que essas funções apresentam oscilações cujas amplitudes decaem com o tempo e quanto maior o tamanho da população maior o decaimento.

Por meio de simulações computacionais foi possível calcular alguns dos expoentes críticos dos modelos. Nossos resultados concordam com os melhores valores conhecidos na literatura. Em particular, foram determinados os expoentes críticos para diferentes pontos críticos do modelo SIRS, o que nos permitiu inferir que o modelo pertence a classe da percolação direcionada, e somente no limite de imunidade permanente, no qual o modelo mapeia-se no modelo SIR, há a mudança na classe de universalidade passando a pertencer a classe da percolação dinâmica. Essa é a primeira determinação da classe de universalidade do modelo SIRS. Isto mostra que este modelo está na mesma classe de universalidade do processo de contato, em concordância à conjectura de Grassberger [21], que afirma que modelos com um único estado absorvente pertencem à classe de universalidade da percolação direcionada. 


\section{Referências Bibliográficas}

[1] Blower, S. Rev. Med. Virol. 14, 275-288 (2004).

[2] Kermack, W. O. and McKendrick, A. G. R. Soc. of Lond. Proc. Ser. A 115, 700-721.

[3] Grassly, N. C. and Fraser, C. Nat. Rev. Micro. 6, 477-487 (2008).

[4] Harris, T. E. Ann. Prob. 2, 969 (1974).

[5] Hethcote, H. W. SIAM J. Appl. Math. 42, 599-653 (2000).

[6] Mollison, D. The Structure of Epidemic Models. (Cambridge UP, Cambridge, 1995).

[7] Stollenwerk, N. and Jansen, V. A. A. Criticality in epidemiology, in Complex Population Dynamics: Nonlinear Modeling in Ecology, Epidemiology and Genetics. (World Scientific Lecture Notes in Complex Systems, Oldenburg, Potsdam and Tel Aviv, 2007).

[8] Wearing, H. J., Rohani, P., and Keeling, M. J. PLoS Med. 2, 1-7 (2005).

[9] May, R. M. Science 303, 790-793 (2004).

[10] Anderson, R. M. and May, R. M. Nature 280, 361-367 (1979).

[11] Anderson, R. M. and May, R. M. Nature 280, 455-461 (1979).

[12] Anderson, R. M. and May, R. M. Infectious Diseases of Humans Dynamics and Control. (Oxf. Scie. Publ., London, 2008).

[13] Keeling, M. J. and Rohani, P. Modeling Infectious Diseases in Humans and Animals. (Princ. Univ. Press, Princepton and Oxford, 2008).

[14] Mills, C. E., Robins, J. M., and Lipsitch, M. Nature 16, 904-906 (2004).

[15] Wang, W. and Zhao, X.-Q. SIAM J. Appl. Math. 66, 1454-1472 (2006). 
[16] Green, D. M., Kiss, I. Z., and Kao, R. R. J. Theor. Biol. 239, 289-297 (2006).

[17] Chowell, G., Miller, M. A., and Viboud, C. Epid. Inf. 136, 852-864 (2008).

[18] Nishiura, H., Brockmann, S. O., and Eichner, M. Theo. Biol. and Med. Mod. 5, 1-12 (2008).

[19] Santos, L. B. L., Costa, M. C., Pinho, S. T. R., Andrade, R. F. S., Barreto, F. R., Teixeira, M. G., and Barreto, M. L. Phys. Rev. E 80, 016102 (2009).

[20] Dickman, M. . Nonequilibrium Phase Transitions in Lattice Models. (Cambridge Universty Press, Cambridge, 1999).

[21] Grassberger, P. and de la Torre, A. Ann. Phys. 122, 373-396 (1979).

[22] Hinrichsen, H. Adv. in Phys. 49, 815-958 (2000).

[23] Prigogine, I. Monographs in Statistical Physics and Thermodynamics, volume I. (John Wiley \& Sons, New York-London, 1962).

[24] Ziff, R. M. Phys. Rev. Lett. 69, 2670-2673 (1992).

[25] Grassberger, P. J. of Phys. A 22, 3673-3679 (1989).

[26] Dickman, A. G., Dickman, R., and Barbosa, F. A. Rev. Bras. de Ens. de Fis. 28, 23-33 (2006).

[27] Ziff, R. M. and Brosilow, B. J. Phys. Rev. A 46, 4630-4633 (1992).

[28] Renshaw, E. Modelling Biological Populations in Space and Time. (Cambridge Universty Press, Cambridge, 1995).

[29] van Kampen, N. G. Stochastic Process in Physics and Chemistry. (North-Holland, Amsterdam, 1992).

[30] Grassberger, P. Math. Bios. 63, 157-173 (1983).

[31] Satulovsky, J. E. and Tomé, T. Phys. Rev. E 49, 5073-5079 (1994).

[32] Arashiro, E. and Tomé, T. J. Phys. A 40, 887-900 (2007).

[33] Tomé, T., Rodrigues, Á. L., Arashiro, E., and de Oliveira, M. J. Comp. Phys. Comm. 180, 536-539 (2009). 
[34] de Carvalho, K. C. Dinâmica de Populações: um estudo a partir de autômatos celulares probabilísticos. (Dissertação de Mestrado, Instituto de Física da Universidade de São Paulo, São Paulo, 2005).

[35] Rodrigues, A. L. Dinâmica de Populações: Modelo predador-presa estocástico e difusivo em um reticulado. (Dissertação de Mestrado, Instituto de Física da Universidade de São Paulo, São Paulo, 2009).

[36] Tomé, T. and de Oliveira, M. J. Phys. Rev. E 79, 061128 (2009).

[37] de Aguiar, M. A. M., Rauch, E. M., and Bar-Yam, Y. Phys. Rev. E 67, 047102 (2003).

[38] Silva, S., Ferreira, J., and Martins, M. Phys. A 377, 689 - 697 (2007).

[39] Novak, M. A. and May, R. M. Nature 359, 826-829 (1992).

[40] Szabó, G. and Fáth, G. Physics Reports 446, 97 - 216 (2007).

[41] Lloyd, A. L. and May, R. M. Science 292, 1216-1317 (2001).

[42] Pastor-Satorras, R. and Vespignani, A. Phys. Rev. Lett. 86, 3200-3203 (2001).

[43] Tomé, T. and de Oliveira, M. J. Dinâmica Estocástica e Irreversibilidade. (Edusp, São Paulo, 2001).

[44] Tânia, T. Irreversibilidade. Modelos de rede com dinâmicas estocásticas. (Tese de Livre-Docência, Instituto de Física da Universidade de São Paulo, São Paulo, 1996).

[45] Amaku, M., Coutinho, F. A. B., Azevedo, R. S., Burattini, M. N., Lopez, L. F., and Massad, E. Phys. Rev. E 67, 051907 (2003).

[46] Anderson, R. M. and May, R. M. Nature 318, 323-329 (1985).

[47] Dammer, S. M. and Hinrichsen, H. Phys. Rev. E 68, 016114 (2003).

[48] Gonçalves, S., Kuperman, M., and Gomes, M. F. C. Phys. A 342, 256 -262 (2004).

[49] Lipowski, A. and Eopata, M. Phys. Rev. E 60, 1516-1519 (1999).

[50] Stollenwerk, N. and Jansen, V. A. A. J. Theor. Biol. 222, 347-359 (2003). 
[51] Chen, J. Appl. Math.- J. Chin. Univ. 19, 101-108 (2004).

[52] Joo, J. and Lebowitz, J. Phys. Rev. E 70, 036114 (2004).

[53] Liu, Q.-X., Wang, R.-H., and Jin, Z. J. Stat. Mech. 2009, P07007 (2009).

[54] Cardy, J. L. and Grassberger, P. J. Phys. A 18, L267-L271 (1985).

[55] Grassberger, P. Z. Phys. B 47, 365-374 (1982).

[56] Brauer, F. and van den Driessche, P. Math. Bios. 171, 143-154 (2001).

[57] Park, K. and Kim, I. Phys. Rev. E 66, 027106 (2002).

[58] Binder, K. and Heermann, D. W. Monte Carlo Simulation in Statistical Physics: An Introduction. (Springer-Verlag, Berlin, 1992).

[59] Tomé, T. and de Oliveira, M. J. Phys. Rev. E 72, 026130 (2005).

[60] de Oliveira, M. M. and Dickman, R. Braz. J. Phys. 36, 685-689 (2009).

[61] Jensen, I. Phys. Rev. A 45, 563-566 (1992).

[62] Dickman, R. Phys. Rev. E 60, R2441-R2444 (1999).

[63] Muñoz, M. A., Dickman, R., Vespignani, A., and Zapperi, S. Phys. Rev. E 59, 6175-6179 (1999).

[64] Hinrichsen, H. Phys. A 369, 1-28 (2006).

[65] Murray, J. D. Mathematical Biology. (Springer-Verlag, New York, 1980).

[66] Fiedler-Ferrara, N. and do Prado, C. P. C. Caos-uma introdução. (Edgard blücher, São Paulo, 1995).

[67] Seydel, R. From Equilibrium to Chaos: Practical Bifurcation and Stability Analysis. (Springer-Verlag, New York, 1947).

[68] de Souza, D. R. and Tomé, T. Stochastic lattice gas model describing the dynamics of an epidemic. (artigo submetido: arXiv.org:0908.1296), (2009).

[69] van den Berg, J., Grimmett, G. R., and Schinazi, R. B. Ann. of Appl. Prob. 8, 317-336 (1998). 
[70] Zhang, F. and Zhao, X. J. of Math. Anal. and Appl. 325, 496-516 (2007).

[71] Tao, Z., Zhongqian, F., and Binghong, W. Prog. Nat. Scie. 16, 452-457 (2006).

[72] D’Innocenzo, A., Paladini, F., and Renna, L. Phys. A 364, 497-512 (2006).

[73] Hethcote, H. W., Stech, H. W., and Driessche, V. D. SIAM J. Appl. Math. 40, 1-9 (1981).

[74] Méndez, V. Phys. Rev. E 57, 3622-3624 (1998).

[75] Smith, H. L. J. Math. Biol. 17, 163-177 (1983).

[76] Ross, S. M. Introduction to probability models. (Academic Press, San Diego, 2003).

[77] Salinas, S. R. A. Introdução à Física Estatística. (Edusp, São Paulo, 1999).

[78] Arashiro, E., Rodrigues, A. L., de Oliveira, M. J., and Tome, T. Phys. Rev. E 77, 061909 (2008). 